\title{
Final Report on the Flowsheet Model for the Electrochemical Treatment of Liquid Radioactive Wastes
}

by

D. T. Hobbs

Westinghouse Savannah River Company

Savannah River Site

Aiken, South Carolina 29808

S. Prasad

Department of Chemical Engineering - USC SC USA

A. E Farell

Department of Chemical Engineeringt- USC

SC USA

J. W. Weidner

Department of Chemical Engineering - USC

SC USA

R. E. White

Department of Chemical Engineering - USC

SC USA

This paper was prepared in connection with work done under the above contract number with the U.S. Department of Energy. By acceptance of this paper, the publisher and/or recipient acknowledges the U.S. Government's right to retain a nonexclusive, royalty-free license in and to any copyright covering this paper, along with the right to reproduce and to authorize others to reproduce all or part of the copyrighted paper. 


\section{DISCLAIMER}

Portions of this document may be illegible in electronic image products. Images are produced from the best available original document. 
WSRC-TR-95-0435, revision 0

Keywords: Electrolysis, Alkaline, Salt Solution, Waste Management

Retention time: permanent

October 30, 1995

TO: $\quad$ S. D. Fink, 773-A

FROM: D. T. Hobbs, 773-A

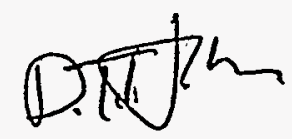

Final Report on the Flowsheet Model for the Electrochemical Treatment of - Liquid Radioactive Wastes (U)

Attached is the final report prepared by the University of South Carolina under contract \#AA00900T, Task \#112, developing engineering models for the electrochemical destruction of nitrates and organic compounds in liquid radioactive wastes.

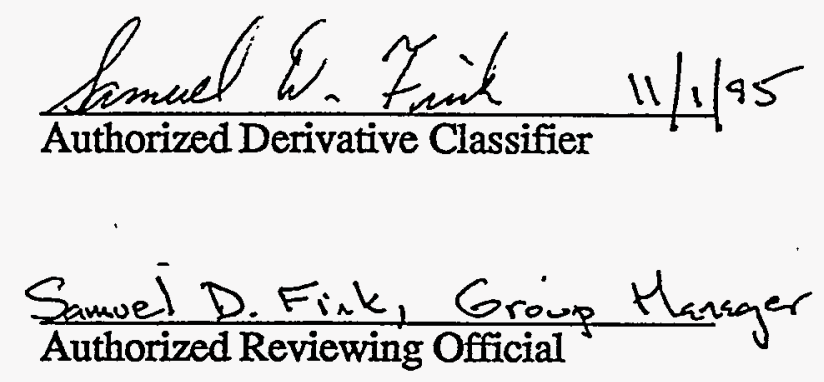

Savannah River Technology Center

Westinghouse Savannah River Company

Aiken, SC 29802

Prepared for the Department of Energy Office of Technology Development, Office of Environmental Management under Contract DE-AC09-88SR18035 
This report was prepared as an account of work sponsored by an agency of the United States Government. Neither the United.States Government nor any agency thereof, nor any of their employees, makes any warranty, express or implied, or assumes any legal liability or responsibility for the accuracy, completeness, or usefulness of any information, apparatus, product, or process disclosed, or represents that its use would not infringe privately owned rights. Reference herein to any specific commercial product, process, or service by trade name, trademark, manufacturer, or otherwise does not necessarily constitute or imply its endorsement, recommendation, or favoring by the United States Government or any agency thereof. The views and opinions of authors expressed herein do not necessarily state or reflect those of the United States Government or any agency thereof.

This report has been reproduced directly from the best available copy.

Available to DOE and DOE contractors from the Office of Scientific and Technical Information, P.O. Box 62, Oak Ridge, TN 37831; prices available from (615) 576-8401.

Available to the public from the National Technical Information Service, U.S. Department of Commerce; 5285 Port Royal Road, Springfield, VA 22161. 
FLOWSHEET MODEL FOR THE ELECTROCHEMICAL TREATMENT OF LIQUID RADIOACTIVE WASTES

\author{
A' Final Report Submitted To. \\ Dr. David T. Hobbs \\ Westinghouse Savannah River Company \\ WSRCISCUREF Task Order \# 112
}

By

S. Prasad, A.E. Farell, J.W. Weidner and R.E. White

Department Of Chemical Engineering

University Of South Carolina

Columbia, SC 29208

July 14, 1995 


\section{CONTENTS}

$\underline{\text { Sections }}$

Page No.

Abstract

1. Introduction

1

2. Overview of flowsheet modeling tasks accomplished 3

3. The Electrochemical cell model

3.1 Background 5

3.2 Divided cell in batch mode $\quad 7$

3.2.1 Model assumptions 9

3.2.2 Batch cell model develpopment $\quad 10$

3.3 Results of simulation and optimization studies $\quad 15$

3.3.1 Batch simulation results $\quad 15$

3.3.2 Batch optimization $\quad 17$

$\begin{array}{ll}4 \text { The Evaporator model } & 21\end{array}$

4.1 Model assumptions $\quad 22$

4.2 Model development $\quad$ - $\quad$. 22

4.3 Results of simulation studies $\quad 23$

Notation 24

References $\quad 26$

Tables and plots $\quad 28$ through 54

Appendix I $\quad 55$

Overview of Speedup models $\quad 56$

$\begin{array}{lc}\text { Cost Analysis } & 62\end{array}$

Speedup Code 65 


\begin{abstract}
The objective of this report is to describe the modeling and optimization procedure for the electrochemical removal of nitrates and nitrites from low level radioactive wastes. The simulation is carried out in SPEEDUP ${ }^{\text {TM }}$, which is a state of the art flowsheet modeling package. The flowsheet model will provide a better understanding of the process and aid in the scale-up of the system. For example, the flowsheet model has shown that the electrochemical cell must be operated in batch mode to achieve 95\% destruction. The flowsheet model is detailed in this report along with a systematic description of the batch optimization of the electrochemical cell. Results from two batch runs and one optimization run are also presented.
\end{abstract}




\section{Introduction}

The objective of this project is to develop a dynamic flowsheet model for the electrochemical treatment of liquid radioactive wastes. The flowsheet includes the electrochemical reactor, an evaporator/crystallizer, gas recovery and processing for final disposal of the liquid wastes. The objective of the process is to destroy or remove the hazardous species.

A schematic diagram of the flowsheet ${ }^{1}$ is given in Figure 1. A brief description of the units in the flowsheet is given below.

a) Electrochemical Reactor: The main purpose of this unit is to destroy the nitrates and nitrites. The flowsheet model has shown that the single pass undivided electrochemical cell gives a low conversion per pass, and therefore a divided cell operating in batch mode is required.

b) Evaporator/Crystallizer : The main purpose of the evaporator is to concentrate the caustic $(\mathrm{NaOH})$. The crystallizer separates the solids, that are produced during evaporation. The evaporator models have been connected to Properties Plus, Aspen Tech's rigorous physical properties package. It will handle nitrates, nitrites and solids.

c) Gas Treatment: This unit is used to treat the off gases (coming out of the $\mathrm{EC}$ reactor) if need arises, so that environmental release regulations are met.

d) Dissolution Tank \& Waste Disposal: The solids separated in the crystallizer are dissolved in an appropriate solvent and șent to waste disposal facility.

The flowsheet model has been developed in SPEEDUP ${ }^{\mathrm{TM}}$, Aspen Tech's rigorous flowsheeting package. This model will serve as a tool in providing information as follows:

1) a clearer understanding of the process,

2) determination of the boundaries of operation and identification of operating constraints,

3) optimization of the electrochemical cell and its operation based on material and energy costs, 


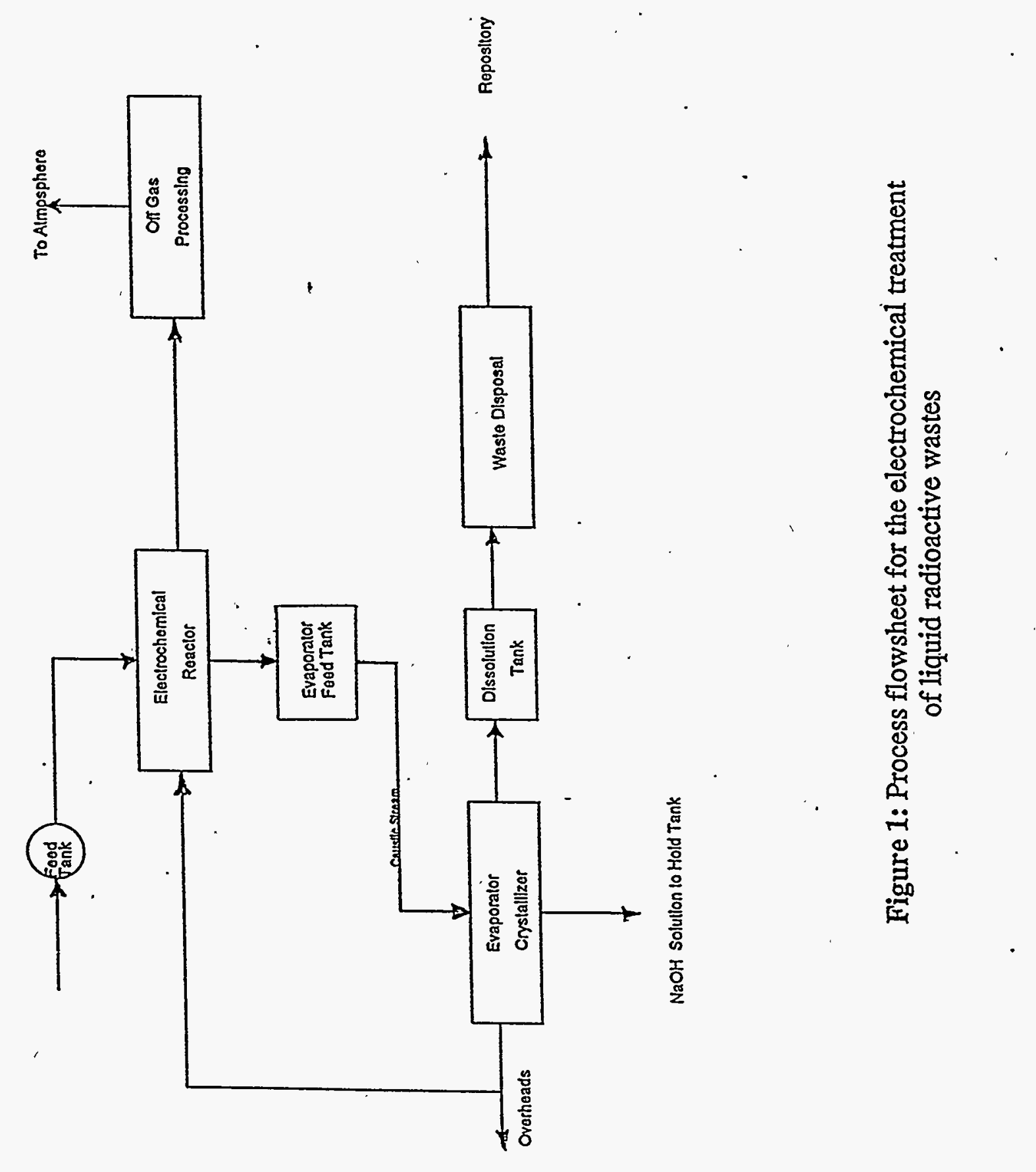


4) scale-up of the system, and

5) safety analysis.

In this report we document the flowsheet model and the methodology for the batch optimization of the electrochemical cell. An overview of the two SPEEDUP models and a detailed cost analysis are delineated in Appendix I.

\section{Overview of Flowsheet Modeling Tasks Accomplished}

The flowsheet model comprises an. electrochemical reactor and an evaporator as shown in Figure 2. Qptimization of the batch cell has also been studied. The optimal operation of the cell will provide a much better estimate of the amount and composition of gases generated, after which the off-gas processing unit can be designed. The outline below summarizes the work accomplished.

a) Preliminary analysis with the flowsheet model indicated a necessity for using a divided cell in batch mode.

b) The mass balances for the electrochemical cell were programmed into SPEEDUP ${ }^{\text {TM }}$ and checked for consistency with the differential model developed by Coleman ${ }^{2}$. These balances were for a cell operating at steady state and having constant current efficiencies.

c) The development of a dynamic batch cell model based on a boundary layer approach has been completed. It includes diffusion and migration as the major flux components and has the capability of handling multiple reactions and rigorous thermodynamic calculations.

d) Models for single, double, and triple effect evaporators have been developed for the $\mathrm{NaOH}-\mathrm{H}_{2} \mathrm{O}$ system. All of these are dynamic models. They produce a highly concentrated caustic stream.

e) The dynamic evaporator models have been connected to Properties Plus (an Aspen Data Bank). Connection to Properties Plus provides a quick and accurate evaluation of enthalpies and solubilities. This also allows handling of nitrates and nitrites along with solid phase calculations.

f) An optimization strategy to minimize the capital plus operating costs for the batch electrochemical cell has been developed. It uses a Neural Net 


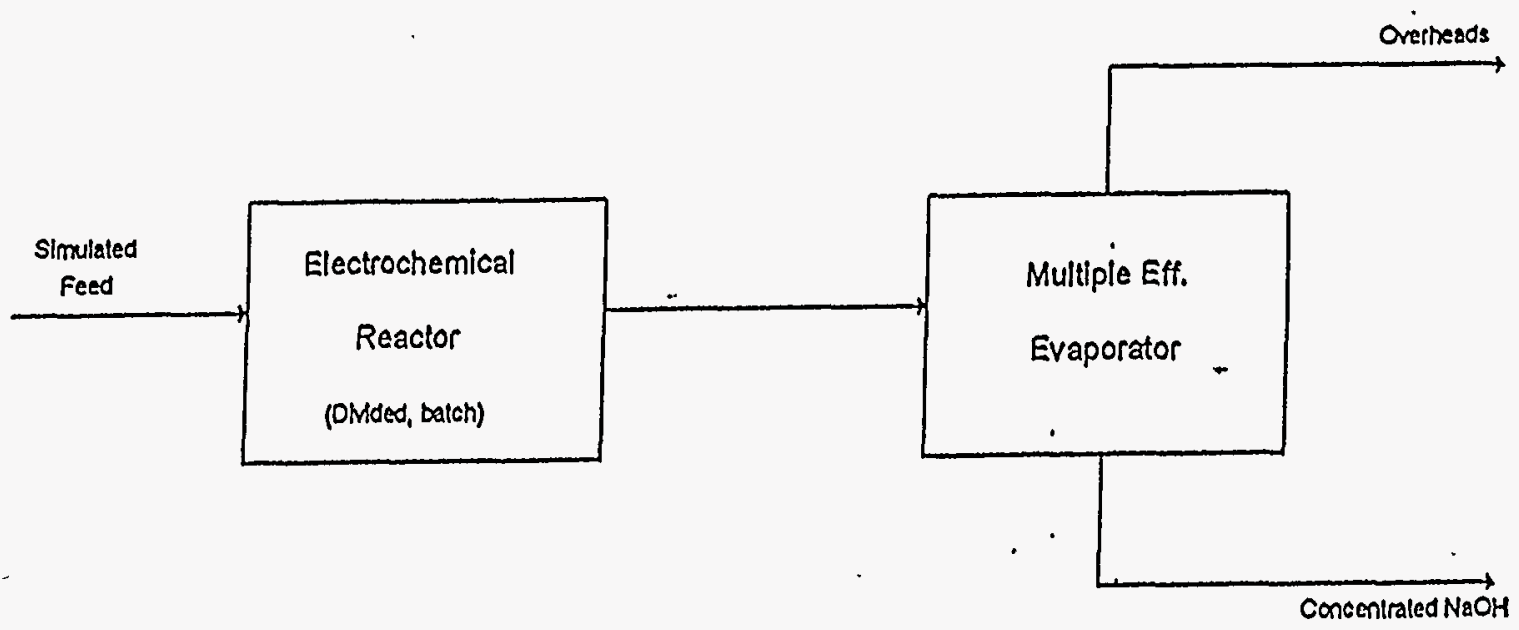

Figure 2: Segment of the flowsheet that has been modeled 
mapping to evaluate the optimal current at which the cell can be operated at each point in time.

g) A number of case studies have been run, with the boundary layer electrochemical cell model studies accounting for the most of them. A few case studies aiming to validate the evaporator model have also been run.

The following sections describe the electrochemical cell model, the evaporator model and the batch optimization procedure.

\section{The Electrochemical Reactor Model}

The electrochemical reactor is the center of the flowsheet for the treatment of hazardous wastes. The objective of the reactor is to destroy or remove the hazardous species from the solution. The substances comprising the waste (decontaminated salt solution) simulant are tabulated in Table 1. The simulated feed $^{1}$ is assumed to consist only of nitrates, nitrites, and hydroxides.

\subsection{Background}

A number of parallel plate electrochemical cell models exist in the literature. Parrish and Newman ${ }^{3}$ presented a one-dimensional, distributed-parameter model to analyze the current distribution of a single reaction in a channel-flow cell where concentration gradients in the flow direction were ignored. Sakellaropolous and Francis ${ }^{4}$ included multiple reactions in their model in order to analyze product selectivity. They investigated two parallel electrocatalytic reductions of vinyl chloride to either ethyl chloride or ethylene. They also presented an optimization of the yield of the product based on the potential, reactant concentration, conversion, possible fluid mixing, and possible-slow diffusion in the electrocatalyst pores.

White et al. $^{5}$ presented a two-dimensional model of an undivided electrochemical cell which was used to model multiple reactions at the cathode. This model described two series reactions for the electrowinning of copper from a chloride solution and used Newman's ${ }^{6}$ BAND algorithm to predict product selectivity and current and energy efficiencies. The current inefficiencies in the study were due to the diffusion of the copper intermediate away from the electrode surface. The above models ${ }^{3-6}$ form the basis of the work by Coleman et $a .^{2}$ in which they developed a rigorous distributed parameter divided cell model that describes the destruction of nitrates and nitrites in alkaline waste solutions. The model assumes 
laminar flow and includes the effects of the separator, ionic migration, electrode resistances, multiple reactions, and cell gap. Also, all the time dependency is incorporated into the recirculation tank since the volume of the tank is much greater than that of the cell. The governing differential equations are transformed into a set of coupled algebraic equations using a finite difference approximation for the derivatives. The solution procedure uses the BAND algorithm to solve for these transformed steady-state continuity and electroneutrality equations in the catholyte and anolyte regions of the electrochemical cell and an implicit time stepping technique is used to account for the dynamics of the recirculation tank. The model is used to predict the partial current densities, concentration profile, and the potential profile for a given set of operating conditions. This model is, however, computationally intensive for optimization studies and for use in the flowsheet simulation of the entire treatment process.

Previous investigations have devised solution procedures and strategies to reduce computer time using a boundary-layer approach while maintaining the key features of the various electrochemical cell models. The model presented by White et al. ${ }^{5}$ was further modified by Mader et al. ${ }^{7}$ that substantially reduced computational time. The axial concentration gradient was assumed to be linear and equated to the ratio of the change in concentration (from inlet to outlet) to the reactor length. This changed the model from two-dimensional to one-dimensional (radial direction). Caban and Chapman ${ }^{8}$ presented a model which mainly focused on simpler techniques for the solution of ordinary differential equations. They used orthogonal collocation with new approximating functions to solve for transport in the boundary layer (with reaction term included), which gave them concentration profiles and current densities that agree well with rigorous calculations. Lee and Selman ${ }^{9}$ presented a similar model as Caban and Chapman ${ }^{8}$ but they added the effects of separator and electrode resistances. The model developed was for a twodimensional parallel-plate flow reactor, using the $\mathrm{Zn} / \mathrm{Br}_{2}$ system as an example. Smeltzer and Fedkiw ${ }^{10}$ used an innovative technique to analyze the effect of periodic cell voltage control ${ }^{11}$ on the reduction of nitrobenzene. To model the reactor, they used the analytical solution to the Laplace equation in conjunction with an analytical solution to the transient diffusion equation within the stagnant boundary layer at the electrode surface.

In the present work, the stagnant boundary-layer approach is extended in order to include the transport of ions via migration as well as diffusion across the boundary layer. Coleman et $a l^{2}$ showed that the migrational component of the flux can dominate when the current resulting from the hydrogen evolution reaction is significant. Migration can cause the repulsion of the negatively charged nitrate and nitrite ions away from the cathode surface, thus significantly reducing the partial current densities of the desired reactions. 
Since the destruction of nitrates and nitrites is a combination of an electrochemical reactor and recirculation tanks in total recycle (Figure 2), bulk concentrations of reactants and products must be tracked as a function of time. In addition to the work by Coleman et $a l^{2}$, several time dependent models for the parallel plate electrochemical cell with recirculation have been developed ${ }^{12-14}$. The common assumption in most models is that the reactor is in plug flow. In addition, they do not consider the effect of potential, ionic migration, electrode kinetics, flashing of gases produced in the reactor or include time dependence in the reactor and the recirculation tank.

Preliminary studies ${ }^{1,15,16}$ on the nitrate system have suggested that in the range of operation of the electrochemical cell, the conversion per pass achieved is very low $(\approx 0.05 \%)$. Thus, the concentration profile in the bulk of the cell is relatively flat, with the only gradients existing in a small region in the vicinity of the electrodes. This supplements the validity of the boundary-layer model, which solves for the concentration profile only in the small region $(\delta)$ beside the electrodes. The differential model solves for the profile throughout the cell.

This report delineates the development of an electrochemical reactor model based on the boundary layer approach, suitable for use in the process flowsheet model. It will also describe in detail, the systematic development of the batch optimization methodology formulated to minimize capital plus operating costs. Results from a few independent case studies (including one optimization run) are presented. The boundary layer model has been designed mainly to be used as a module in the flowsheet and for optimization studies. The differential model, though precise, takes a significant amount of time to run. The boundary layer model can give accurate results much quicker.

The equations for the boundary-layer model are written in SPEEDUP $^{\text {Th. }}$, Aspen Technology's dynamic flowsheet simulator. Since the process stream is non-ideal (due to the presence of polar species like water and a large number of gases), the use of rigorous thermodynamics is desirable. The use of SPEEDUP ${ }^{\text {iu }}$ as the programming environment further facilitates the use of rigorous thermodynamics. The vapor-liquid-equilibrium (VLE) data is obtained by connecting the program to Properties Plus, which is Aspen Technology's physical properties database.

\subsection{Divided Cell in Batch Mode}

Figure 3 shows the batch system. Most of the existing models assume that the cell is in plug flow and do not consider the effect of potential, electrode gap, ionic migration or electrode kinetics. Moreover, they do not consider flashing 


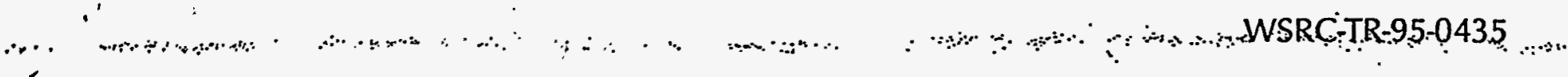

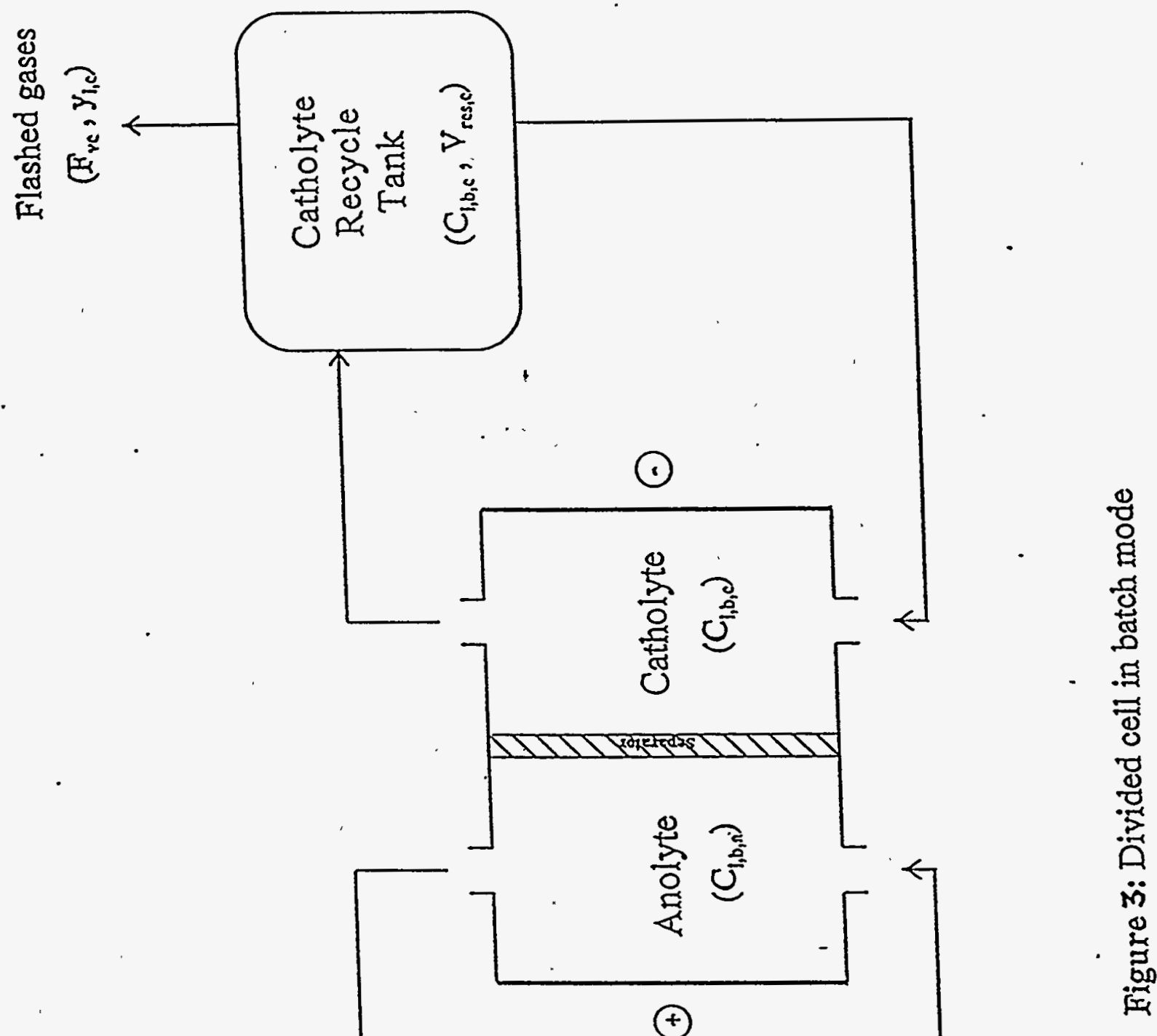


(separation of dissolved gases from the solution) of the gases produced in the reactor. All the above mentioned effects have been included in this work. The divided cell, two continuously recycling streams (anolyte and catholyte) and two recirculation tanks (one each for the two streams) are grouped together and treated as batch reactors with gas generation. The simulated feed composition of the anolyte and catholyte at the start of the batch run is given in Table 2. The divided cell is a parallel plate electrochemical reactor with an ion-exchange membrane separating the cathode and the anode. The reduction of nitrates and nitrites occurs at the surface of the cathode. The separator minimizes oxidation of the nitrites back to nitrates at the anode. The purpose of the reservoir is to thoroughly mix the incoming process stream with the reservoir contents. It also enables the gases trapped in the stream to flash.

Batch mode operation is preferred over continuous mode because of the very low conversion $^{2}$ per pass observed. Also, divided cell system is preferred over an undivided cell to increase energy efficiency and to prevent hydrogen and ammonia from mixing with oxygen.

\subsubsection{Model Assumptions:}

The following assumptions have been made in developing the boundary layer electrochemical cell model.

1. The dynamics of the reactor are neglected in the presence of recirculation tank dynamics.

2. No homogeneous chemical reactions occur in the reactor.

3. Dilute solution theory applies.

4. The Nernst - Einstein equation $\left(\mathrm{u}_{\mathrm{i}}=\mathrm{D}_{\mathrm{i}} / \mathfrak{R T}\right)$ applies.

5. The Butler-Volmer equation can be used to describe the reactions at the electrode surface.

6. Isothermal conditions exist.

7. The gases produced at the electrode surface stay in solution in the reactor and are flashed upon entering the recirculation tank. 
8. The solution conductivity is uniform in each of the anolyte, catholyte, and separator regions.

9. Perfect mixing is achieved in the recirculation tank.

10. The physical transport parameters are constant.

11. Density of the process stream remains constant.

12. Concentration of gases in the anolyte stream is low.

Assumption 1 is valid because the volume of the reactor is small compared to the recirculation tank. Assumptions 2 through 6 are common to most parallel-plate electrochemical reactor models. Assumption 7 holds because the amount of gas produced at each pass is always below saturation limits, owing to the fact that the conversion per pass is quite low. Assumption 8 arises from the fact that the conductivity is a function of the sum of the species concentrations which remains almost unchanged (since all the species in the simulated waste carry unit charges and electroneutrality is maintained). Assumptions 9 through 11 are common in CSTR modeling. Assumption 12 is based on results from preliminary studies ${ }^{1,16}$.

\subsubsection{Batch Cell Model Development:}

The function of the electrochemical reactor is to destroy the nitrates and nitrites. This is achieved by reducing them to gases such as nitrogen, ammonia and nitrous oxide. The main reactions presumed to be occurring inside the electrochemical cell are given below:

$$
\begin{array}{cc}
\text { Reaction } & \mathrm{U}^{\theta}(\mathrm{V}) \\
\mathrm{NO}_{3}^{-}+\mathrm{H}_{2} \mathrm{O}_{(l)}+2 e^{-} \rightarrow \mathrm{NO}_{2}^{-}+2 \mathrm{OH}^{-} & 0.01 \\
\mathrm{NO}_{2}^{-}+5 \mathrm{H}_{2} \mathrm{O}_{(l)}+6 e^{-} \rightarrow \mathrm{NH}_{3(g)}+7 \mathrm{OH}^{-} & -0.165 \\
2 \mathrm{NO}_{2}^{-}+4 \mathrm{H}_{2} \mathrm{O}_{(l)}+6 e^{-} \rightarrow \mathrm{N}_{2}(g)+8 \mathrm{OH}^{-} & 0.406 \\
2 \mathrm{NO}_{2}^{-}-3 \mathrm{H}_{2} \mathrm{O}_{(l)}+4 e^{-} \rightarrow \mathrm{N}_{2} \mathrm{O}_{(g)}+6 \mathrm{OH}^{-} & 0.15 \\
2 \mathrm{H}_{2} \mathrm{O}_{(l)}+2 e^{-} \rightarrow \mathrm{H}_{2(g)}+2 \mathrm{OH}^{-} &
\end{array}
$$




$$
\begin{array}{ll}
4 \mathrm{OH}^{-} \rightarrow \mathrm{O}_{2(g)}+2 \mathrm{H}_{2} \mathrm{O}_{(l)}+4 e^{-} & 0.401 \\
\mathrm{NO}_{2}^{-}+2 \mathrm{OH}^{-} \rightarrow \mathrm{NO}_{3}^{-}+\mathrm{H}_{2} \mathrm{O}_{(l)}+2 e^{-} & 0.01
\end{array}
$$

Due to assumption 12, the reverse rate of reactions (2) - (5) is low and hence reactions (1) - (5) occur at the cathode and reactions (6) and (7) occur at the anode. All the above reactions can be written in the following general format ${ }^{6}$.

$$
\sum_{i} s_{i j} M_{i}^{z_{i}} \rightarrow n_{j} e^{-}
$$

In this format, the stoichiometric coefficient $s_{i j}$ is positive for products and negative for reactants when the reaction is-written as a reduction.

The Butler-Volmer rate expression is used to relate the partial current $\left(i_{j}\right)$ associated with reaction " $\mathrm{j}$ " to the surface concentration $\left(C_{i, s}\right)$ of species " $\mathrm{i}$ " and the overpotential $\left(\eta_{j}\right)$ for reaction " $\mathrm{j}$ ". The Butler-Volmer rate expression relative to reference conditions can be written for the catholyte $\mathrm{as}^{17}$,

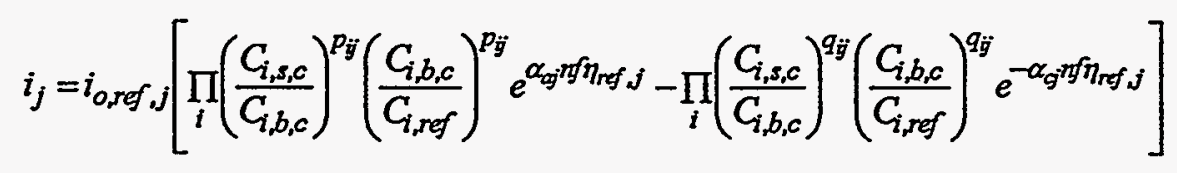

where,

$$
\begin{aligned}
& \eta_{r e f, j}=V_{c}-\phi_{c}-U_{r e f, j} \text { for reactions at the cathode } \\
& \eta_{r e f, j}=V_{a}-\phi_{a}-U_{r e f, j} \text { for reactions at the anode } \\
& U_{r e f, j}=U_{j}^{\theta}+\frac{1}{n_{j} f_{i}} \sum_{i} \ln \left(\frac{1}{C_{i, r e f}}\right)
\end{aligned}
$$

and, $\quad p_{i j}=s_{i j}, q_{i j}=0$ if $s_{i j}>0 ; p_{i j}=0, q_{i j}=-s_{i j}$ if $s_{i j}<0$

The expression relating $\phi_{c}$ and $\phi_{a}$ (based on the constant voltage drop assumption) is given below.

$$
\phi_{a}=\phi_{c}+i_{t} A R_{\text {cell }}
$$

where,

$$
R_{c e l l}=\frac{I}{A}\left(\frac{S_{a}}{\kappa_{a}}+\frac{S_{s} N_{m}}{\kappa_{s}}+\frac{S_{c}}{\kappa_{c}}\right)
$$


where $\quad \kappa_{c}=\frac{F^{2}}{\Re T} \sum_{i} z_{i}^{2} D_{i} C_{i, b, c}$

and

$$
\kappa_{a}=\frac{F^{2}}{\Re T} \sum_{i} z_{i}^{2} D_{i} C_{i, b, a}
$$

In equation 9 , the term $\left(C_{i, s, c} / C_{i, b, c}\right)$ is unknown. Therefore a relation between this quantity and other system variables must be developed. Both diffusion and migration contribute to the flux of species " $i$ " through the diffusion layer and therefore the flux is given by,

$$
N_{i}=-D_{i} \frac{d C_{i}}{d x}-\frac{z_{i} D_{i} F}{\mathfrak{R} T} C_{i} \frac{d \phi}{d x}
$$

Since the potential drop across the catholyte is constant (due to assumption 8), Ohm's law allows the $(d \phi / d x)$ term to be substituted by $\left(-i_{l} / k_{c}\right)$ to give,

$$
N_{i}=-D_{i} \frac{d C_{i}}{d x}+\frac{z_{i} D_{i} F}{\mathfrak{R} T} \frac{i_{t}}{\kappa_{c}} C_{i}
$$

Furthermore, the flux of species " $i$ " in the boundary layer is assumed to be constant and related to the total current density $\left(i_{t}\right)$ as follows,

$$
N_{i}=-\sum_{j} \frac{s_{i j} i_{j}}{n_{j} F}
$$

Substituting equation 14 into equation 13 and integrating across the boundary layer from $x=0$ to $x=\delta_{i}$ gives the ratio of surface to bulk concentrations.for species " $i$ ' as,

$$
\frac{C_{i, s, c}}{C_{i, b, c}}=\left(\frac{N_{i}}{D_{i} \gamma_{i} C_{i, b, c}}\right)+\left(1-\frac{N_{i}}{D_{i} \gamma_{i} C_{i, b, c}}\right) e^{\gamma_{i} \delta_{i}}
$$

where, $\quad \gamma_{i}=\frac{z_{i} F i_{t}}{\Re T \kappa_{c}}$

and,

$$
i_{t}=\sum_{j} i_{j}
$$

The boundary-layer thickness, $\delta_{i}$, is related to the mass transfer coefficient (which in turn is related to the Nusselt number) as follows: 


$$
{ }_{i}=\frac{D_{i}}{k_{m, i}}=\frac{2 S}{N u_{i}}
$$

Newman ${ }^{6}$ gives an expression for the average Nusselt number for flow between two planar electrodes which is accurate for long electrodes (i.e. fully developed flow):

$$
N u_{i}=1.8488\left(\frac{R e S c_{i} d_{e}}{L}\right)^{1 / 3}-0.4
$$

in which, $\quad R e=\frac{d_{e} \mathrm{v}}{v_{1}} \quad$ and, $\quad S c_{i}=\frac{v}{D_{i}}$.

The -0.4 term on the right hand side of equation 18 is included to account for a fully developed boundary layer in a long channel. Equations analogous to 9 through 15 can be written for the anolyte boundary layer as well.

Butler-Volmer equations (equation 9) for each reaction are solved simultaneously along with equation 11 and a set of equations governing the surface concentrations (equation 15) to evaluate the individual current densities. Coleman et al. ${ }^{2}$ use equations 9 through 13 along with a convective term in the direction of flow to evaluate the current densities. This approach requires coupled partial differential equations to be solved throughout the cell gap using a numerical procedure. The boundary-layer model assumes that all the concentration gradients lie within a 'region near the electrode surface. Hence, once the boundary-layer thickness $\left(\delta_{i}\right)$ is estimated for a particular flow configuration, the current densities can be evaluated. Therefore, the analytical solution for the surface concentration (equation 15) is applicable for any flow system in which a boundary-layer thickness can be estimated (e.g., rotating disk electrode, parallel plate under turbulent flow conditions). The results presented in this study are for a laminar system. In case of a turbulent flow system, the estimated boundary layer thickness would decrease and therefore, reactions 1-4 would be enhanced. For this reason, the boundary layer model is very versatile and can be modified easily to handle any flow system or cell configuration. The distributed parameter model cannot be modified as easily since the velocity profile in the catholyte/anolyte governing equations would have to be changed. 
Governing Equations for a Batch Run:

The batch system consists of the electrochemical reactor and two recirculation tanks. The main purpose of the recirculation tanks is to allow processing of a large system inventory. It also aids in the flashing of gases trapped in the process streams. Due to assumption 1 which states that the dynamics of the reactor are negligible, the species molar balance in the catholyte portion of the batch cell (Figure 2) is written as,

$$
\frac{d\left(V_{r e s, c} C_{i, b, c}\right)}{d t}=-\sum_{j} \frac{s_{i j} i_{j} A}{n_{j} F}-A N_{i, s}-F_{v c} y_{i, c}
$$

where, $N_{i, s}$ represents, the net flux through the separator. The vapor flowrate $\left(F_{v c}\right)$ and mole-fractions $\left(y_{i, c}\right)$ are evaluated using the "flash" routine in the SPEEDUP library. The input parameters to the "flash" routine are the inlet flowrate, inlet composition, pressure and temperature of the flash tank. The physical properties are obtained using Properties Plus. A similar procedure can be written for the anolyte portion.

An equation analogous to equation 13 can be written for the flux of species "i" across the separator, as follows,

$$
N_{i, s}=-D_{i, e} \frac{d C_{i}}{d x}+\frac{z_{i} \dot{D}_{i, e} F}{\mathfrak{R} T} \frac{i_{t}}{\kappa_{s}} C_{i}
$$

Integrating equation 20 by using the known concentrations on both sides of the separator and rearranging gives,

$$
N_{i, s}=\left[\frac{C_{i, b, a}}{C_{i, b, c}}-e^{\gamma_{i, s} \delta_{s}}\right] *\left[\frac{D_{i, e} \gamma_{i, s} C_{i, b, c}}{1-e^{\gamma_{i, s} \delta_{s}}}\right]
$$

where, $\quad D_{i, e}=\frac{D_{i}}{N_{m}} \quad$ and $\quad \gamma_{i, s}=\frac{z_{i} F i_{t}}{\mathfrak{R T} \kappa_{s}}$

where, $\quad \kappa_{s}=\frac{F^{2}}{2 \mathfrak{R} T} \sum_{i} z_{i}^{2} D_{i, e}\left(C_{i, b, c}+C_{i, b, a}\right) N_{m}$.

The separator used in this study is permeable to all species. The effective diffusion coefficient and the conductivity are characterized by a MacMullin number ${ }^{18}, N_{m}$, which is a function of the separator's porosity and tortuosity. 
The boundary-layer model assumes that the gases produced remain in solution inside the electrochemical reactor. After passing through the reactor, a flash occurs in the recirculation tank. The SPEEDUP program is connected to Properties Plus so that the physical properties and VLE (vapor-liquid equilibrium) calculations can be accurately determined. Properties Plus uses the UNIFAC approach to perform the VLE calculations.

\subsection{Results of Simulation and Optimization Studies}

The physical and kinetic parameters shown in Table 3 are used to perform batch runs (a low voltage run and a high voltage run). Single-pass studies are performed at various times during one batch run (low voltage run) in order to illustrate that an optimal current exists. The optimization algorithm estimates the changes in this optimal current during the batch run. Some of the values such as exchange current densities are presently approximated due to lack of experimental data.

\subsubsection{Batch Simulation Results:}

The simulation of the batch cell provides a rough estimate of the energy consumed and time required for $95 \%$ reduction of nitrates and nitrites. Also, at the cathode, it is desirable to maximize the current efficiency of reactions $1-4$ and minimize the current efficiency of reaction 5 (production of $\mathrm{H}_{2}$ ). At the anode, it is desirable to maximize the efficiency of reaction 6 (oxidation of $\mathrm{OH}$ ) and minimize that of reaction 7 (oxidation of nitrite to nitrate). Two test case batch runs were performed at cell voltages of $3.5 \mathrm{~V}$ (low voltage run) and $5.65 \mathrm{~V}$ (high voltage run). In each case, catholyte reservoir volume and anolyte reservoir volume were kept at $700 \mathrm{ml}$ and $7000 \mathrm{ml}$ respectively.

\section{Low voltage run}

Figure 4 shows a plot of the current efficiencies at the cathode vs. total coulombs passed for a batch run performed at a constant cell voltage of $3.5 \mathrm{~V}$. The total coulombs passed is the time integral of the operating current. The cell current ranged from a maximum of $0.42 \mathrm{~A} / \mathrm{cm}^{2}$ (at startup) and a minimum of $0.3 \mathrm{~A} / \mathrm{cm}^{2}$. Initially, nitrate reduction (reaction 1) has the largest current efficiency. It gradually decreases throughout the run as the nitrate concentration decreases. In contrast, the fraction of current going into reactions 2 through 5 increases through the first half of the run. The initial increase in the current associated with reactions 2 through 4 is due to an increase in nitrite concentration. However, towards the end of the run the nitrite concentration decreases and therefore the rate of reactions 
2 through 4 decreases. By the end of the run, very little nitrate and nitrite remain and almost all the current is due to $\mathrm{H}_{2}$ evolution (reaction 5). The current efficiencies at the anode are not shown since reaction 6 consumes nearly all of the current.

Figure 5 shows the ionic concentrations in the catholyte recirculation tank vs. coulombs passed. It can be seen that the concentration of nitrates and nitrites are reduced $95 \%$ over the course of the run. The nitrite concentration shows an initial increase because the rate of production of nitrite from reaction 1 exceeds its destruction rate (reactions 2, 3, and 4) which is evident from Figure 4.

The catholyte off-gas compositions are shown in Figure 6. It can be seen that $\mathrm{N}_{2}$, $\mathrm{N}_{2} \mathrm{O}$, and $\mathrm{H}_{2}$ are the major gases produced at the beginning of the run even though the current efficiencies for reactions 4 and 5 are lower than those of reaction 2 $\left(\mathrm{NH}_{3}\right.$ production). This is because the solubility of $\mathrm{NH}_{3}$ is much higher than those of $\mathrm{N}_{2}, \mathrm{~N}_{2} \mathrm{O}$, and $\mathrm{H}_{2}$. After most of the nitrates and nitrites are destroyed, hydrogen becomes the major off-gas.

The plot of total current vs. coulombs passed is shown in Figure 7. It decreases gradually during the course of the simulation.

Figure 8 shows a prediction of the total gas flowrate vs. coulombs passed. Around 500,000 coulombs, the curve shows an abrupt rise. This is due to the increase in $\mathrm{H}_{2}$ generation.

\section{High voltage run}

Since the objective of the process is to destroy both nitrates and nitrites as quickly as possible, a batch run at $5.65 \mathrm{~V}$ was performed to investigate the consequence of operating at high destruction rates. The cell current ranged from a maximum of $1.38 \mathrm{~A} / \mathrm{cm}^{2}$ (at startup) and a minimum of $0.85 \mathrm{~A} / \mathrm{cm}^{2}$. The rest of the parameters were left unchanged. The resulting plots are shown in Figures 9 through 11.

A plot of the cathodic current efficiencies vs. total coulombs passed is shown in Figure 9. It can be seen that, except for early in the batch when the $\mathrm{NH}_{3}$ production rate is high, most of the cell current goes into $\mathrm{H}_{2}$ production (reaction 5). The high $\mathrm{H}_{2}$ partial current results because reactions 1-4 are under masstransfer control during the entire batch run. This is the reason why no peaks (see Figure 4) are obtained. The large rate of $\mathrm{H}_{2}$ production represents a significant amount of energy going into an undesired product. By the end of the run, very little nitrate and nitrite remain and hence the efficiency of reaction 5 is the highest (about 90\%). 
Figure 10 shows the ionic concentrations in the catholyte recirculation tank vs. coulombs passed for the high voltage run. The cell voltage is maintained constant at $5.65 \mathrm{~V}$. Unlike the low voltage case, the nitrite concentration shows a constant decrease because the rate of nitrite destruction from reactions 2,3 , and 4 is much greater than the rate of production from reaction 1 . This is due to the high current associated with reaction 2. The catholyte off-gas compositions are shown in Figure 11. It can be seen that $\mathrm{H}_{2}$ and $\mathrm{NH}_{3}$ are the major gases throughout the run as indicated by the high current efficiencies associated with their production.

Figure 12 shows a comparison of the nitrate and nitrite concentrations as a function of time for the two batch runs. It can be seen that the initial overall destruction rate (rate of destruction of nitrate and nitrite combined) is greater in the high voltage run than in the low voltage run. To obtain $95 \%$ conversion of the total concentration of nitrates and nitrites at $3.4 \mathrm{~V}$ requires approximately 7.4 hours, while at $5.65 \mathrm{~V}$ requires 6.4 hours.

\subsubsection{Batch optimization:}

The previous sections focused on batch simulations where the cell voltage was held constant. However there will likely be an optimal operational path in which the cell voltage (or cell current) is varied throughout the batch run. This optimal path will help achieve the basic design goal of this process, viz., to obtain as large destruction of nitrates and nitrites as possible within a short period of time for a minimum input of energy and capital investment. For this process, two parameters which affect the process economics are destruction current density and destruction efficiency. A methodology describing how- the model can be used to determine optimal batch cell operation is presented.

\section{Background}

To minimize capital costs, it is necessary to maximize the amount of waste destroyed in a specific time period. This would, in turn, reduce the size of electrode area required. Maximizing the amount of waste destroyed during in a certain time period is equivalent to maximizing the destruction current (current going into reactions 1 to 4 ). Figure 13 shows a plot of destruction current vs. total current at different points in time (represented by total charge passed) during the low voltage batch simulation. A peak in the destruction current on each curve corresponds to an optimum total current. The formation of a peak is mainly due to the migration effect which repels the nitrates and nitrites away from the cathode, thereby increasing the current going into $\mathrm{H}_{2}$ production (reaction 5). Note that the 
low voltage run operates at a very low destruction rate throughout most of the batch; the high voltage run operates near the maximum destruction rate at the start of the batch, but moves beyond the maximum after the start of the batch.

Clearly, adjusting the operating current to pass through these maxima throughout the batch will maximize the destruction rate and hence minimize the time to reach $95 \%$ conversion of nitrates and nitrites. However, such a strategy may generate an unacceptable amount of $\mathrm{H}_{2}$. For example, applying an operating current of 1.4 $\mathrm{A} / \mathrm{cm}^{2}$ (the peak destruction rate) at the start of the batch will result in $0.2 \mathrm{~A} / \mathrm{cm}^{2}$ going into $\mathrm{H}_{2}$ production. Production of excessive amounts of $\mathrm{H}_{2}$ causes high energy (electrical energy) losses resulting in increased operating costs. Thus, operating at the maxima will lead to low capital but high operating costs. An optimization formulation which will provide a balance between capital and operating costs and lead to minimum overall cost is,

$$
\begin{aligned}
& \text { Minimize [Capital cost + Operating cost] } \\
& \text { subject to } \\
& \text { 1) Nitrate and nitrite reduction } \geq 0.95 \\
& \text { 2) Processing time } \leq t_{p} \\
& \text { 3) Destruction efficiency } \geq \varepsilon_{d}
\end{aligned}
$$

The destruction efficiency, $\varepsilon_{d}$, can be set to achieve a feasible optimum current which will bring about minimized overall costs. The choice of $\varepsilon_{\mathrm{d}}$ may depend on a number of factors like $\mathrm{H}_{2}$ and $\mathrm{NH}_{3}$ production, destruction rate of nitrates and nitrites, total processing time, and safety. To illustrate how the optimal current would vary in order to maintain an acceptable destruction efficiency, $\varepsilon_{d}$ versus the total current is plotted in Figure 14. The symbol " 0 " indicates the maximum destructive current for which a destruction efficiency of at least 0.98 is obtained. The symbol " $x$ " in the figure corresponds to the maxima from Figure 13.

Notice that operating at the maximum destruction current yields a slightly reduced efficiency (and increased $\mathrm{H}_{2}$ evolution). By reducing the total current slightly from the maximum, much better efficiencies are attained while reducing the destruction rate only slightly. Also shown in Figure 14 is the efficiency during the low voltage run (indicated by the symbol "*"). A destruction efficiency of nearly 1.0 was attained during the first half of the batch run and as a result very little $\mathrm{H}_{2}$ was produced. The efficiency dropped to about 0.1 by the end. Unfortunately the overall destruction rate was low. By comparison, at the beginning of the batch, the high voltage case yielded very high destruction rates, but an efficiency of only 0.82. Near the end the batch, this efficiency was around 0.02 . 


\section{Procedure}

An examination of the batch cell governing equations and the optimization objective function shows that the optimum current $\left(\mathrm{i}_{\mathrm{opt}}\right)$ is mainly a function of $\mathrm{NO}_{3}{ }^{-}$and $\mathrm{NO}_{2}{ }^{-}$concentration and destruction efficiency $\left(\varepsilon_{\mathrm{d}}\right)$. Therefore, several single-pass optimization runs were performed to obtain $i_{\text {opt }}$ for different values of $\mathrm{NO}_{3}^{-}, \mathrm{NO}_{2}^{-}$, and $\varepsilon_{\mathrm{d}}$. The $\mathrm{NO}_{3}{ }^{-}$concentration was varied from $0.1 \mathrm{M}$ to $1.95 \mathrm{M}$, $\mathrm{NO}_{2}^{-}$concentration was varied from $0.03 \mathrm{M}$ to $0.6 \mathrm{M}$, and $\varepsilon_{\mathrm{d}}$ was varied from 0.82 to 0.99 . Figure 15 shows a 3-D plot of $\mathrm{i}_{\text {opt }}$ as a function of $\mathrm{NO}_{3}{ }^{-}$and $\mathrm{NO}_{2}{ }^{-}$at two different destruction efficiencies ( 0.98 and 0.82$)$. It can be seen that operating at a lower $\varepsilon_{d}$ yields higher currents. But from Figure 11 , it can be seen that higher currents lead to significant $\mathrm{H}_{2}$ evolution.

The input-output data obtained from the single-pass optimization runs was used to train a Neural Network. The purpose of the Neural Network is to obtain a mapping between the output vector $\left(\mathrm{i}_{\mathrm{opt}}\right)$ and input vectors $\left(\mathrm{NO}_{3}{ }^{-}, \mathrm{NO}_{2}^{-}\right.$and $\left.\varepsilon_{\mathrm{d}}\right)$. A brief introduction to Neural Networks, followed by a description of the training and testing procedure is given in the next section. The Neural Net mapping function is used in conjunction with the batch cell model to perform a batch optimization run.

\section{Function identification using a Neural Network}

A Neural Network consists of a large number of simple processors called neurons ${ }^{19}$ that are reminiscent of biological nervous systems. The network function is determined largely by the appropriate weighted connections between these neurons. A typical network consisting of an input layer, a hidden layer and an output layer is shown in Figure 16. Each neuron in the input layer has one single external input. Each neuron in the hidden layer has an input from every neuron in the input layer and an additional fixed value input, called the bias. Finally, each neuron in the output layer has an input from every neuron in the hidden layer and a bias. The output layer provides the solution arising from the combination of the inputs. More complicated networks have additional hidden layers.

In this work, the purpose of the Neural Network is to obtain a mapping between the output vector $\left(\mathrm{i}_{\mathrm{opt}}\right)$ and input vectors $\left(\mathrm{NO}_{3}{ }^{-}, \mathrm{NO}_{2}{ }^{-}\right.$and $\left.\varepsilon_{\mathrm{d}}\right)$ via the backpropogation learning rule ${ }^{20}$. This rule helps to adjust the weights and biases of the network so as to minimize the sum squared error of the network. Three neurons in the input layer, three in the hidden layer and one neuron in the output layer are used in this work. The network was trained using $68 \%$ of the data generated through single-pass optimization runs. The plot of network prediction vs. training data is shown in Figure 17 . The rest $32 \%$ of the data was used for 
testing the trained network. The plot of network prediction vs. test data is shown in Figure 18. From Figures 17 and 18 it is clear that the Neural Network with one hidden layer does a very good job of identifying the functional relationship between $\mathrm{i}_{\text {opt }}$ and $\mathrm{NO}_{3}{ }^{-}, \mathrm{NO}_{2}{ }^{-}, \varepsilon_{\mathrm{d}}$.

\section{Results of optimization runs}

In the previous two batch runs reported in section 3.3.1, the cell voltage was fixed. In the optimization run, the optimal value of the cell current (and hence the cell voltage) at every point in time during the run is evaluated by the Neural Network mapping function, based on a value of $\varepsilon_{d}$ (which stays fixed throughout the batch run) and the concentrations of $\mathrm{NO}_{3}{ }^{-}$and $\mathrm{NO}_{2}{ }^{-}$existing at that time. The physical and kinetic parameters were unchanged. Figures 19 through 22 represent the results for one of the optimization runs where the constraint on $\varepsilon_{d}$ is set at 0.98 . These plots have been shown so that comparisons with previous batch runs can be made.

Figure 19 shows a plot of the current efficiencies at the cathode vs. total coulombs passed for the optimization run $\left(\varepsilon_{\mathrm{d}}=0.98\right)$. The cell current ranged from a maximum of $1.057 \mathrm{~A} / \mathrm{cm}^{2}$ (at startup) and a minimum of $0.062 \mathrm{~A} / \mathrm{cm}^{2}$ (at the end). Comparing with Figure 4, it can be seen that the current associated with reaction 5 $\left(\mathrm{H}_{2}\right.$ production $)$ is very low throughout the run. This was one of the objectives of the optimization routine.

The catholyte off-gas compositions are shown in Figure 20. It can be seen that $\mathrm{N}_{2}$, and $\mathrm{H}_{2}$ are the major components in the gas phase at the beginning of the run even though the current efficiency for reaction 5 is the lowest. This is because $\mathrm{H}_{2}$ has the lowest solubility in comparison to $\mathrm{NH}_{3}$ and $\mathrm{N}_{2} \mathrm{O}$. But in contrast to Figures 6 and 11 , where the $\mathrm{H}_{2}$ production increases towards the end, the optimization run produces significantly less $\mathrm{H}_{2}$. In fact, $\mathrm{NH}_{3}$ and $\mathrm{N}_{2} \mathrm{O}$ generation increases considerably.

Figure 21 shows a comparison of the nitrate and nitrite concentrations as a function of time for the two batch runs and the optimization run. It can be seen that the overall destruction rate (rate of destruction of nitrate and nitrite combined) is greatest during the optimization run. It takes the low voltage run approximately 7.4 hours, the high voltage run approximately 6.4 hours and the optimization run approximately 5.1 hours to reduce the total concentration of nitrates and nitrites by $95 \%$. 
A plot of how the optimal operation current changes during the course of the run is shown in figure 22. It can be seen that the current follows an exponentially decreasing path. Although not shown here, the cell voltage also follows an exponentially decreasing path.

From Figures 19 and 20 it is clear that the optimization algorithm prevents, $\mathrm{H}_{2}$ generation beyond a certain limit. Hence, it can now be suitably used to minimize total (capital plus operating) cost. Optimization runs were performed at different destruction efficiencies (varying from 0.83 to 0.99 ) and the total cost evaluated for each of these runs. Appendix 1 gives a description of how the costs were evaluated, with the help of an example.

The yearly payment on capital cost vs. destruction efficiency is plotted in Figure 24a. The curve shows a minimum at ${ }^{\prime} E_{d}=0.93$. Figure $24 \mathrm{~b}$ shows the plot of yearly operating cost vs. destruction efficiency. The curve seems to asymptotically decrease with increase in destruction efficiency. Figure $24 \mathrm{c}$ shows the plot of yearly total cost vs. destruction efficiency. It can be seen that the lowest cost is obtained by operating the cell at about $95 \%$ destruction efficiency. Additional simulations have shown that the cost function is very sensitive in the region $0.94<E_{d}<1.0$. Therefore, the minimum would strongly depend on the accuracy and robustness of the Neural Network in predicting the optimal current in the region of interest.

\section{The Evaporator Model}

The outlet stream from the electrochemical reactor is mostly $\mathrm{NaOH}$, but small amounts of nitrates and nitrites will be present. The function of the evaporator is to concentrate the $\mathrm{NaOH}$, which can then be recycled back as the anolyte to the divided cell reactor. This is achieved by using steam to evaporate sufficient water to produce a more concentrated $\mathrm{NaOH}$ solution.

In order to achieve a significant reduction in the capital and operating costs, a dynamic triple effect evaporator (in feed forward configuration) was studied. Steam is used to provide the heat input to the first effect. The superheated vapor that is formed (due to evaporation) is then used to heat the liquor in the second effect and so on. For modeling purposes, it is assumed that the dissolved gases are stripped from the outlet stream (from the $\mathrm{EC}$ reactor) before feeding into the evaporator. 


\subsection{Model Assumptions}

The assumptions below have been made to simplify the calculational procedure:

1) perfect mixing is achieved,

2) vapor holdup is negligible relative to the mass of holdup of thick liquor in the evaporator,

3) vapor phase is pure water,

4) no heat losses,

5) complete condensation of steam takes place in the heat exchanger section,

6) heat transfer area and heat transfer coefficient are constant, and

7) energy holdup in the walls of the metal tubes is negligible.

\subsection{Model Development}

The governing equations are given below.

\section{Total Mass Balance:}

$$
\frac{d(\rho V)}{d t}=Q_{f} \rho_{f}-Q_{l} \rho_{l}-Q_{v} \rho_{v}
$$

Component Molar Balance:

$$
\frac{d\left(V C_{i}\right)}{d t}=Q_{f} C_{i, f}-Q_{l} C_{i, l}-\frac{Q_{v} P}{R_{g} T} y_{i}
$$

Energy Balance:

$$
\frac{d\left(V \sum_{i} C_{i, l} H\right)}{d t}=Q_{f} \sum_{i} C_{i, f} H_{f}+E_{i n}-Q_{l} \sum_{i} C_{i, l} H_{l}-\frac{Q_{v} P}{R_{g} T} H_{v}-E_{l o s}
$$


Mass Equilibrium ${ }^{21}$ :

$$
m\left(X_{i, l}\right) T^{s a t}+b\left(X_{i, l}\right)-\Upsilon=0
$$

where, $X_{i, l}=\frac{C_{i, l}}{\sum_{i} C_{i, l}}$

The temperature inside the evaporator $(r)$ is superheated (due to boiling point elevation) and is related to the saturated temperature by means of equation (23). It might be noted here, that, the enthalpies in the energy balance are evaluated by Properties Plus, by use of the Soave-Redlich-Kwong (SRK) equation of state. $E_{\text {in }}$ is the heat input to the heat exchanger section of the evaporator by means of steam. Hence, $E_{\text {in }}$ would be equal to the heat transfer rate through the heat exchanger surface, which in turn would be equal to the heat given out by the condensing steam.

\subsection{Results of Simulation Studies}

The product solution left over after destruction of nitrates and nitrites is mainly a caustic $(\mathrm{NaOH})$ solution. This solution is fed continuously to the triple effect evaporator. Superheated steam at $350^{\circ} \mathrm{C}$ is passed through the first effect. The amount of evaporation taking place in each effect is monitored by plotting the change of mass fraction of $\mathrm{NaOH}$ in the solution with time. The operating conditions are tabulated in Table 4. The steady state predictions are tabulated in Table 5.

In order to study the optimization and control of the evaporator system, it is essential to understand the dynamics correctly. This is accomplished by giving a step change in one of the input variables and observing the response of the desired output variables. Test studies were carried out at different feed weight fractions, and evaporator pressures. Results from one such test study are presented. In this study, a $10 \%$ step change was given in the inlet concentration of $\mathrm{NaOH}$ and the responses of the desired output variables, viz., mass fraction of $\mathrm{NaOH}$ in each effect was observed. The feed weight fraction of $\mathrm{NaOH}$ in this study has been arbitrarily chosen to be 0.38 .

The plot of the mass fraction of $\mathrm{NaOH} v s$. time for the first effect is shown in Figure 24. The response is similar to first order dynamics. Figures 25 and 26 show the same plot for second and third effects, respectively. Both the curves exhibit an 
inverse response probably because the initial steady-state is itself unstable. Another reason could be that the chosen physical paratmeters are not very realistic. A comparison with experimental data is required at this point to ascertain the accuracy of the chosen parameters.

From the dynamic simulations, it can be seen that most of the evaporation takes place in the first effect. The same behavior was observed in all other test studies as well. Therefore, one can conclude (although premature) that a single-effect evaporator would be sufficient to concentrate the $\mathrm{NaOH}$ to the desired value. The amount of evaporation can be changed by changing parameters like pressure, holdup, flowrate and steam properties. 


\section{NOTATION}

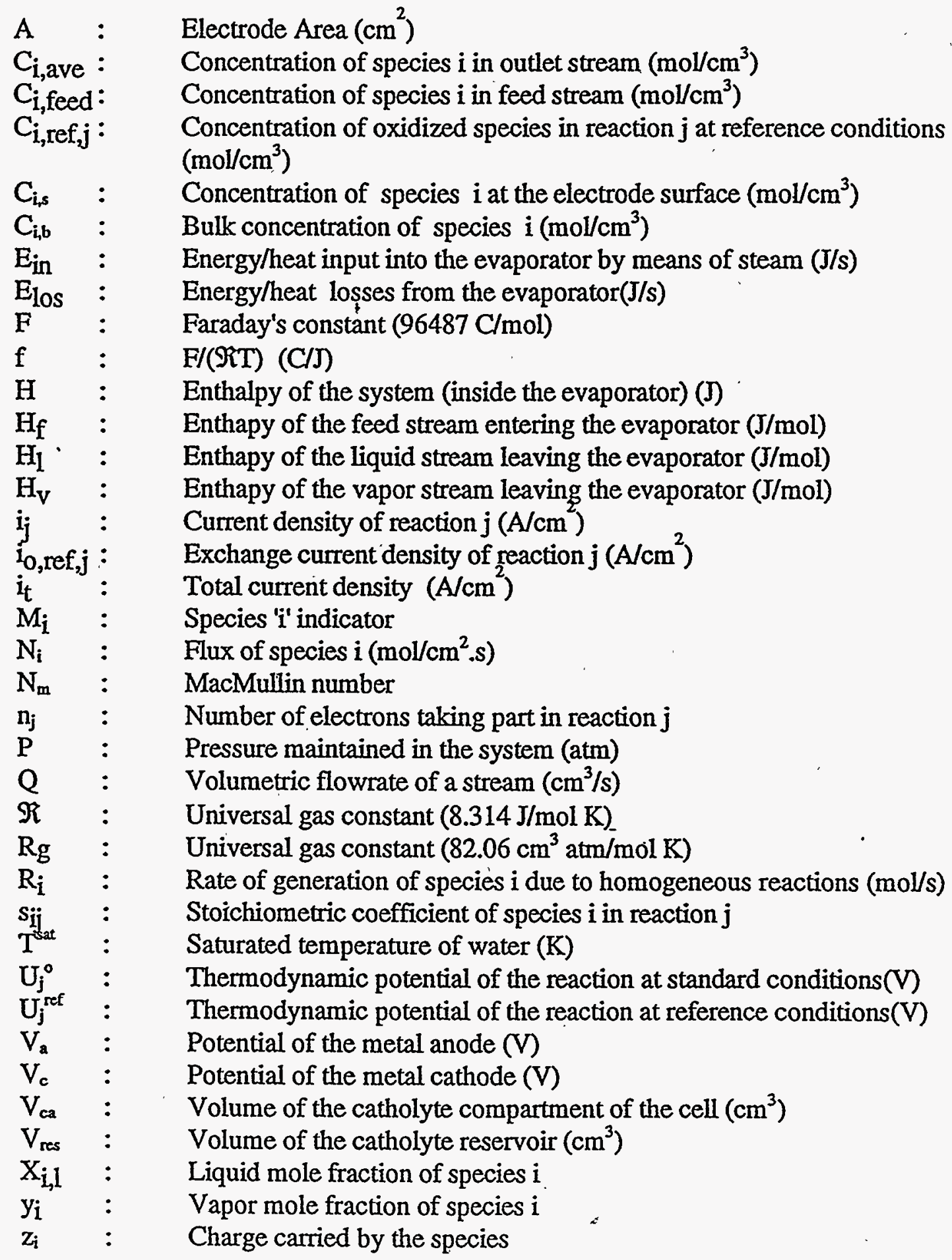




\section{REFERENCES}

1. Hobbs, D.T., "Electrochemical Treatment of Nuclear Waste at the Savannah River Site", in "Electrochemistry for a Cleaner Environment", J.D.Genders and N.L.Weinberg, Editors, The Electrosynthesis Company, Amherst, New York (1992).

2. Coleman, D., White, R.E., and Hobbs, D.T., J. Electrochem. Soc., 142, 1152 (1995).

3. Parrish, W.R., and Newman, J., J. Electrochem. Soc., 117, 43 (1970).

4. Sakellaropoulos, G., and Francis, G., J. Electrochem. Soc., 126, 1928 (1979).

5. White, R.E., Bain, M., and Raible, M., J. Electrochem Soc., 130, 1037 (1983).

6. Newman, J.S., "Electrochemical Systems", 2nd Ed., Prentice Hall, Englewood Cliffs, NJ, 1991.

7. Mader, M.J., Walton, C.W., and White, R.E., J. Electrochem. Soc., 133, 1124 (1986).

8. Caban, R., and Chapman, T.W., Chem. Eng. Sci., 36, 849 (1981).

9. Lee, J., and Selman, J.R., J. Electrochem. Soc., 129, 1670 (1982).

10. Smeltzer, J.C., and Fedkiw, P.S., J.'Electrochem. Soc., 139, 1358 (1992).

11. Smeltzer, J.C., and Fedkiw, P.S., J. Electrochem. Soc., 138, 3665 (1991).

12. Nguyen, T.V., Walton, C.W., and White, R.E., J. Electrochem. Soc., 133, 1130 (1986).

13. Smeltzer, J.C., and Fedkiw, P.S., J. Electrochem. Soc., 139, 1366 (1992).

14. Pickett, D.J., "Electrochemical Reactor Design", 2nd ed., Elsevier Scientific, New York (1979). 
15. Hobbs, D.T., Genders, J.D., and Hartsough, D., presented at the 185th meeting of the Electrochemical Soc., San Francisco (1994).

16. Hobbs, D.T., and Ebra, M., "Electrochemical Processing of Alkaline Nitrate and Nitrite Solutions", AIChE Symp Series No. 254, 83, 149 (1987).

17. Fan, D., and White, R.E., J. Electrochem. Soc., 138, 2952 (1991).

18. Van Zee, J.W., Watson, A.T., and White, R.E., J. Electrochem. Soc., 133, 501 (1986).

19. Lippman, R.P, "An Introduction to Computing with Neural Nets", IEEE ASSP Magazine, 4 (April 1987).

20. Bhat, N.V., Minderman, P.A., McAvoy, T., and Wang, N.S. "Modeling Chemical Process Systems via Neural Computation", IEEE Control Systems, 24 (April 1990).

21. Holland, C.D., and Liapis, A.I., "Computer Methods for Solving Dynamic Separation Problems", McGraw-Hill, N.Y., N.Y.(1983).

22. Wingard, D., Personal communication, University of South Carolina, Columbia, South Carolina (1994).

23. Peters, M.S., and Timmerhaus, K.D., "Plant Design and Economics for Chemical Engineers", McGraw-Hill, N.Y., N.Y. (1980).

24. Edgar, T.F., and Himmelblau, D.M., "Optimization of Chemical Processes", McGraw-Hill, N.Y., N.Y. (1988). 


\begin{tabular}{|c|c|}
\hline Component & Concentration (M) \\
\hline $\mathrm{NaNO}_{3}$ & 1.95 \\
\hline $\mathrm{NaNO}_{2}$ & 0.6 \\
\hline $\mathrm{NaOH}$ & 1.33 \\
\hline $\mathrm{NaAl}(\mathrm{OH})_{4}$ & 0.31 \\
\hline $\mathrm{Na}_{2} \mathrm{SO}_{4}$ & .0 .14 \\
\hline $\mathrm{Na}_{2} \mathrm{CO}_{3}$ & 0.16 \\
\hline $\mathrm{NaCl}$ & 0.022 \\
\hline $\mathrm{NaF}$ & 0.015 \\
\hline $\mathrm{Na}_{2} \mathrm{CrO}_{4}$ & 0.0033 \\
\hline $\mathrm{Na}_{3} \mathrm{PO}_{4}$ & 0.0085 \\
\hline $\mathrm{Na}_{2} \mathrm{SiO}_{3}$ & 0.0038 \\
\hline $\mathrm{NaB}\left(\mathrm{C}_{6} \mathrm{H}_{5}\right)_{4}$ & 0.0026 \\
\hline
\end{tabular}

Table 1: Composition of the decontaminated salt solution simulant

\begin{tabular}{|c|c|c|}
\hline Species & Init. Catholyte Comp.(M) & Init. Anolyte Comp.(M) \\
\hline $\mathrm{NO}_{3}^{-}$ & 1.95 & $1.95 \mathrm{e}-3$ \\
$\mathrm{NO}_{2}^{-}$ & 0.6 & $0.6 \mathrm{e}-4$ \\
$\mathrm{OH}^{-}$ & 1.33 & 3.8797 \\
$\mathrm{Na}^{+}$ & 3.88 & 3.88 \\
\hline
\end{tabular}

Table 2: Simulated feed composition as used by Coleman et al $^{2}$ 


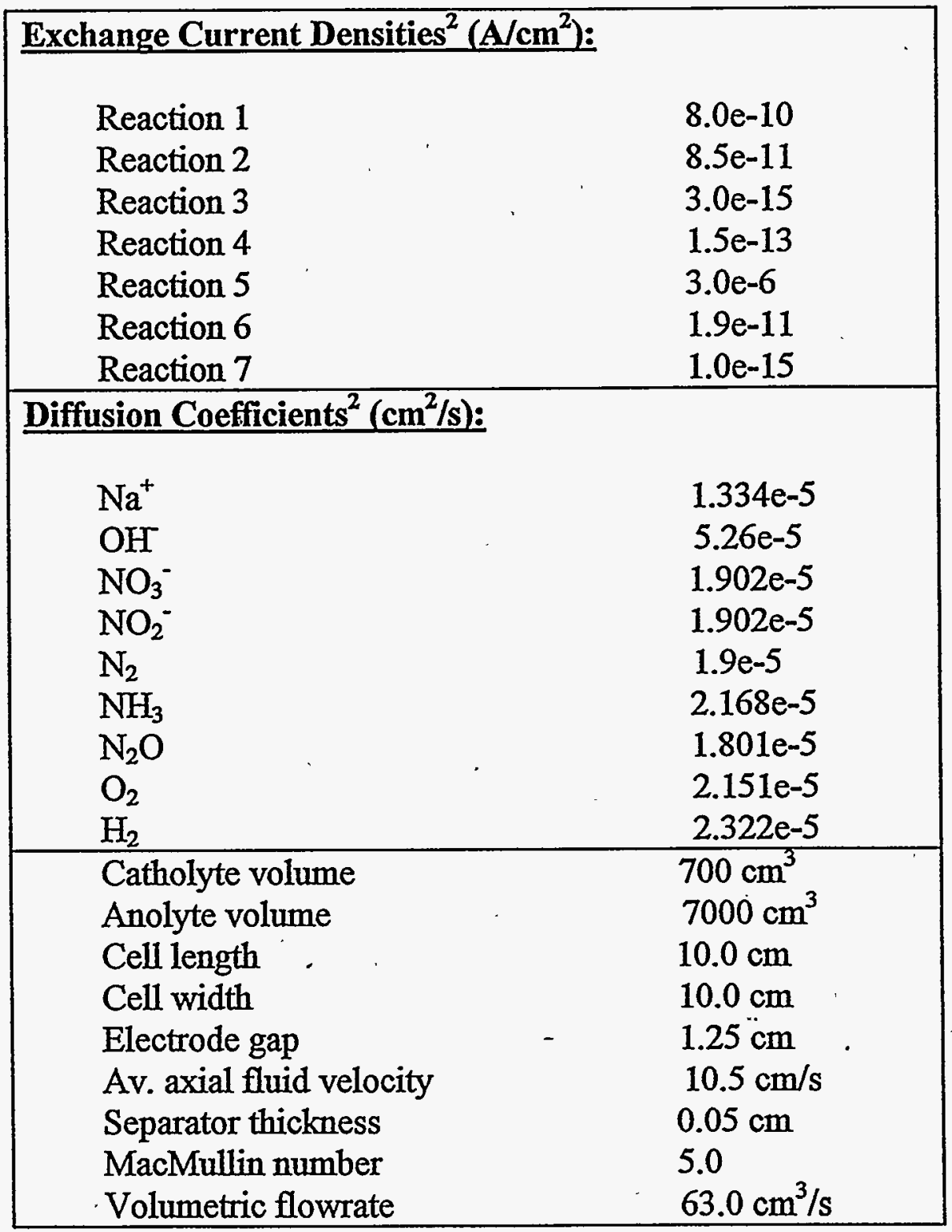

Table 3 : Kinetic parameters, physical parameters and operating conditions 


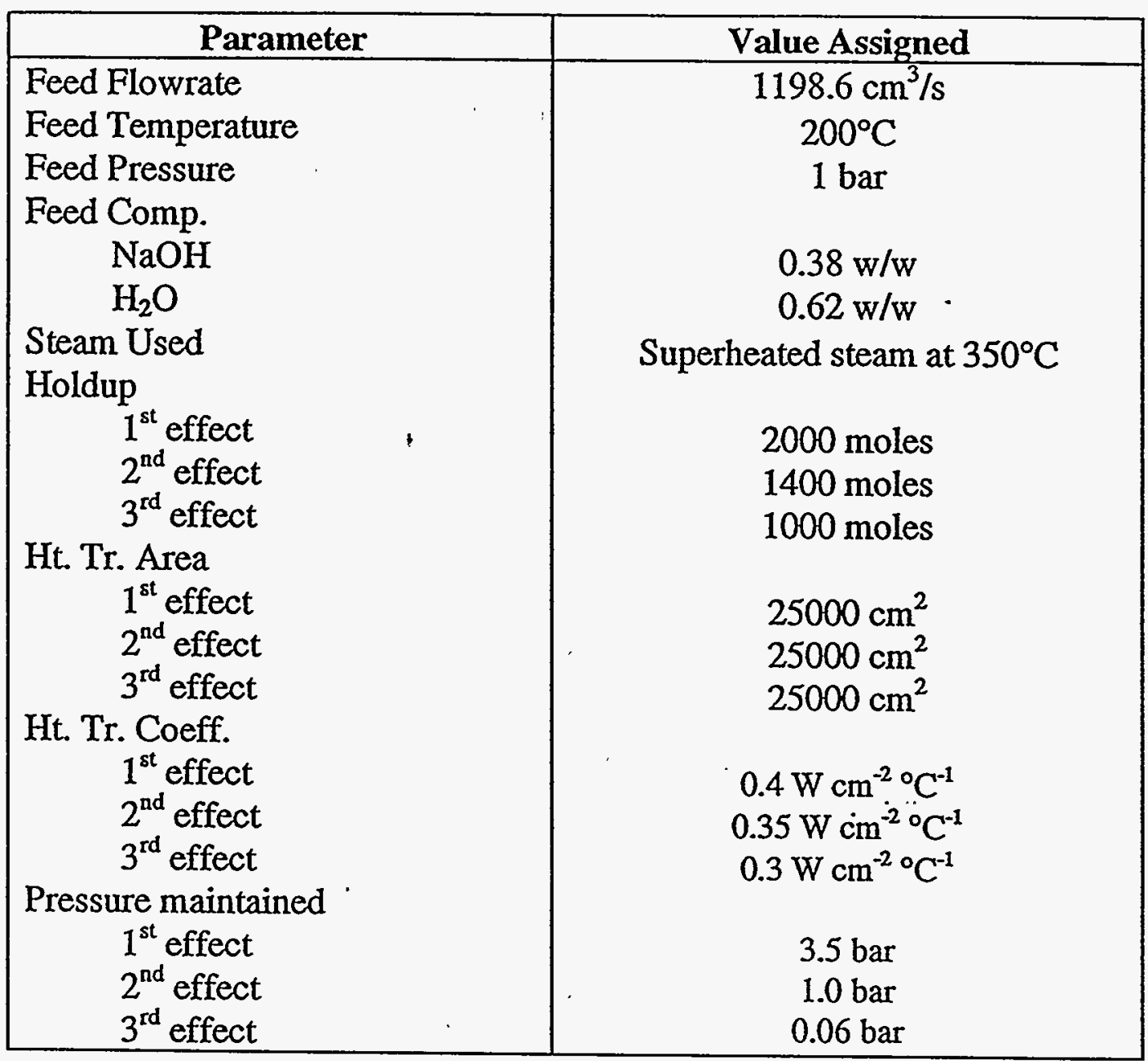

Table 4 : Operating Conditions for the Triple Effect Evaporator 


\begin{tabular}{|c|c|}
\hline Variable & S.S Value \\
\hline Liquid flowrate & $345.653 \mathrm{~cm}^{3} / \mathrm{s}$ \\
$1^{\text {st }}$ effect & $286.527 \mathrm{~cm}^{3} / \mathrm{s}$ \\
$2^{\text {nd }}$ effect & $213.825 \mathrm{~cm}^{3} / \mathrm{s}$ \\
$3^{\text {rd }}$ effect & \\
Vapor flowrate & $108.812 \mathrm{gms} / \mathrm{s}$ \\
$1^{\text {st }}$ effect & $12.392 \mathrm{gms} / \mathrm{s}$ \\
$2^{\text {nd }}$ effect & $16.093 \mathrm{gms} / \mathrm{s}$ \\
$3^{\text {rd }}$ effect & \\
Comp. of NaOH & 0.42 \\
$1^{\text {st }}$ effect & 0.424 \\
$2^{\text {nd }}$ effect & 0.43 \\
$3^{\text {rd }}$ effect & \\
\hline
\end{tabular}

Table 5 : Steady State Predictions for the Triple Effect Evaporator 


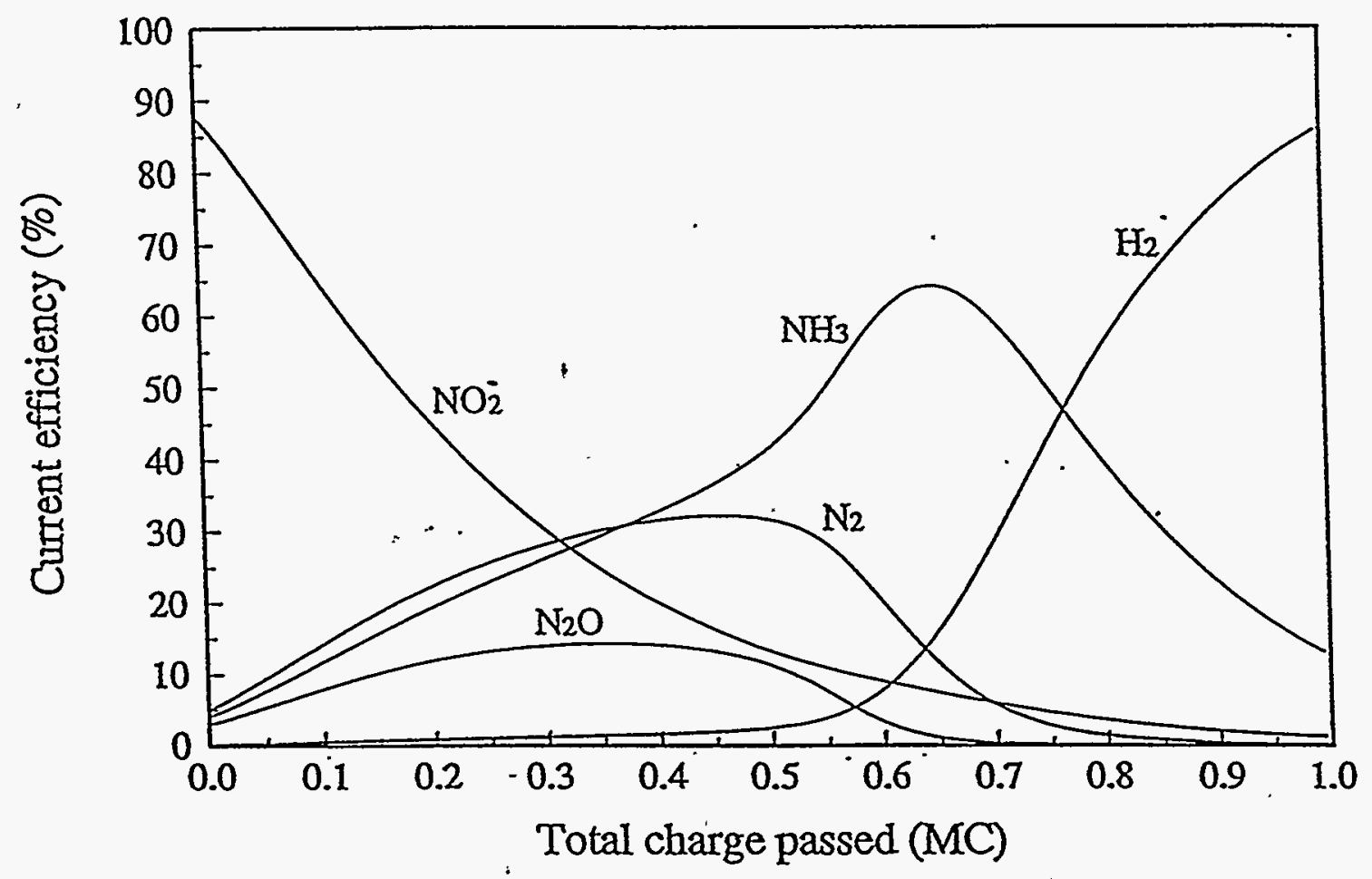

Figure 4: Current efficiencies for the five cathodic reactions as a function of total coulombs passed for the low voltage run. Cell voltage is $3.5 \mathrm{~V}$. Towards the end of the batch reaction $5\left(\mathrm{H}_{2}\right.$ production) increases rapidly. $\mathrm{MC}$ is an abbreviation for "Million Coulombs". 


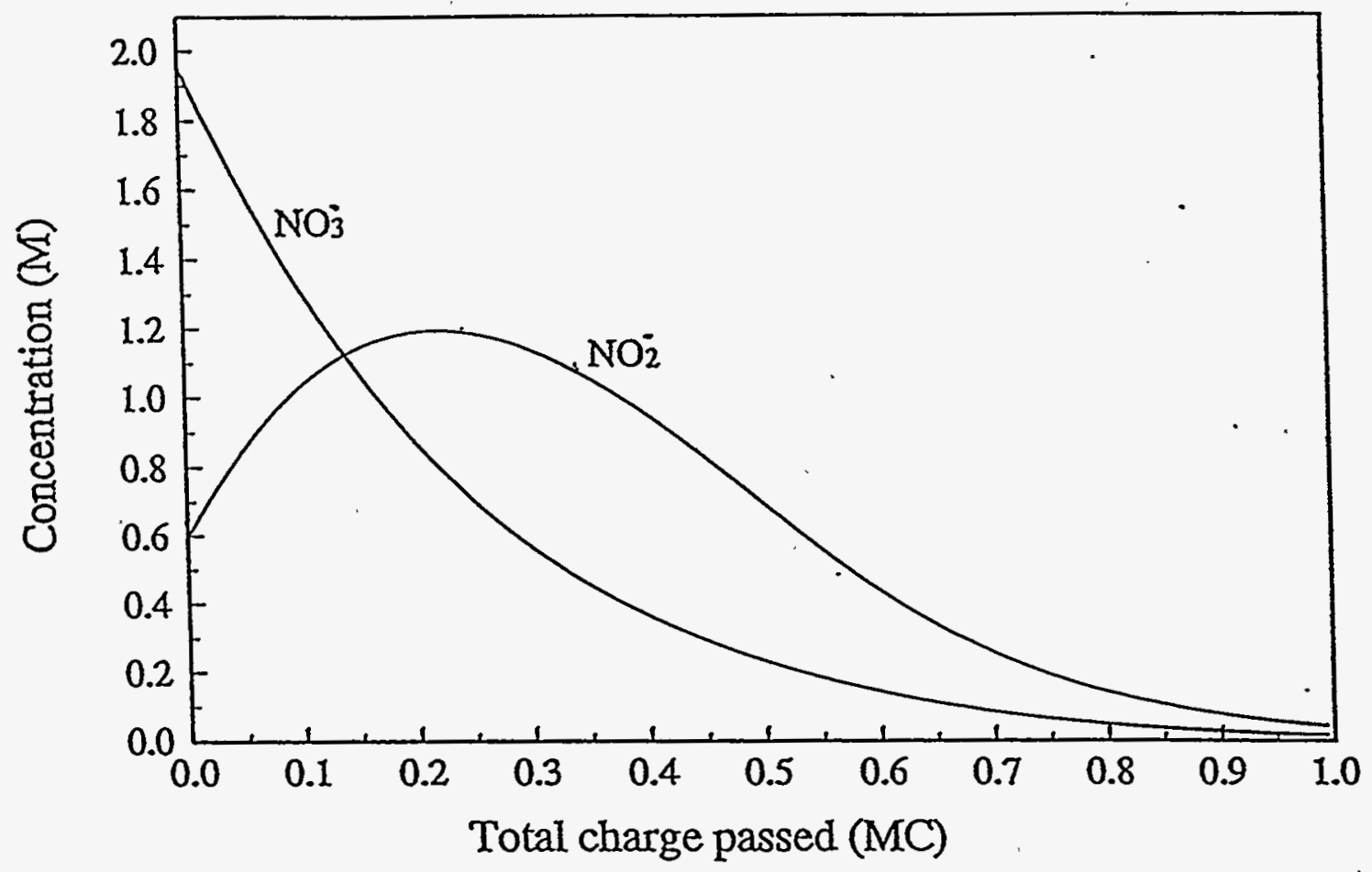

Figure 5: Ionic concentrations in the catholyte recirculation tank as a function of total coulombs passed for the low voltage run. MC is an abbreviation for "Million Coulombs". 


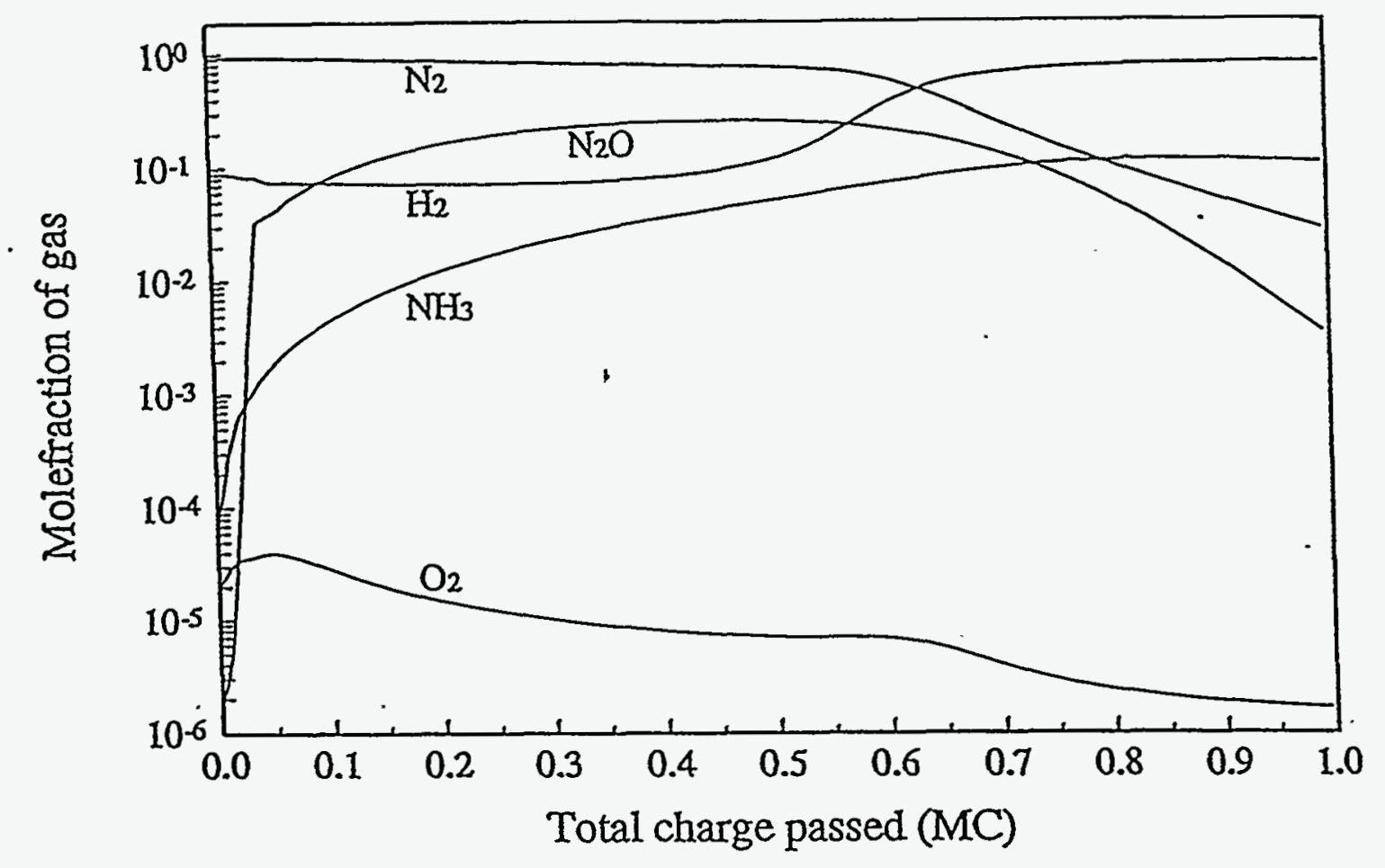

Figure 6: Off-gas composition from the catholyte recirculation tank as a function of total coulombs passed for the low voltage run. $\mathrm{N}_{2}$ is the main component of the off-gas during the initial phase of the simulation while $\mathrm{H}_{2}$ evolution becomes significant during the terminal phase. $\mathrm{NH}_{3}$ and $\mathrm{N}_{2} \mathrm{O}$ are the other major components of the gas phase. MC is an abbreviation for "Million Coulombs". 


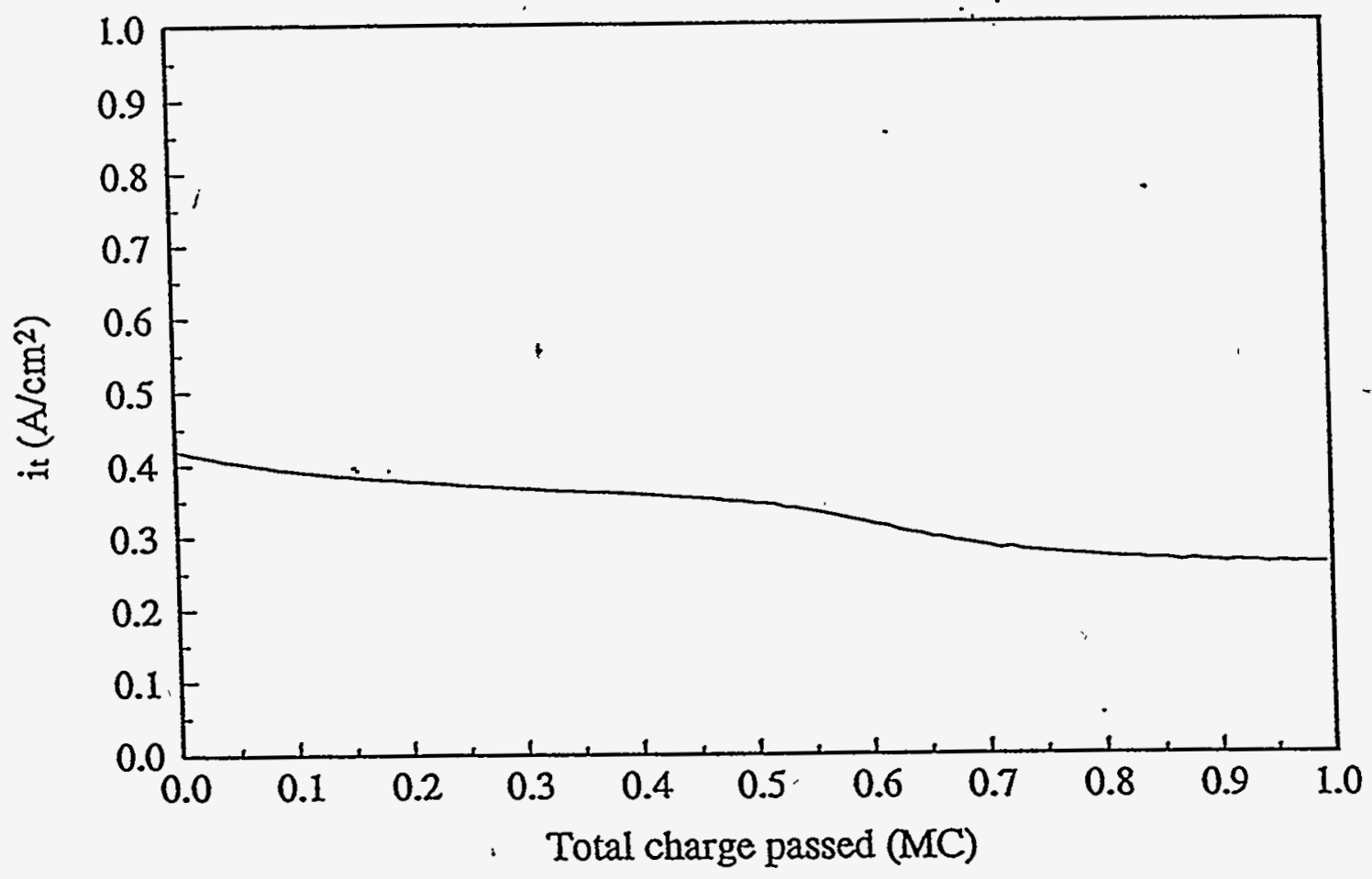

Figure 7: Total cell current as a function of total coulombs passed for the low voltage run. It decreases gradually during the course of the run because of decrease in the concentration of nitrates and nitrites. 


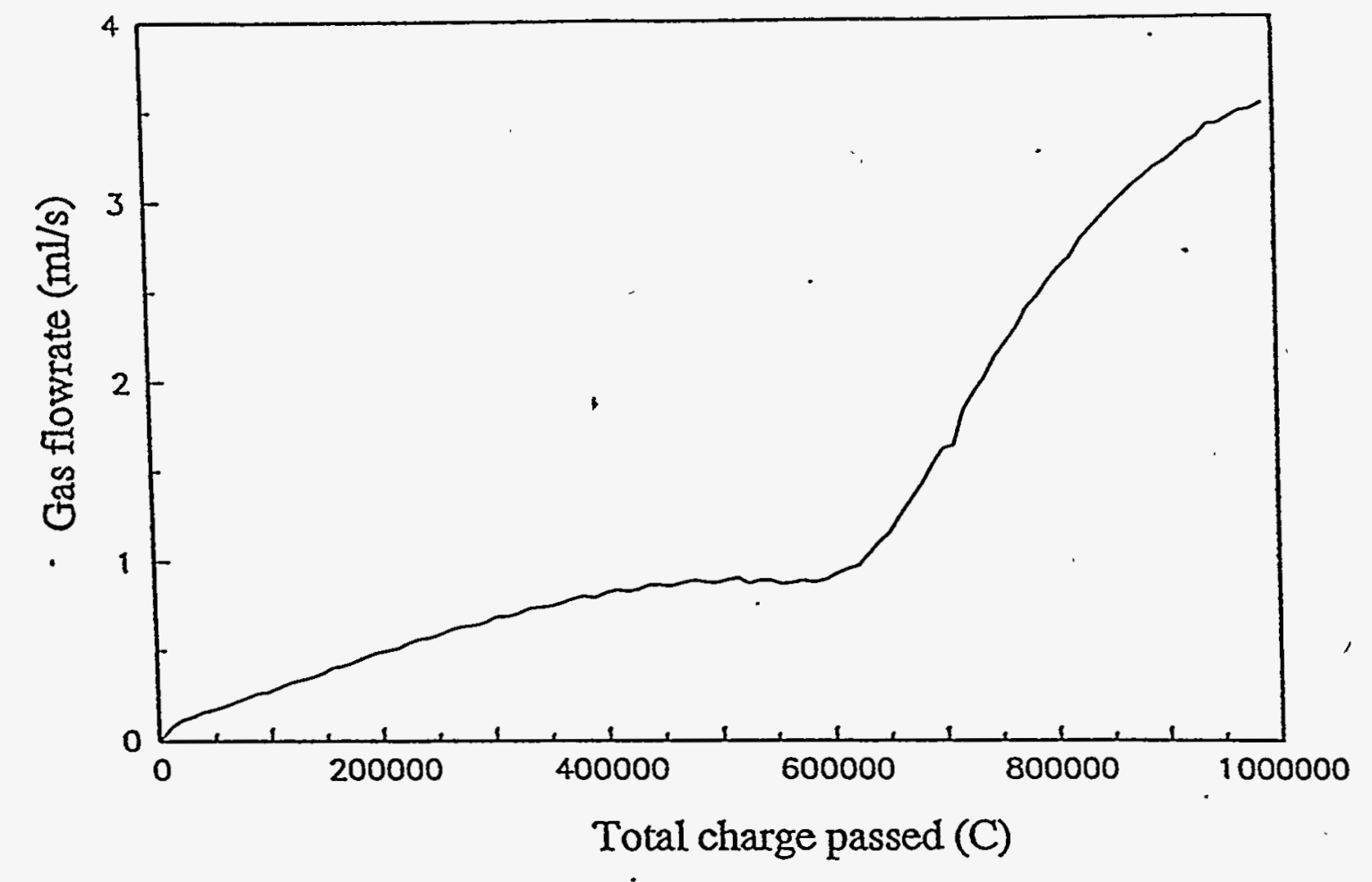

Figure 8: Volumetric gas flowrate as a function of total coulombs passed for the low voltage run. As the run proceeds, the solution gets saturated and hence more and more gas is evolved. The rise in the gas flowrate at around 500,000 coulombs is due to an increase in $\mathrm{H}_{2}$ evolution. 


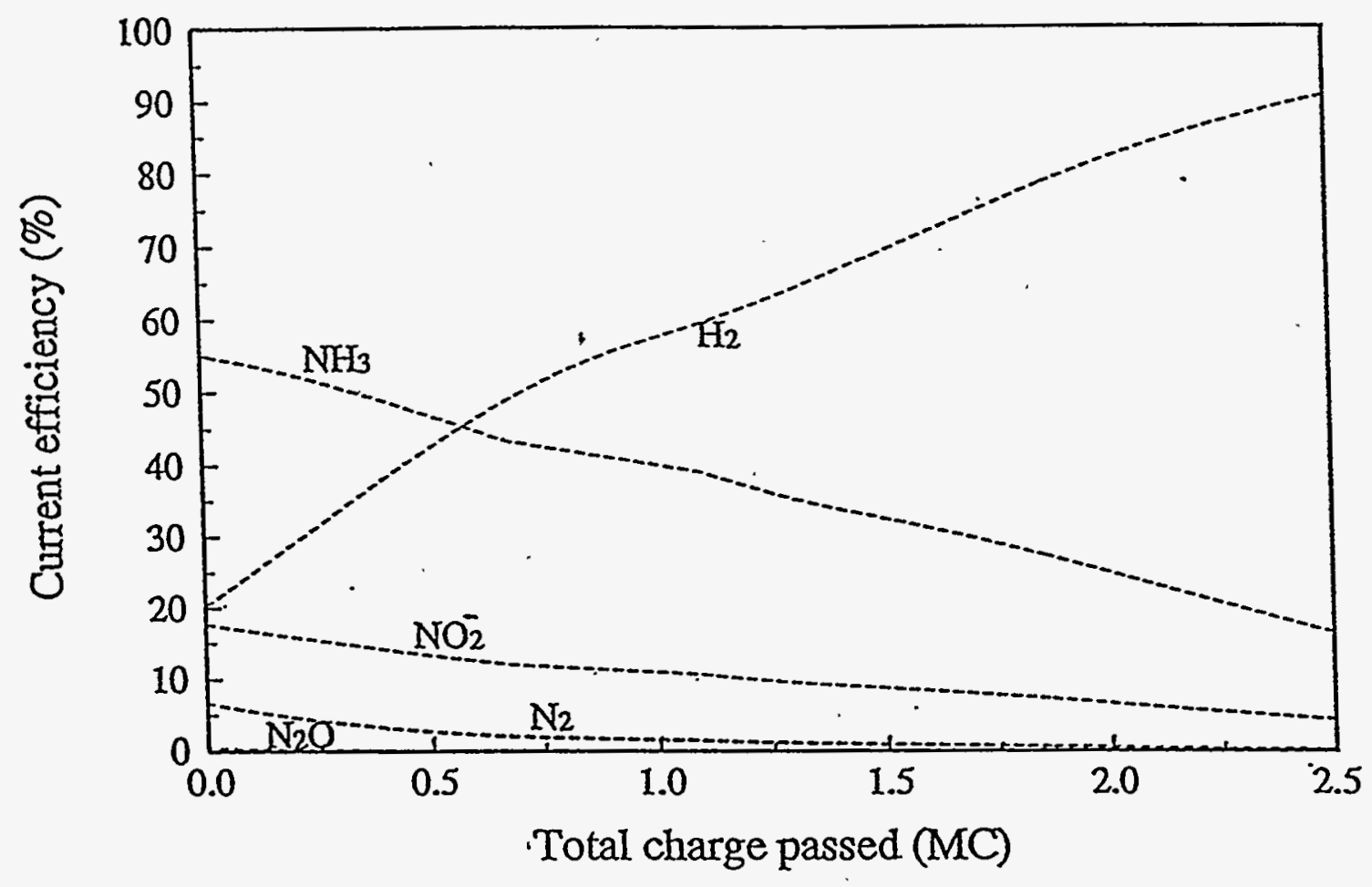

Figure 9: Current efficiencies for the five cathodic reactions as a function of total coulombs passed for the high voltage run. It can be seen that most of the current goes into production of $\mathrm{H}_{2}$ at this high voltage. $\mathrm{MC}$ is an abbreviation for "Million Coulombs". 


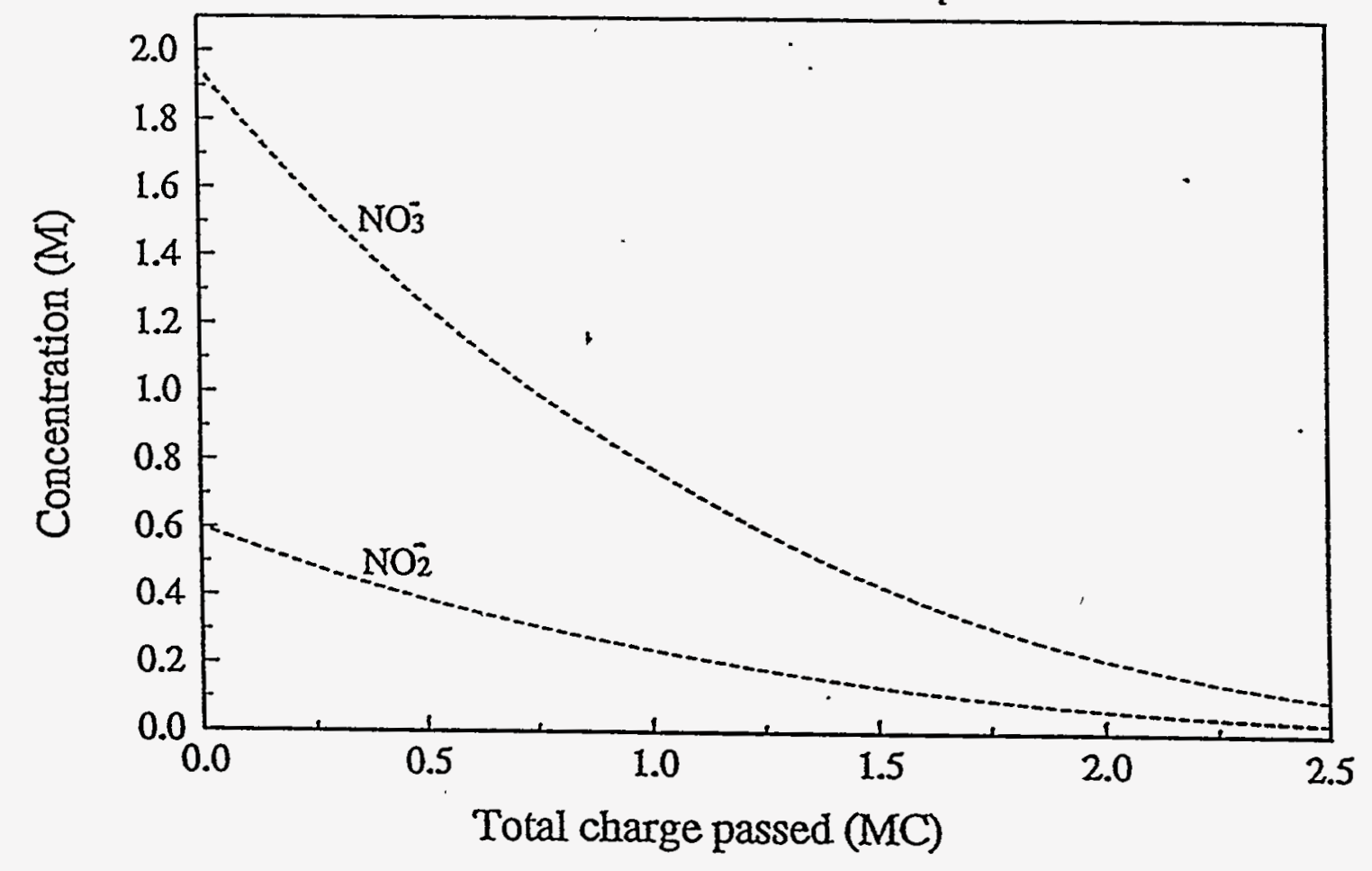

Figure 10: Ionic concentrations in the catholyte recirculation tank as a function of total coulombs passed for the high voltage run. MC is an abbreviation for "Million Coulombs". 


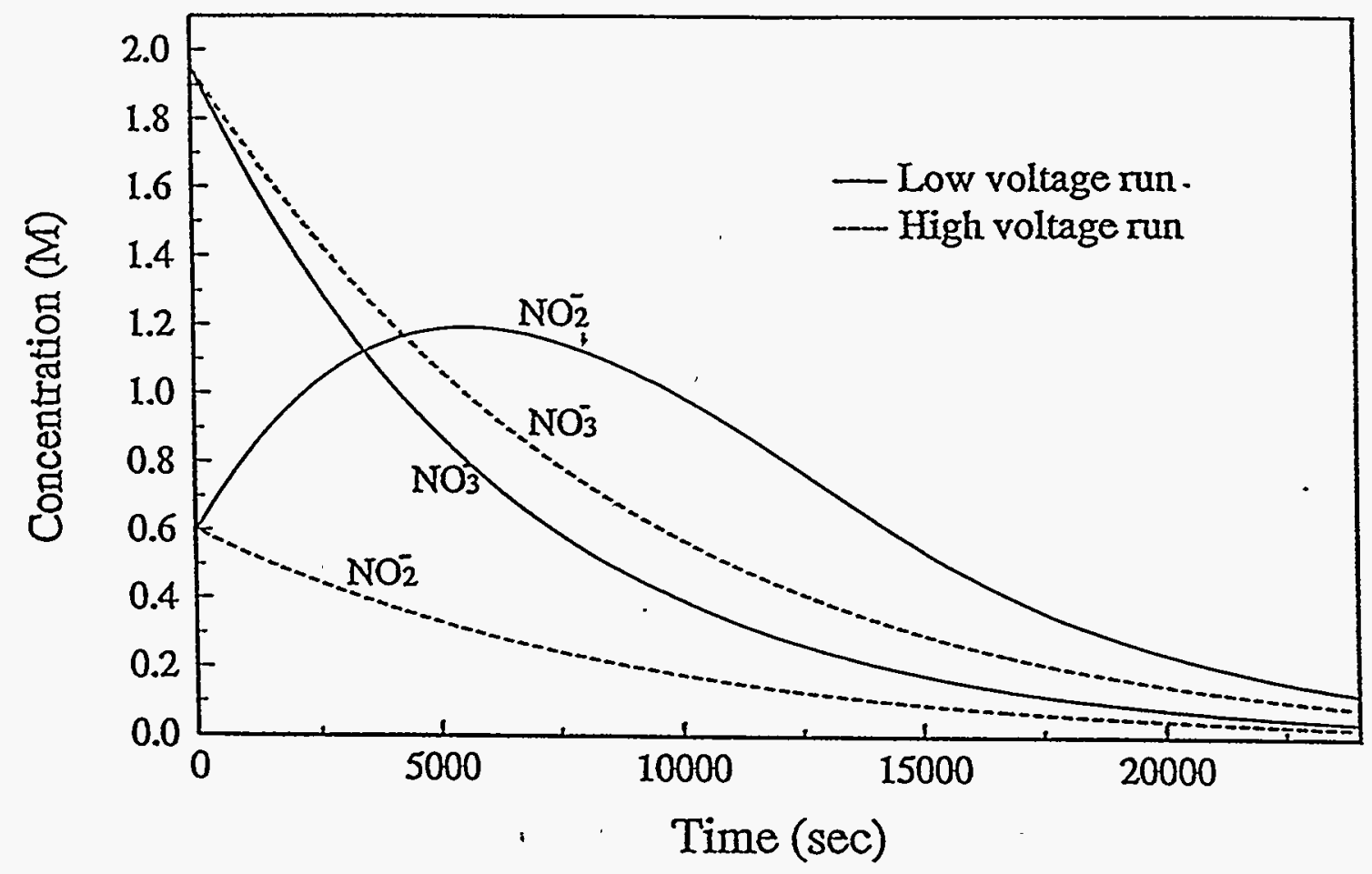

Figure 12: Comparison of nitrate and nitrite concentrations in the catholyte recirculation tank as a function of time for the low and high voltage runs. The slope of the curve corresponds to the destruction rate. It can be seen that the destruction rate of nitrates and nitrites combined is greater at the higher voltage. 


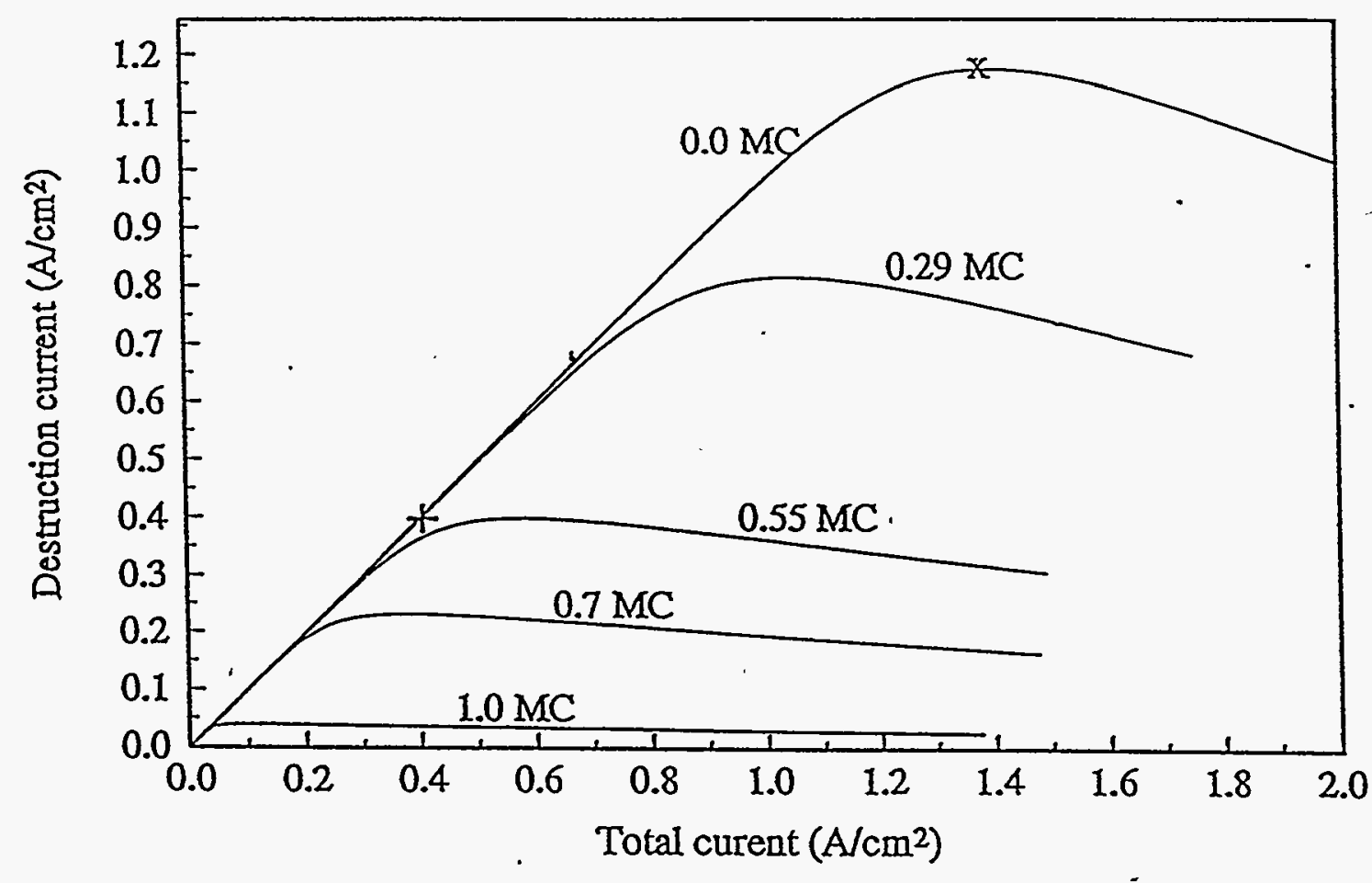

Figure 13: Destruction current vs. total current from the low voltage run. The peaks represent the current which maximizes the destruction of nitrates and nitrites at each point in time. The symbols " + " and " $x$ " denote initial conditions of the low voltage and high voltage runs respectively. $M C$ is an abbreviation for "Million Coulombs". 


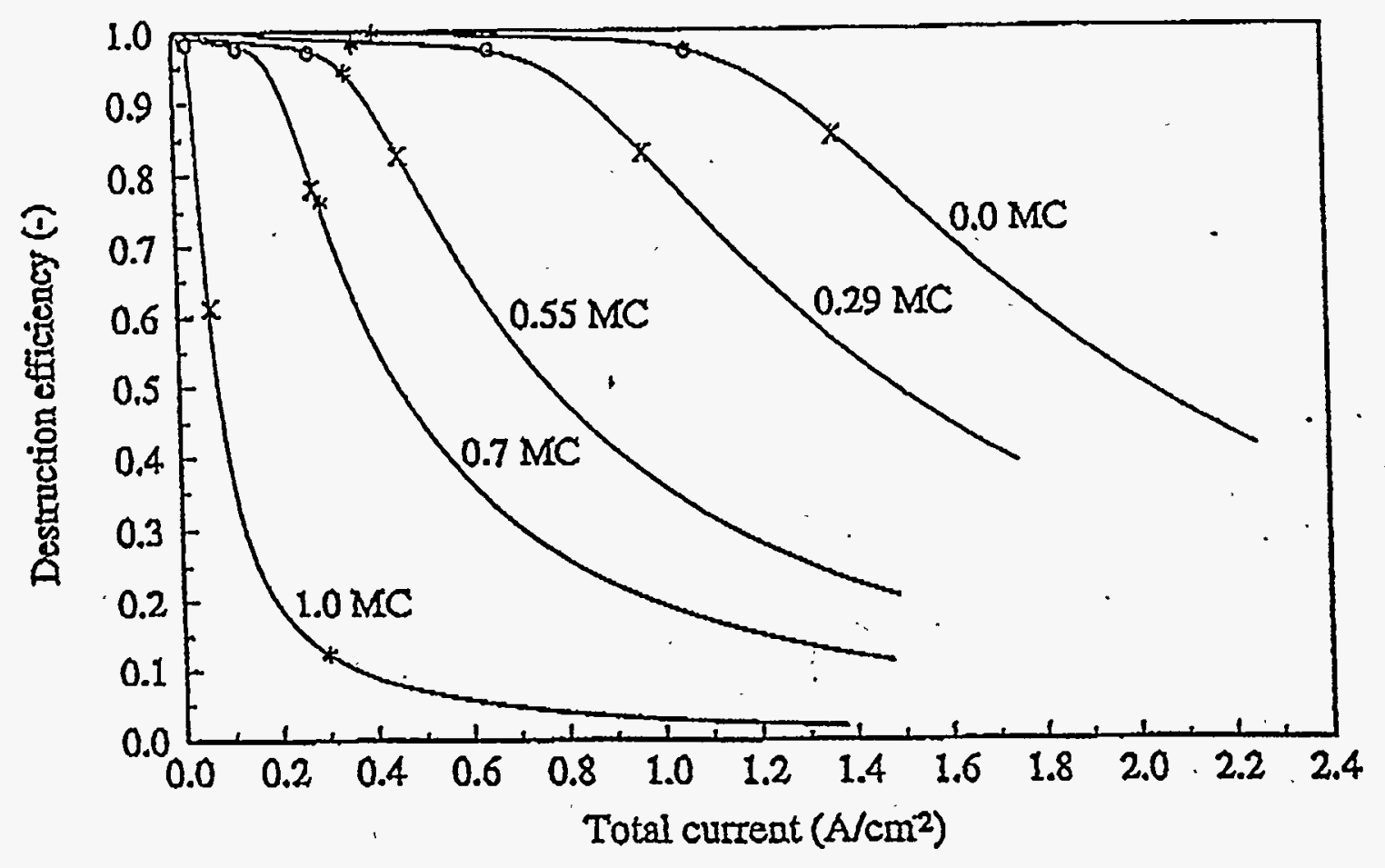

Figure 14: Destruction current efficiency vs. total current from the low voltage run. The circles ("o") denote the optimal operating currents at which the reactor should be operated in order to maximize the destruction of nitrates and nitrites while preventing unacceptable levels of $\mathrm{H}_{2}$ generation at each point in time. The " $x$ 's" denote the position of peaks from Figure 13. The " $*$ 's" denote the destruction efficiency at various times during the low voltage run. $\mathrm{MC}$ is an abbreviation for "Million Coulombs". 
…

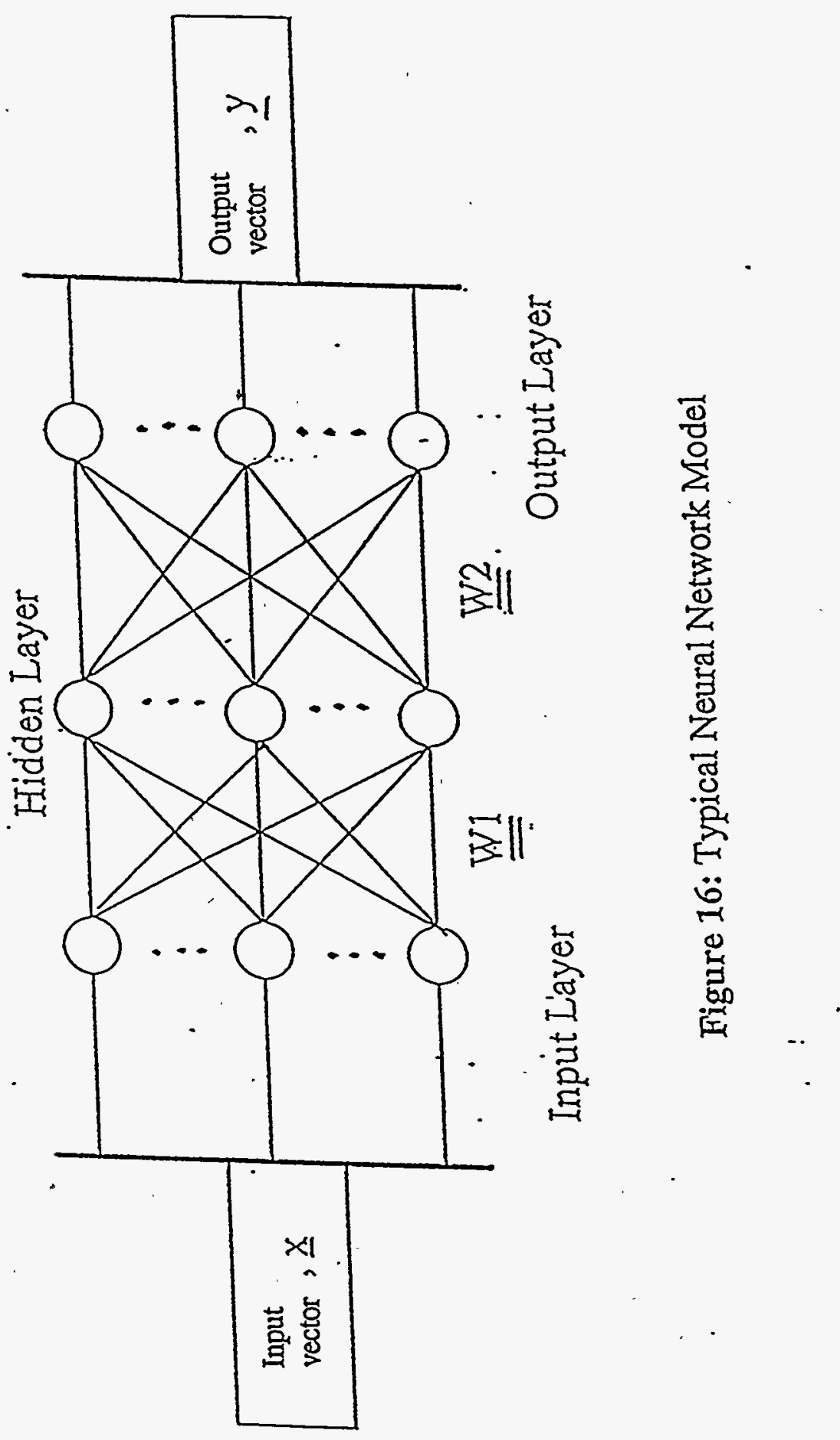




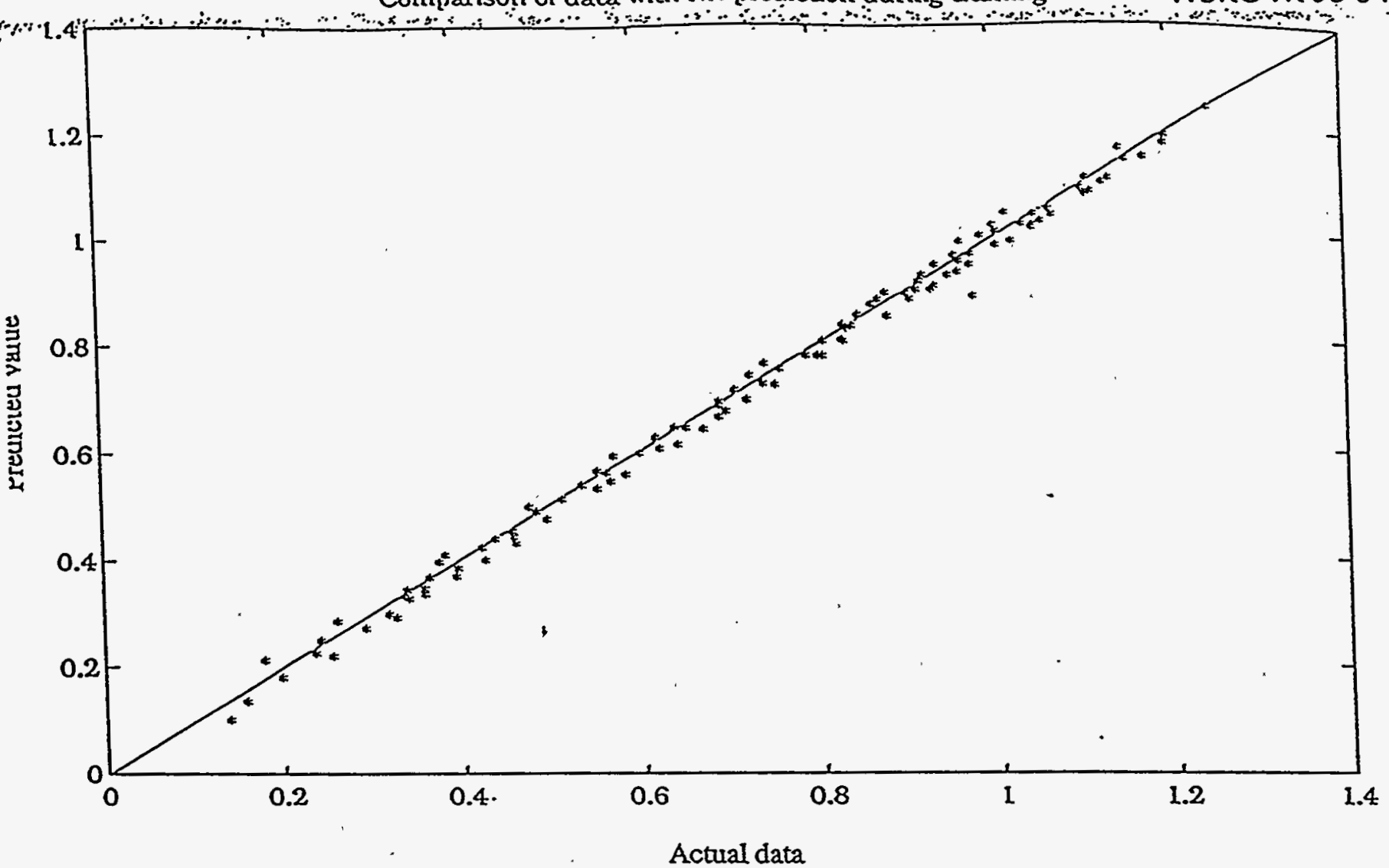

Figure 17: Plot of NN prediction vs. training data. The closer the points are to the diagonal, the better the prediction. A total of 115 data points were used for training the network. 


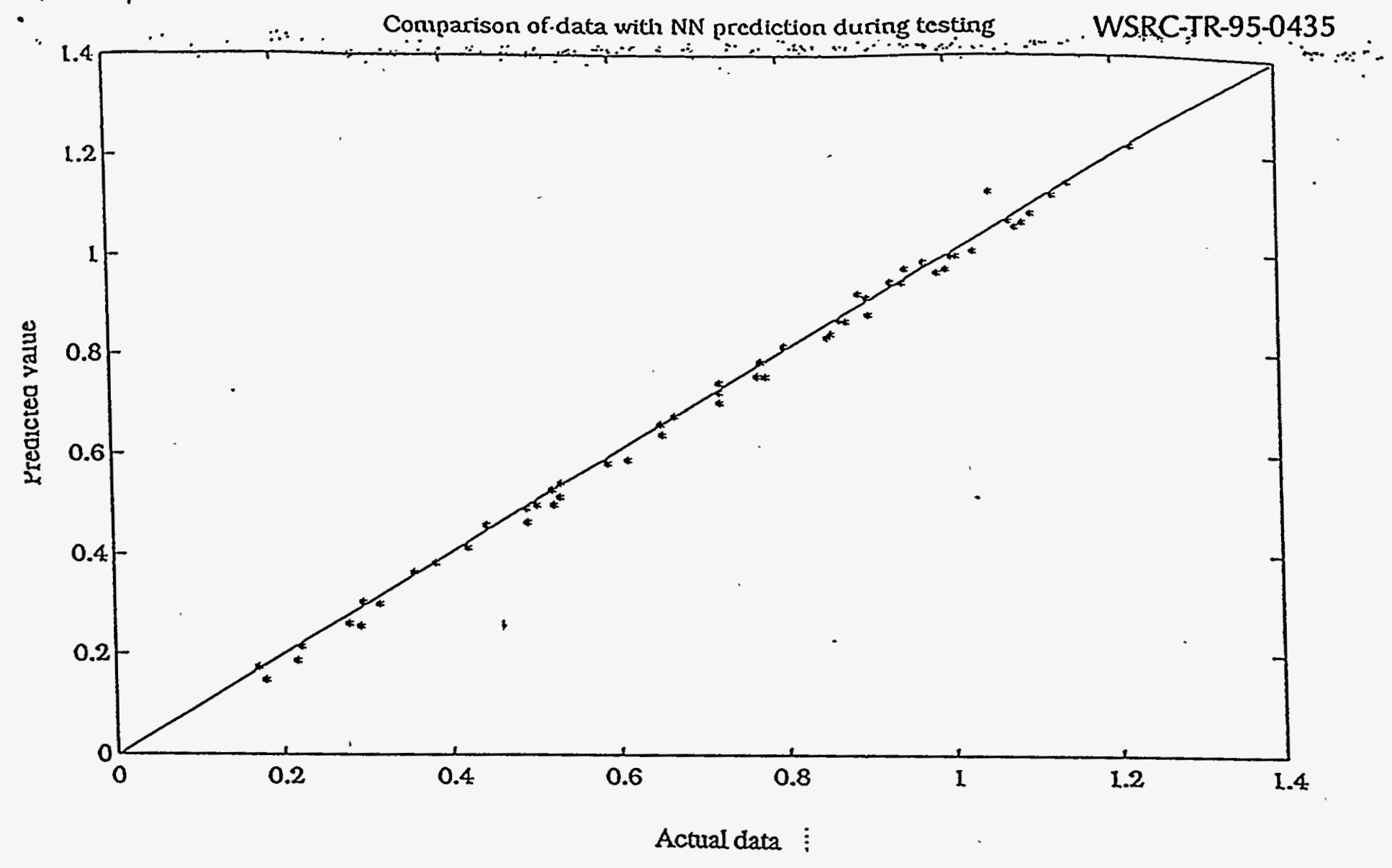

Figure 18: Plot of NN prediction vs. test data. The closer the points are to the diagonal, the better the prediction. A total of 55 data points were used to test the trained network. 


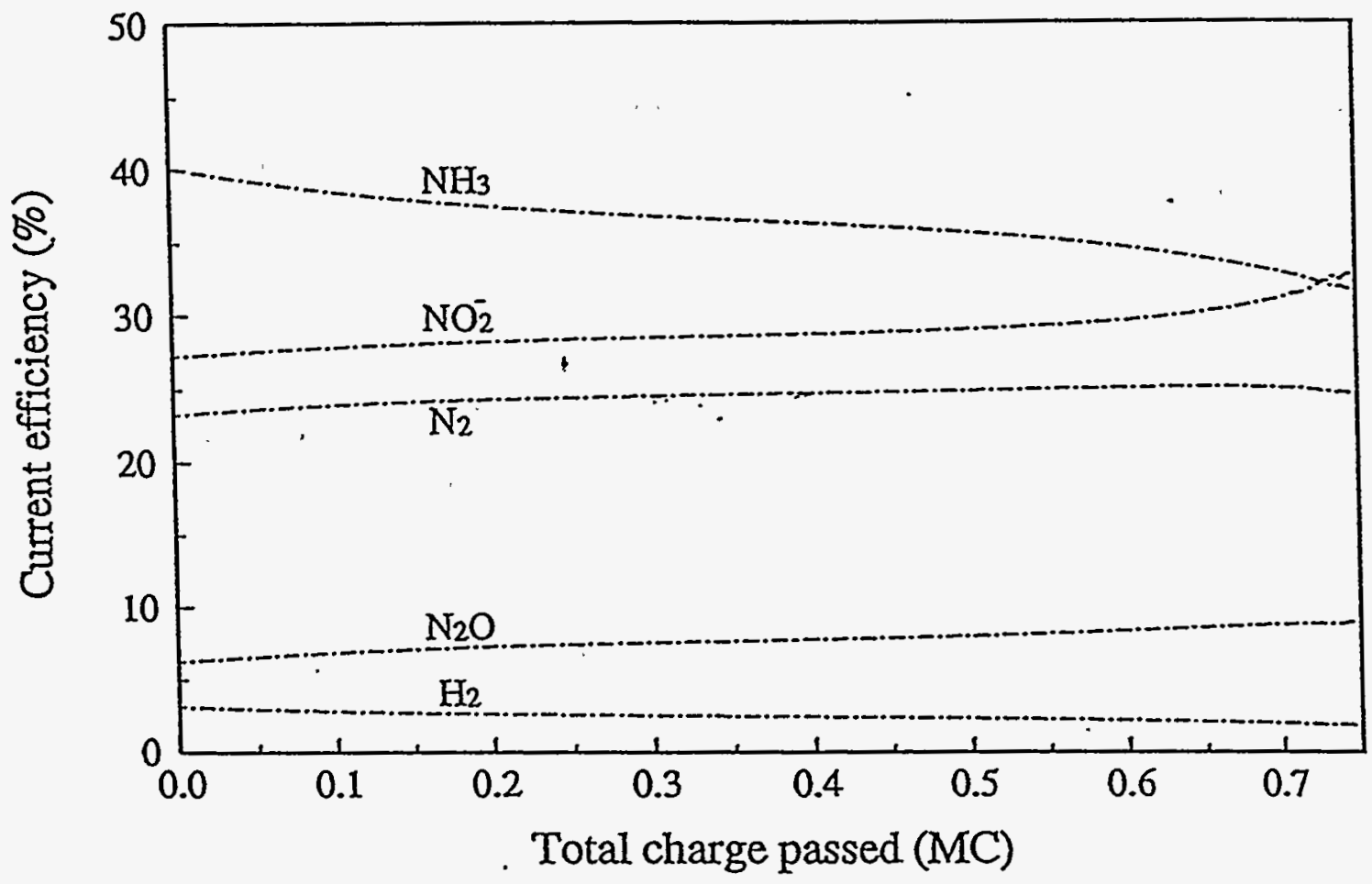

Figure 19: Current efficiencies for the five cathodic reactions as a function of total coulombs passed for the optimization run. The NN mapping function is used to predict cell voltage/current during the run. Compared to Figure 4, there is hardly any production of $\mathrm{H}_{2}$, because the current associated with reaction 5 is negligible. 


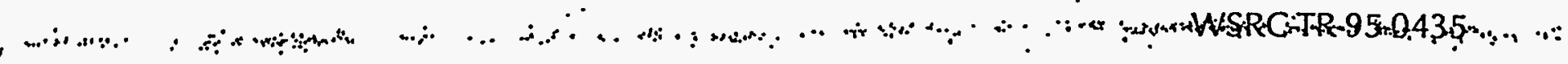

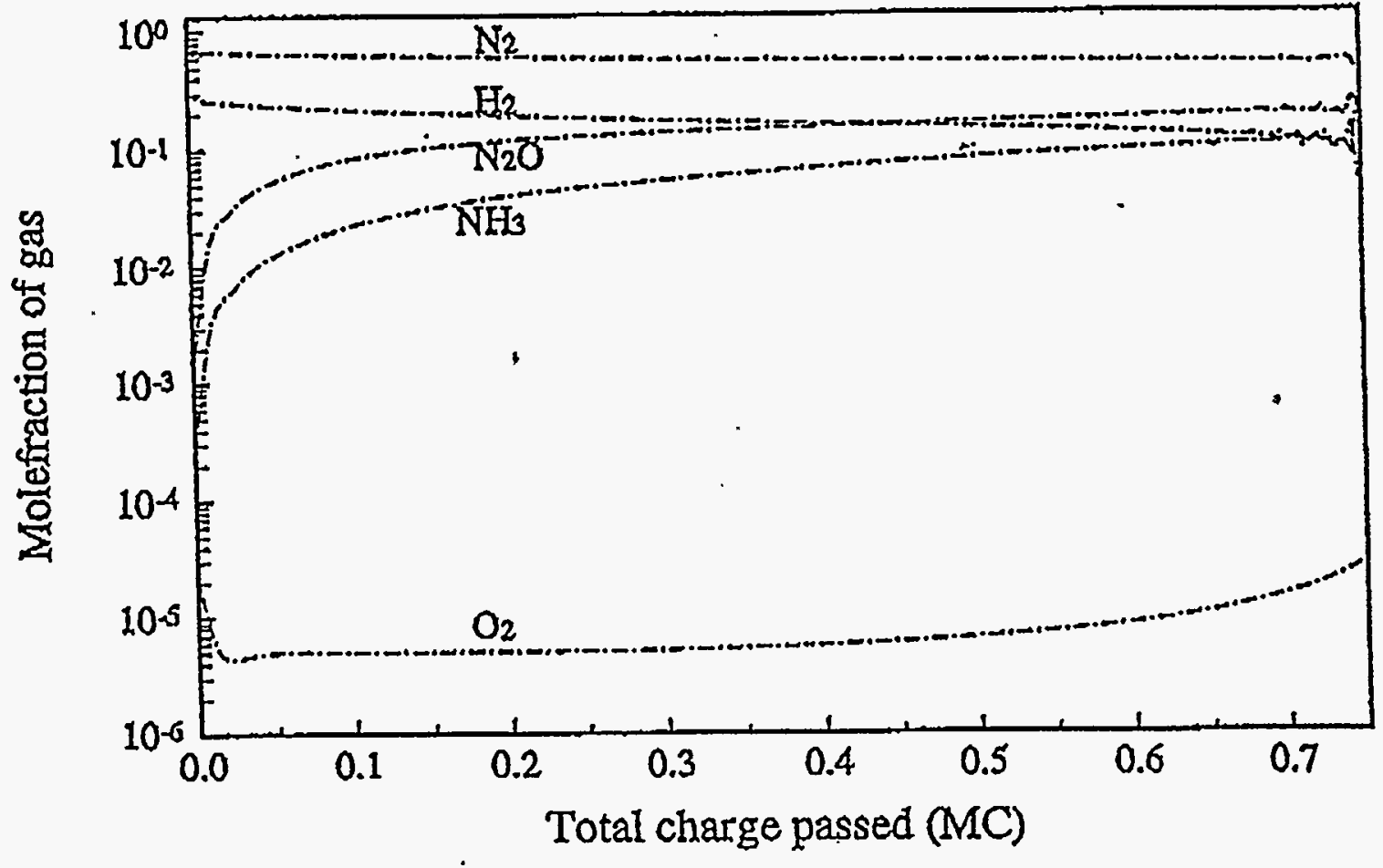

Figure 20: Off-gas composition from the catholyte recirculation tank as a function of total coulombs passed for the optimization run. $\mathrm{N}_{2}$ and $\mathrm{H}_{2}$ are the major components in the gas phase at the beginning of the run even though the current efficiency for reaction 5 is the lowest. This is because $\mathrm{H}_{2}$ has the least solubility among $\mathrm{NH}_{3}$ and $\mathrm{N}_{2} \mathrm{O}$. But in contrast to Figures 6 and 11 , where the $\mathrm{H}_{2}$ production increases towards the end, the optimization run produces significantiy less $\mathrm{H}_{2}$. 


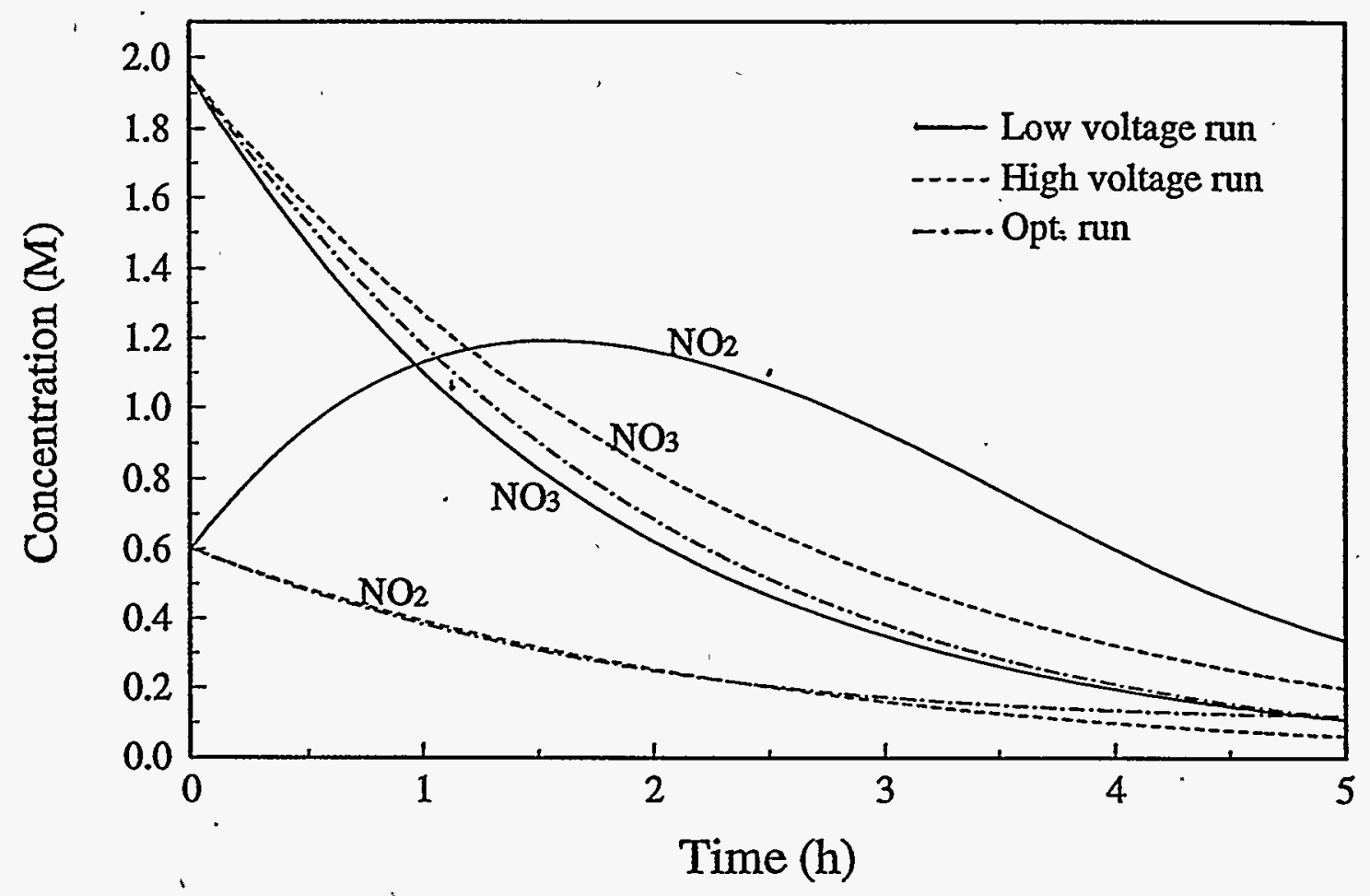

Figure 21: Comparison of the nitrate and nitrite concentrations as a function of time for the two batch runs and the optimization run. It can be seen that the overall destruction rate (rate of destruction of nitrate and nitrite combined) is greatest during the optimization run. 


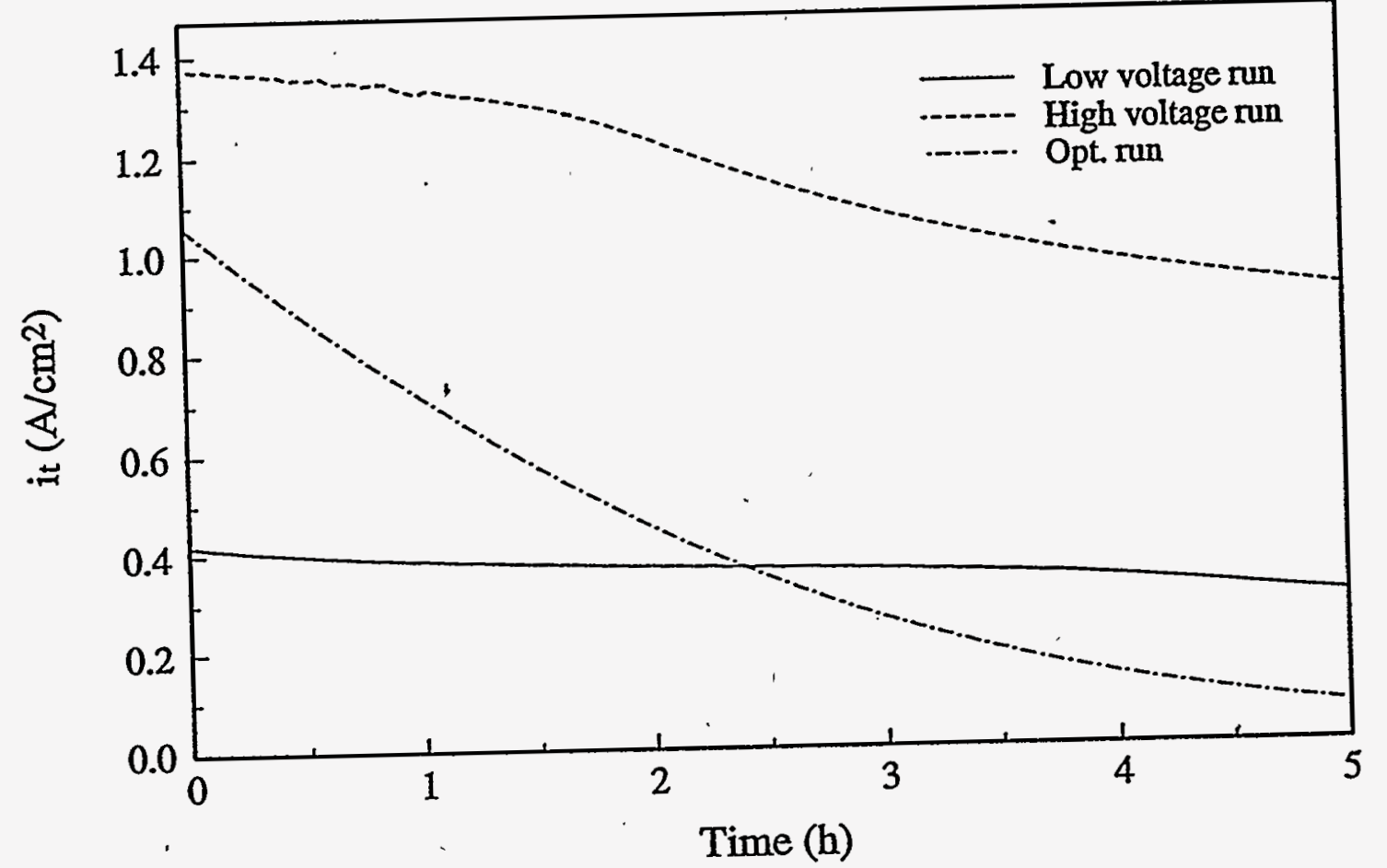

Figure 22: Comparison of cell current profile for the two batch runs runs and the optimization run. The optimal current follows an exponentially decreasing path. 


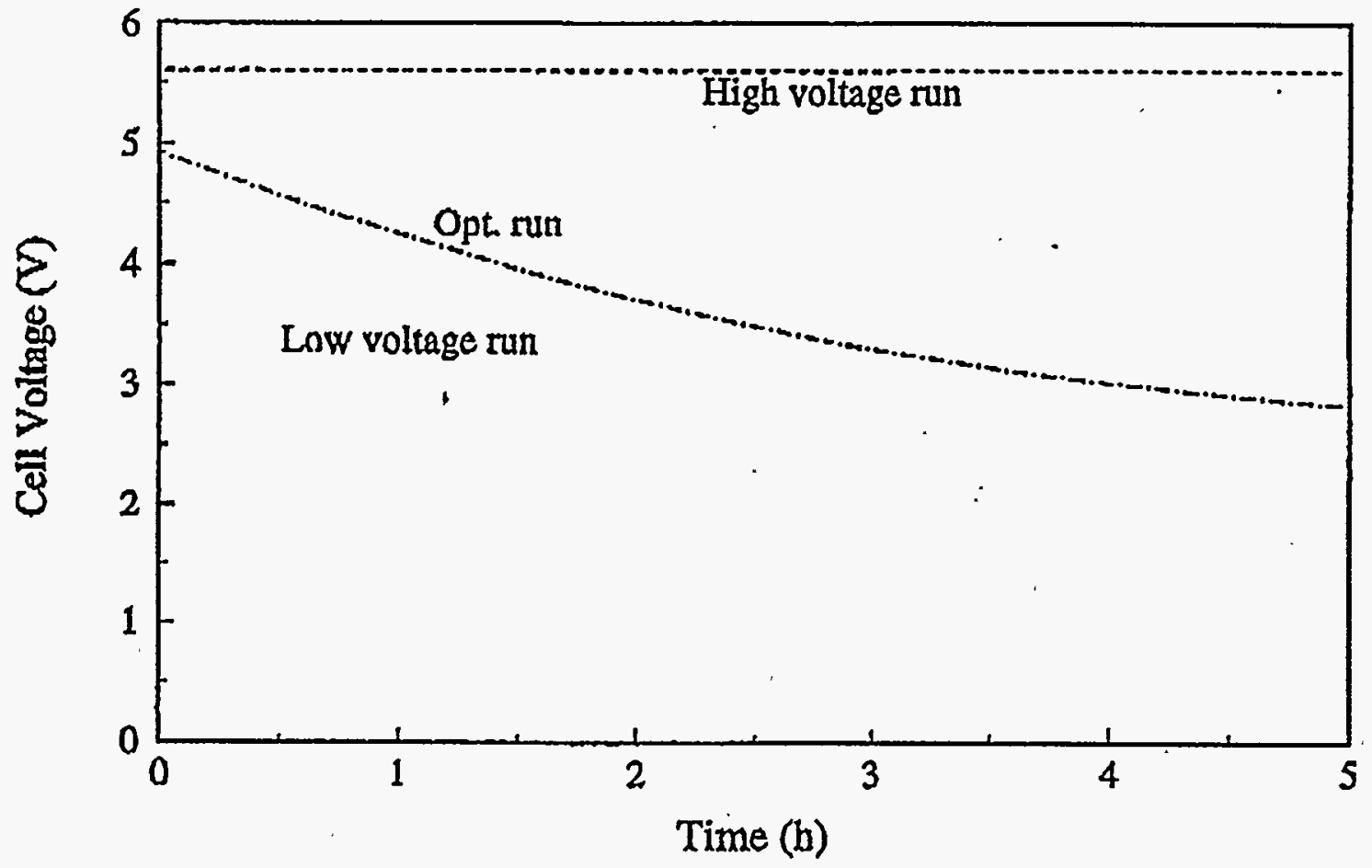

Figure 23: Comparison of cell voltage profile for the two batch runs runs and the optimization run. The optimal voltage follows an exponentially decreasing path. 


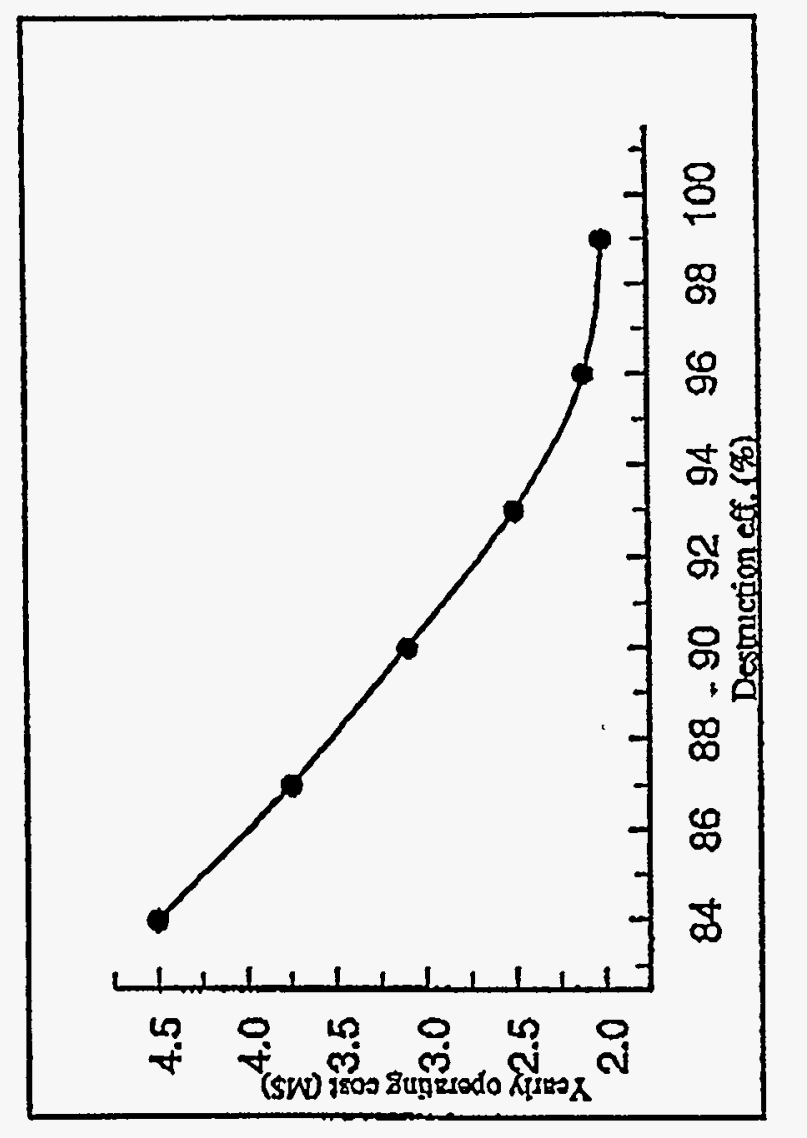

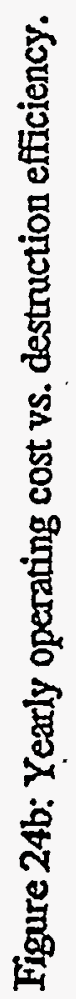
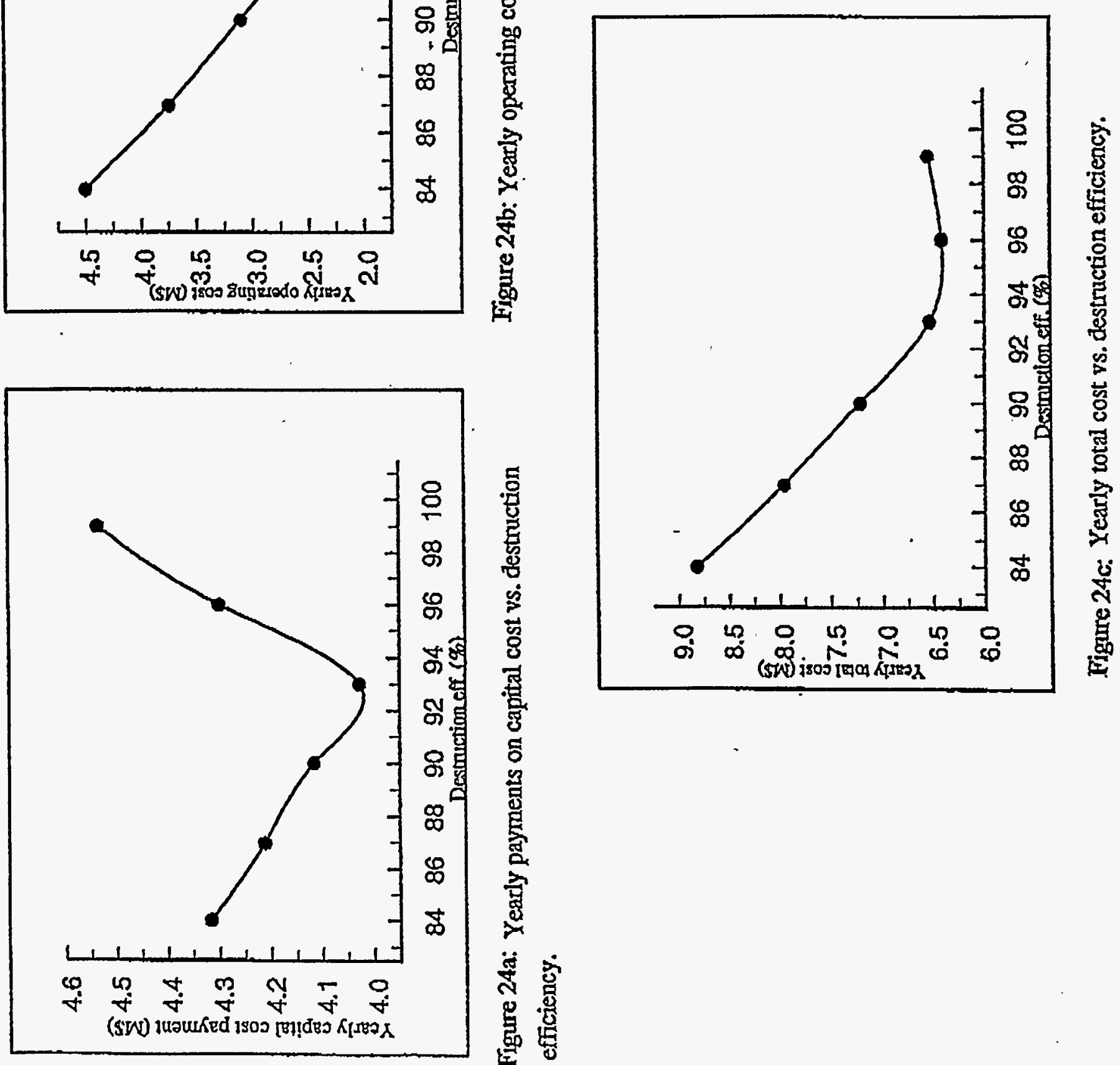
$\ldots$

.

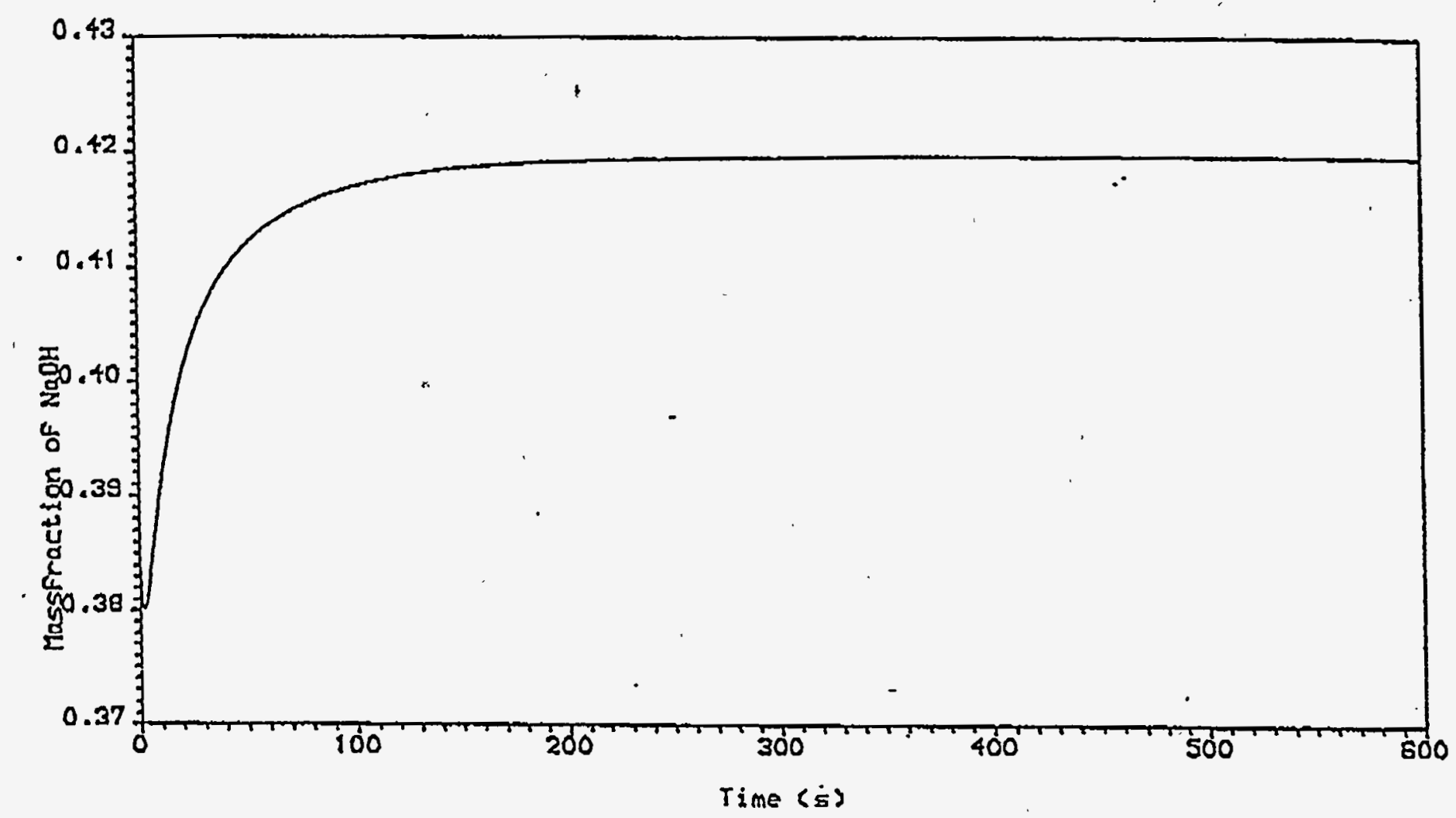

Fig. 25: Plot of massfraction of $\mathrm{NaOH}$ in the 1 st effect vs. time 


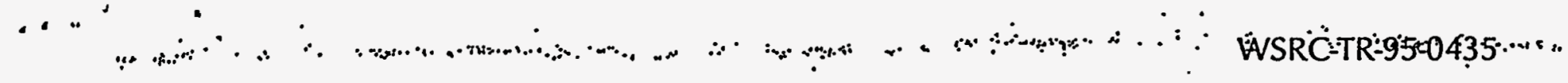

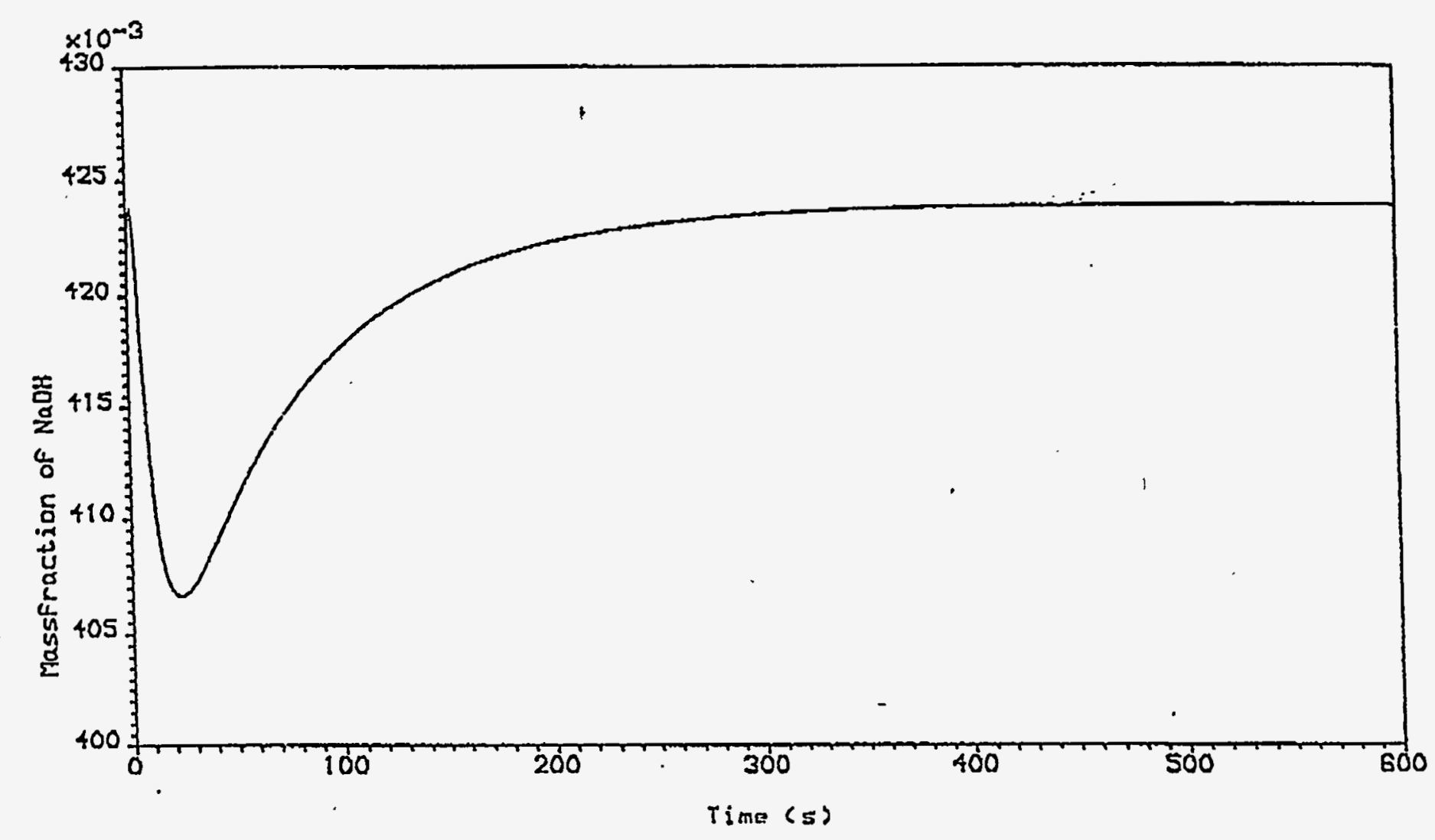

Fig. 26: Plot. of massfraction of $\mathrm{NaOH}$ in the 2 nd effect vs. time 
+1,

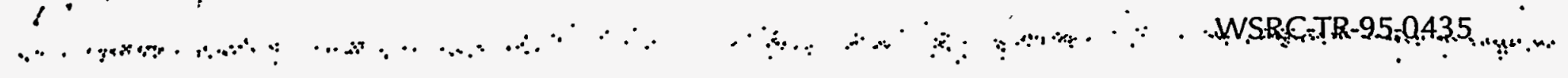

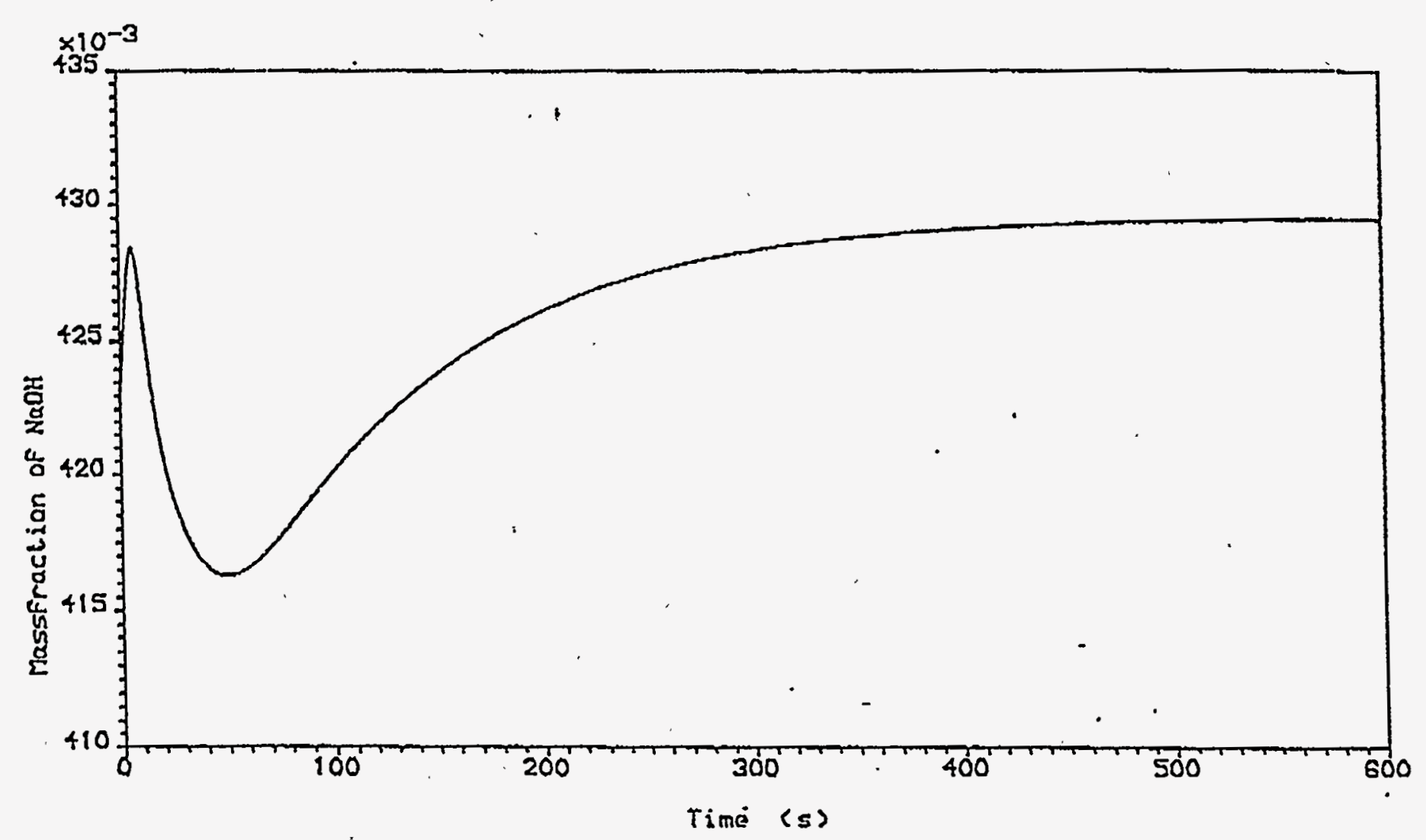

Fig. 27: Plot of massfraction of $\mathrm{NaOH}$ in 3rd effect vs: time 
Appendix I 


\section{Overview of SPEEDUP Models}

\section{[A] Electrochemical Cell Model}

The Batch Electrochemical Cell Model has been written in SPEEDUPTM. The code consists of 18 sections which are described below.

1. Options: This section is used to specify the numerical routines and other parameters (output levels, tolerances, etc.) needed to run the program.

2. Declare: This section is used to declare the characteristics of the different variables and stream types used in the program. It is also used to define the components $\left(\mathrm{NaOH}, \mathrm{N}_{2}\right.$, etc.) that are present in the feed and outlet streams.

3. Model AN_REC_TK: This section contains the governing equations and associated variables/streams for the anolyte recirculation tank.

4. Model CA_REC_TK: This section contains the governing equations and associated variables/streams for the catholyte recirculation tank.

5. Model CON_TKC: This section contains the governing equations and associated variables/streams for the connecting tank. It doesn't physically exist and is simply being used as a tool to connect two streams with different variable sizes.

6. Model D_CELL: This section contains the governing equations and associated variables/streams for the divided electrochemical cell.

7. Model FL_TKC: This section contains the governing equations and associated variables/streams for the flash unit.

8. Model N_NET: This section contains the governing equations and associated variables/streams for the Neural Network.

9. Flowsheet: This section defines all the interconnections between units. These interconnections may be either process flows which are known as "streams" or information carriers which are known as "connections".

10 - 17. UNIT "name": These sections give physical dimensions to the unit operations existing in the process and are described mathematically by the models mentioned above.

18. Operation: This section is used to specify the operating data for the $\mathrm{NO}_{3}^{-} / \mathrm{NO}_{2}{ }^{-}$. reduction process. 


\section{Executing the program.}

1. Specifying the operating variables:

\section{Variables to be SET within Unit.D CELL}

a) FLOW_INC $=$ Inlet catholyte flow to the cell $=63 \mathrm{~cm}^{3} / \mathrm{s}$.

b) FLOW_INA = Inlet anolyte flow to the cell $=63 \mathrm{~cm}^{3} / \mathrm{s}$

c) $D E L=$ Boundary-layer thickness (evaluated from eq. 17 in report) $=0.01645 \mathrm{~cm}$

d) SEP_TH $=$ Separator thickness $=0.05 \mathrm{~cm}$

e) $\mathrm{MAC}=$ MacMullin No. $=5$

Variables to be SET within Unit CA REC TK

f) V_RES $=700 \mathrm{~cm}^{3}$

Variables to be SET within Unit AN REC TK

g) V_RES $=7000 \mathrm{~cm}^{3}$

Variables to be SET within Unit's CON TKC and CON TKA

h) TEMP $=$ Feed temperature to the two flash units $=25^{\circ} \mathrm{C}$

Variables to be SET within Unit's FL TKC and FL TKA

i) VF_OUT $=$ Volumetric flowrate out of the flash units $=63 \mathrm{~cm}^{3}$

Variables to be SET within Unit N NET

j) WT's = Neural network weights

k) $\mathrm{BI}$ 's $=$ Neural network bias terms

1) DEST_EFF $=$ Destruction efficiency for optimal process operation (is varied from 0.84 to 0.98 to determine optimal operating point)

The exchange current densities have been specified directly within the Model D_Cell. 
Variables to be INITLALIZED within Unit D CELL

a) $\mathrm{Q} \_$TOT $=$Total coulombs passed $=0.0$.

Variables to be INITIIALIZED within Unit CA REC TK

b) C_OUT's = Initial concentration of the catholyte

Variables to be INITIALIZED within Unit AN REC TK

c) CON_OUT's = Initial concentration of the anolyte

2. Perform a SAIRUN on the .INP file (outside Speedup) to link the program to Properties Plus.

3. Perform an Initialization Run. (Set Boundfrac to 0.1 in Options section)

4. Perform the Dynamic Run. (Remove Boundfrac and specify time period using Time_Step and Intervals) 


\section{[B] Evaporator Model}

The Options, Declare, Flowsheet and Operation sections serve the same purpose (as in the electrochemical cell model) in the evaporator model. Currently, the model simulates a triple effect evaporator. The number of effects can be decreased or increased by deleting or adding extra UNIT's.

1. Model FEEDER: This section contains the governing equations and associated variables/streams for the evaporator feed tank.

2. Model STMFEEDER: This section contains the governing equations and associated variables/streams for the steam production tank.

3. Model TEFF_EVAP: This section contains the governing equations and associated variables/streams for the evaporator.

4. UNIT "name": These sections physically represent the various process units and are described mathematically by the different models mentioned above.

\section{Executing the program.}

1. Specifying the operating,variables:

Variables to be SET within Unit FEEDER

a) FLOW_OUT $=$ Inlet flow into the evaporator $=1198.6 \mathrm{~cm}^{3} / \mathrm{s}$

b) TEMP $=$ Temperature of the feed stream $=200^{\circ} \mathrm{C}$

c) $\mathrm{PRES}=$ Stream pressure $=1.0 \mathrm{bar}$

d) $\operatorname{COUT}(1)=$ Inlet concentration of $\mathrm{NaOH}=10.893 \mathrm{e}-3 \mathrm{moles} / \mathrm{cm}^{3}$

e) $\operatorname{COUT}(2)=$ Inlet concentration of $\mathrm{H}_{2} \mathrm{O}=38.513 \mathrm{e}-3 \mathrm{moles} / \mathrm{cm}^{3}$

\section{Variables to be SET within Unit STMFEEDER}

f) FLOW_OUT $=$ Inlet steam flowrate $=10 \mathrm{~cm}^{3} / \mathrm{s}$

g) TEMP_OUT $=350^{\circ} \mathrm{C}$ 
Variables to be SET within Unit FIR EFE

h) HOLD $=$ Holdup $=200000 \mathrm{~cm}^{3}$

i) EV_PRESS $=4.76 \mathrm{bar}$

j) S_TMP = Sat. temperature of water @ EV_PRESS $=150^{\circ} \mathrm{C}$

k) $\mathrm{HTCOF}=$ Heat transfer coeff. $=0.4 \mathrm{~W} / \mathrm{cm}^{2} \cdot{ }^{\circ} \mathrm{C}$

1) $\mathrm{HTAREA}=$ Heat transfer area $=20000 \mathrm{~cm}^{2}$

Variables to be SET within Unit SEC EFF

m) HOLD $=$ Holdup $=200000 \mathrm{~cm}^{3}$

n) EV_PRESS $=0.977$ bar

0) S_TMP = Sat. temperature of water @ EV_PRESS $=99^{\circ} \mathrm{C}$

p) $\mathrm{HTCOF}=$ Heat transfer coeff. $=0.35 \mathrm{~W} / \mathrm{cm}^{2} \cdot{ }^{\circ} \mathrm{C}$

q) HTAREA $=$ Heat transfer area $=20000 \mathrm{~cm}^{2}$

Variables to be SET within Unit THR EFF

r) $\mathrm{HOLD}=$ Holdup $=200000 \mathrm{~cm}^{3}$

s) EV_PRESS $=0.0424 \mathrm{bar}$

t) S_TMP = Sat. temperature of water @ EV_PRESS $=30^{\circ} \mathrm{C}$

u) $\mathrm{HTCOF}=$ Heat transfer coeff. $=0.3 \mathrm{~W} / \mathrm{cm}^{2} \cdot{ }^{\circ} \mathrm{C}$

v) $\mathrm{HTAREA}=$ Heat transfer area $=20000 \mathrm{~cm}^{2}$

Variables to be INITIALIZED within Unit FIR EFF
a) $\$ C \_O U T(1)=\mathrm{dC}_{\mathrm{NaOH}_{\mathrm{H}}} / \mathrm{dt}=0$
b) $\$ C \_O U T(2)=\mathrm{dC}_{\mathrm{H} 2 \mathrm{O}} / \mathrm{dt}=0$
c) $\$ E N T H=d($ Enthalpy $) / d t=0$ 
Variables to be INITIALIZED within Unit SEC EFF

d) $\$ C \_$OUT $(1)=\mathrm{dC}_{\mathrm{NaOH}} / \mathrm{dt}=0$

e) $\$ C \_$OUT $(2)=d C_{\mathrm{H} 2} \mathrm{O} / \mathrm{dt}=0$

f) $\$ E N T H=d($ Enthalpy $) / d t=0$

Variables to be INITIALIZED within Unit THR EFE

g) $\$ C \_O U T(1)=\mathrm{dC}_{\mathrm{NaOH}} / \mathrm{dt}=0$

h) $\$ C \_$OUT $(2)=d C_{\mathrm{H} 2 \mathrm{O}} / \mathrm{dt}=0$

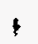

i) $\$ \mathrm{ENTH}=\mathrm{d}($ Enthalpy $) / \mathrm{dt}=0$

2. There is no need to perform an Initialization Run in the case of the evaporator model. A Dynamic Run command can be directly issued. Specify the time period in the Options section in the same way as is done for the electrochemical cell model. 


\section{COST ANALYSIS}

\section{[A] Capital cost estimation:}

a) Estimation of Purchased Equipment Cost (Electrochemical Cell):

At $90 \%$ destruction efficiency, with current optimization, the Speedup program predicts that $\mathbf{5 . 5}$ hours is needed for $95 \%$ destruction of $\mathbf{7 0 0} \mathrm{ml}$ of waste.

Electrode area used for this purpose $(F M 01)=100 \mathrm{~cm}^{2}=0.01 \mathrm{~m}^{2}$

From dimensionless analysis, assuming current density, concentration and density of waste remain unchanged during scale-up:

$$
\begin{aligned}
& \frac{\text { Volume of waste }}{\text { Electrode area }}=\text { Constan } \mathrm{t} \\
& \Rightarrow \text { Volume of waste destroyed by FM21-SP }=14700 \mathrm{ml}=3.89 \mathrm{gal} \\
& \text { in the } 5.5 \mathrm{hrs} \text { (with electrode area }=0.21 \mathrm{~m}^{2} \text { ) } \\
& \qquad \because \\
& \Rightarrow \text { Destruction rate }=0.707 \mathrm{gal} / \mathrm{hr} . \\
& \Rightarrow \text { Yearly destruction rate }=\mathbf{6 1 9 5 . 7} \mathrm{gal} / \mathrm{yr} .
\end{aligned}
$$

Therefore, using FM21-SP, operating continuously at $90 \%$ destruction efficiency, it takes 1 yr to destroy 6195.7 gal of waste by $95 \%$.

Assuming that the FM21-SP is operated only $50 \%$ of the time (the rest $50 \%$ is used for maintenance), amount of waste destroyed in $1 \mathrm{yr}=3097.85 \mathrm{gal}$.

Actual amount of waste to be destroyed in 1 year $=\mathbf{1 0}$ million gal

Electrode area that will be needed $\approx 678 \mathrm{~m}^{2}$.

Cost per unit area ${ }^{22}=\$ 15000$.

Therefore, total cost of the cell $\approx \mathbf{\$ 1 0 . 1 7}$ million. 
b) Estimation of Capital Cost comprising of the following components ${ }^{23}$ :

i) Purchased equipment cost $=\mathrm{EC}$

ii) Installation of purchased equipment $=0.5 \mathrm{EC}$

iii) Instrumentation \& controls $=0.28 \mathrm{EC}$

iv) Piping $=0,66 \mathrm{EC}$

v) Electrical wiring $=0.2 \mathrm{EC}$

vi) Buildings/yard improvements $=0.4 \mathrm{EC}$

Total Capital Cost $=3.04 \mathrm{EC}=3.04 * 10.17=\$ 30.92$ million.

Yearly payment plan $^{24}$ (@10\% interest for $\left.15 \mathrm{yrs}\right)=0.132 *$ Total capital cost

$=\$ 4.08$ million 
[B] Operating cost estimation:

At $90 \%$ destruction efficiency, with current optimization, the Speedup program predicts that $1.438 \mathrm{~kW}-\mathrm{hr}$ of power is needed for $95 \%$ destruction of $700 \mathrm{ml}$ of waste.

But, the FM21-SP can destroy $14700 \mathrm{ml}$ of wate in the same time (5.5 hours).

Therefore, power requirement of the FM21-SP $=\mathbf{3 0 . 1 9 8} \mathbf{k W}-\mathrm{hr}$.

$\Rightarrow$ One FM21-SP operating continuously for 1 year consumes $=\underline{30.198 * 365 * 24}$

5.5

$\approx 48097.1 \mathrm{~kW}-\mathrm{hr}$

Again, one FM21-SP, operating at 90\% destruction efficiency, takes 1 yr to destroy $6195.7 \mathrm{gal}$ of waste by $95 \%$.

Actual amount of waste to be destroyed in 1 year $=\mathbf{1 0}$ million gal.

Therefore, total power consumption would be $\approx 7.76 \times 10^{7} \mathrm{~kW}-\mathrm{hr}$.

Assuming cost per per unit of electricity ${ }^{23}$ to be 4 cents,

Yearly operating cost $\approx \$ 3.1$ million.

TOTAL YEARLY COSTS $=\$ 7.18$ million 
Speedup Code 
\#\#\#\# for optimal operation. It uses a Neural Network mapping to

\#\#\#\# evaluate the cell current. It includes the effect of migration

\#\#\#\# and also accounts for the flashing of the off-gases. It

\#\#\#\# considers movement of NO3-, NO2-, OH- and Nat ions across the
OPTIONS
ROUTINES
RK4
EXECUTION
SS_TOL
ABS_TOL
MAXVARSTEP
PRINILEVEI
TARGET
\#
BOUNDFRAC
ITERATIONS
NONREDITER
TIME_STEP
INTERVALS
$=1 \cdot 0 \mathrm{E}-5$
$=1.0 \mathrm{E}-5$
$=1 \cdot 0 \mathrm{E}-5$
$=100$
$=0$
= TERMINAL
$=0.1$
$=300$
$=10$
$=1.0$
$=21000$

\section{DECLARE}

TYPE

\# VAR_TYPE
VOL_FLOW
VOLUME
CONCN
CURR
POTEN
RESIST
CHARGE
GAMMA
KAPPA
CONSTANT
DIMIESS_NUM
CONVERSION
DELTA
CUR_EFE
MOI_FLOW
MOLEERACTION
VAPERACTION
TEMPERATURE
PRESSURE
ENTH_MOL_VAP
ENTH_MOL_LIQ
WEIGHT
BIAS

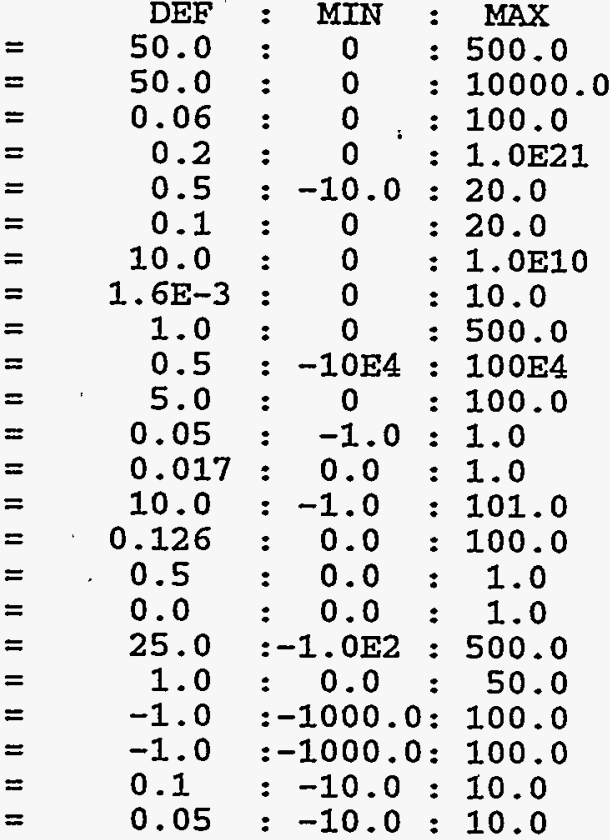

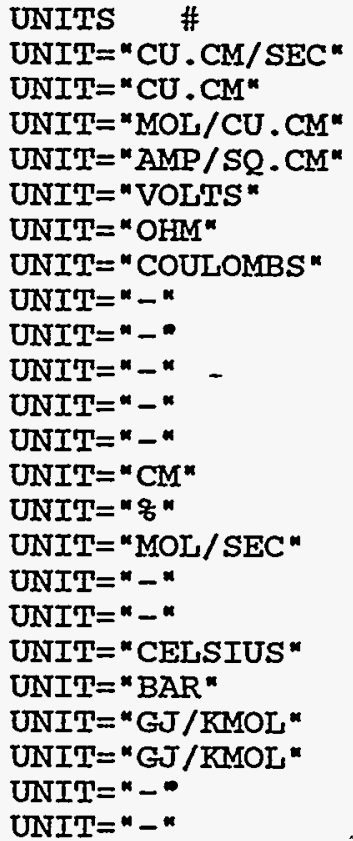

\section{STREAM LIQUID \\ SET}

NOCOMP $=10$

TYPE

$$
\text { VOL_ELOW, CONCN (NOCOMP) }
$$

STREAM MAINSTREAM

SET

NOCOMP $=9$

TYPE 
NaOH, NaNO3, KNO3, N2, H3N, N2O, O2, H2, H2O OPTIONS

OPSET $\quad=$ SYSOP3

WSRC-TR-95-0435

STREAM VAPOUR

$S E T$

NOCOMP $=9$

TYPE

MOL_FLOW, MOLEFRACTION (NOCOMP)

MODEL AN_REC_TK

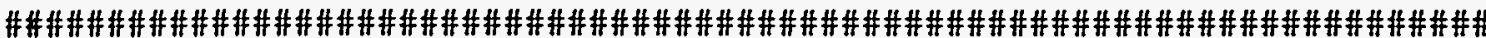
\#\#\#\# Represents the model for the Anolyte Recirculation Tank \#\#\#

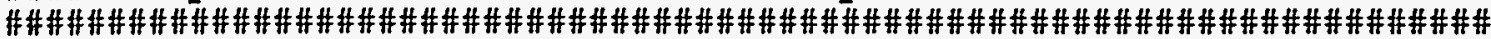

TYPE

FLOW_IN, FLOW_OUT CON_IN,C_OUT,CON_OUT V_RES

STREAM

INPUT 1 OUTPUT 1
FLOW IN, CON IN

FLOW_OUT, CON_OUT

EQUATIONS

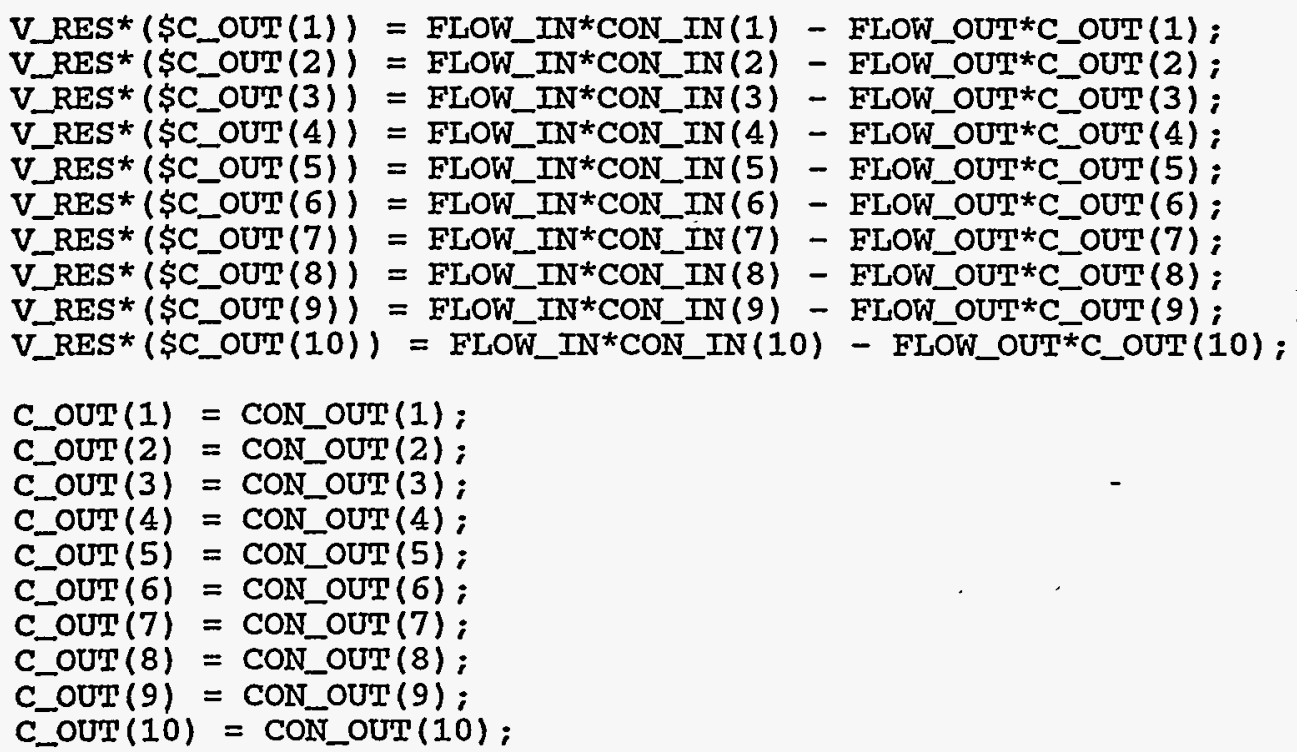

MODEL CA_REC_TK

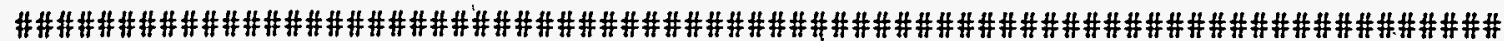
\#\#\#\# Represents the model for the catholyte Recirculation Tank \#\#\#

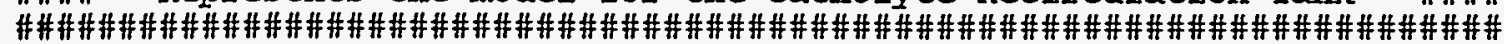

TYPE

FLOW IN, FLOW OUT

CON_IN, C_OUT,CON_OUT

V_RES

TOT_NO3_CONV
AS VOL FLOW

AS ARRĀY (10) OF CONCN

AS VOLUME

AS CONVERSION

STREAM

INPUT 1

OUTPUT 1 


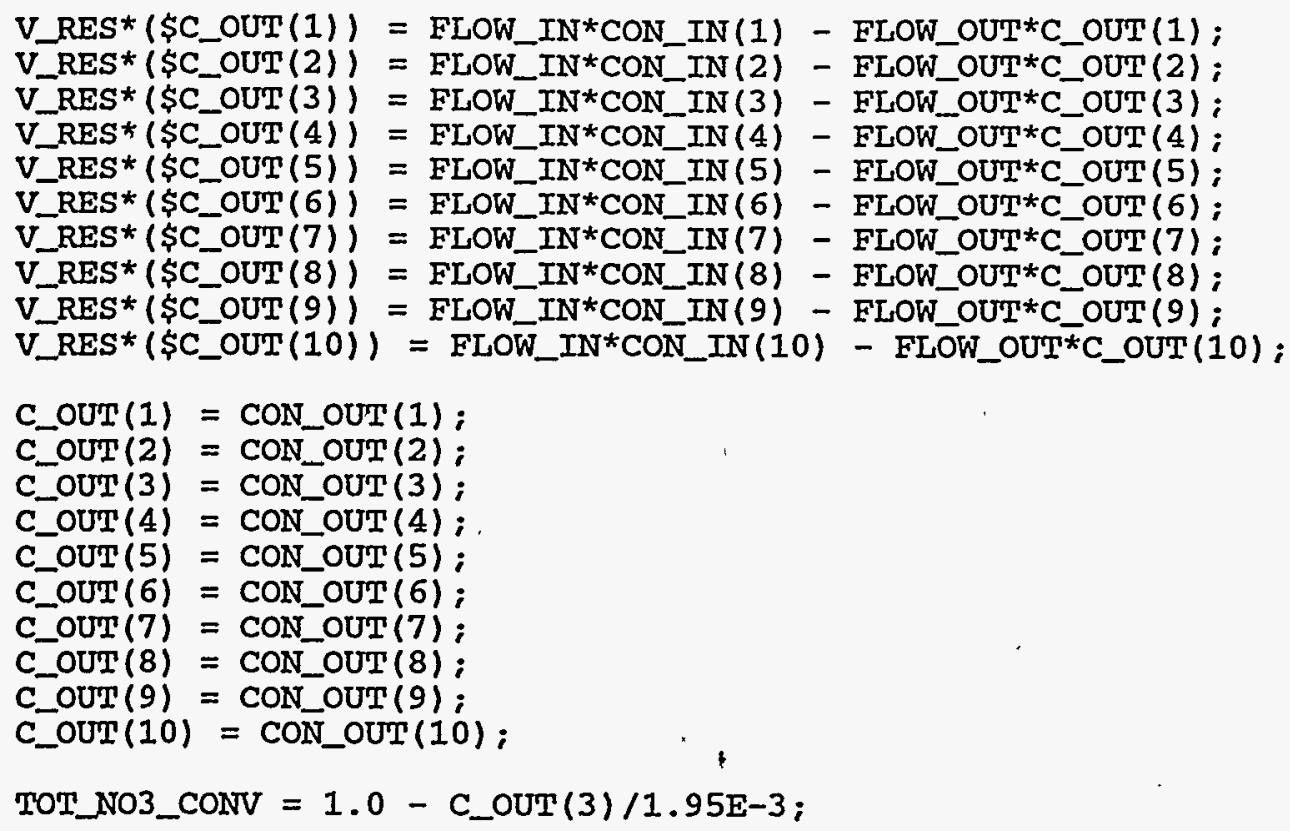

VF_IN

C.IN

SUMC

MF_OUT

$\mathbf{Z}$

TEMP

PRES

$\begin{array}{ll}\text { AS } & \text { VOL_FLOW } \\ \text { AS } & \text { ARRAY (10) OF CONCN } \\ \text { AS } & \text { CONCN } \\ \text { AS } & \text { MOL_FLOW } \\ \text { AS } & \text { ARRAY(9) OF MOLEFRACTION } \\ \text { AS TEMPERATURE } \\ \text { AS PRESSURE }\end{array}$

AS PRESSURE

STREAM

INPUT 1 VF_IN, C_IN

OUTPUT 1 MF_OUT, $\bar{Z}$, TEMP, PRES

EQUATIONS

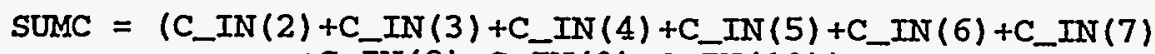
+ C__IN $(8)+$ C_IN $(9)+C$ _IN $(10))$;

VF_IN*SUMC = MF_OUT;

$Z(1)$ *SUMC $=C$ IN (2);

$\mathrm{Z}(2) *$ SUMC $=$ C_IN $(3)$;

$\mathrm{Z}(3)$ * SUMC $=$ C_IN (4);

$\mathrm{Z}(4)$ *SUMC $=\mathrm{C}_{\text {_IN }}(5)$;

$\mathrm{Z}(5) *$ SUMC $=C$ - IN $(6)$;

$Z(6) *$ SUMC $=$ C_IN $(7)$;

$\mathrm{Z}(7)$ * SUMC $=$ C_IN $(8)$;

$\mathrm{Z}(8)$ * SUMC $=$ C_IN (9);

$\mathrm{Z}(9)$ * SUMC $=$ C_IN $(10)$;

TEMP *PRES $=25.0$; 
SET

E_AREA

TYPE

IC, IA

ETA

PHIC, PHIA, V_CELL

RES

GAMAA, GAMAC

KAP

CSTAR

DEL, SEP_TH

C.EFE

QTOT

MAC

FLOW_INC, FLOW_OUTC

FLOW_INA,FLOW_OUTA

CON_INC, CON_OUTC

CON_INA, CON_OUTA

CON_NET

CONV_PASS1, CONV_PASS2,CONV_PASS3

TOT_NNO3_CONV

$\begin{array}{ll}\text { AS } & \text { ARRAY (7) OF CURR } \\ \text { AS } & \text { CURR } \\ \text { AS } & \text { ARRAY (7) OF POTEN } \\ \text { AS } & \text { POTEN } \\ \text { AS } & \text { RESIST } \\ \text { AS } & \text { GAMMA } \\ \text { AS } & \text { KAPPA } \\ \text { AS } & \text { ARRAY(4) OF CONSTANT } \\ \text { AS } & \text { DELTA } \\ \text { AS } & \text { ARRAY(7) OF CUR_EFF } \\ \text { AS } & \text { CHARGE } \\ \text { AS } & \text { DIMLESS_NUM } \\ \text { AS } & \text { VOL_FLOW } \\ \text { AS } & \text { VOL_FLOW } \\ \text { AS } & \text { ARRAY(10) OF CONCN } \\ \text { AS } & \text { ARRAY(IO) OF CONCN } \\ \text { AS } & \text { ARRAY(2) OF CONCN } \\ \text { AS } & \text { CONVERSION } \\ \text { AS } & \text { CONVERSION }\end{array}$

STREAM
INPUT 1
OUTPUT 1
INPUT 2
OUTPUT 2
CONNECTION 1
CONNECTION 2
FLOW INC, CON INC
FLOW_OUTC, CON_OUTC
FLOW_INA, CON_INA
FLOW_OUTA, CON_OUTA
CON_NNET
IC

EQUATIONS

GAMAC $=D E L * 38.92 * I C /(2.0 * K A P) ;$

$\operatorname{CSTAR}(1) *(1.0+$ GAMAC $) *$ CON_INC $(3)=(1.0-$ GAMAC $) *$ CON_INC $(3)-($ DEL $/(96500 *$ $1.902 E-5)) *(I(1) / 2)$;

$\operatorname{CSTAR}(2) *(1.0+$ GAMAC $) *$ CON_INC $(4)=(1.0-$ GAMAC $) *$ CON_INC $(4)+($ DEL $/(96500 *$

$$
1.902 \mathrm{E}-5)) *(I(1) / 2-I(2) / 6-I(3) / 3-I(4) / 2) \text {; }
$$

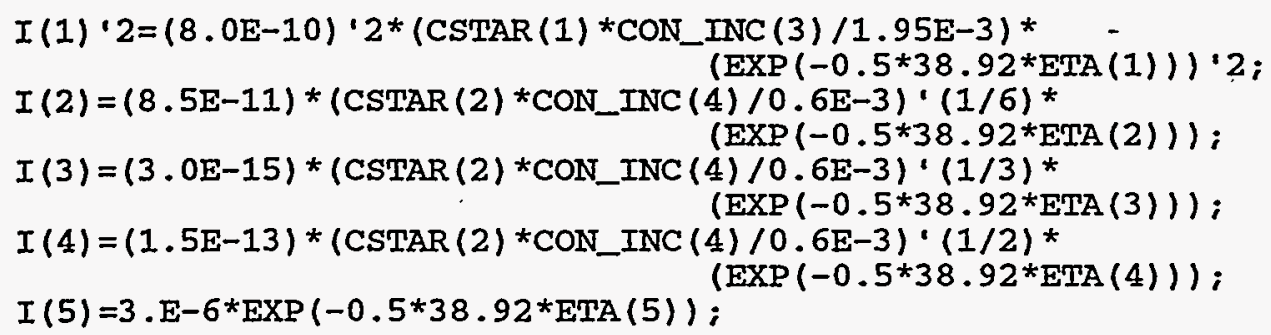


$\operatorname{ETA}(6)=$ V_CELL-PHIA -0.391987 ;

$\operatorname{ETA}(7)=$ V_CELI-PHIA -0.017814 ;

$I A=I(6)+I(7)$;

$I A=I C$;

\$QTOT $=I C * 100.0$;

C_EFF $(1)=I(1) * 100.0 / I C$;

C_EFF $(2)=I(2) * 100.0 / I C$;

C_EFF $(3)=I(3) * 100.0 / I C$;

C_EFF $(4)=I(4) * 100.0 / I C$;

C_EFF $(5)=I(5) * 100.0 / I C$;

C_EFF $(6)=I(6) * 100.0 / I A$;

C_EFF $(7)=I(7) * 100.0 / I A$;

\# DUMMY VARIABLE TO BE PASSES ON TO NNET \#

CON_NET (1) $=$ CON_OUTC (3) ;

CON_NET $(2)=$ CON_OUTC $(4)$;

\section{\# TOTAL BALANCE \#}

FLOW_INC $=$ FLOW_OUTC;

FLOW_INA = FLOW_OUTA;

\# CATHOLYTE \#

\# Na+ BALANCE \#

FLOW_INC*CON_INC(1) - FLOW_OUTC*CON_OUTC(1) - $(1.334 \mathrm{E}-5 / \mathrm{MAC}) *((\mathrm{CON}$ INC (1)

-CON_INA(1))/SEP_TH $\left.-38.92 *\left(C O N \_I N C(1)+C O N \_I N A(1)\right) * I C / 2.0 / K A P\right) * 100=0$;

\# OH- BALANCE \#

FLOW_INC*CON_INC (2) - FLOW_OUTC*CON_OUTC (2) + (1.0/96500.0)*E_AREA

$*(I(1)+I(2) * 7 / 6+I(3) * 4 / 3+\bar{I}(4) * 3 / 2+\bar{I}(5))-(5.26 \mathrm{E}-5 / \mathrm{MAC}) *((\mathrm{CON} \operatorname{INC}(2)$

-CON_INA (2))/SEP_TH $\left.+38.92 *\left(C O N \_I N C(2)+C O N \_I N A(2)\right) * I C / 2.0 / K \overline{A P}\right) * 100=0$;

\# NO3- BATANCE \#

FLOW_INC*CON_INC (3) - FLOW_OUTC*CON_OUTC (3) $-(0.5 / 96500.0) * I(1) * E \_A R E A ं$

$-(1.902 \mathrm{E}-\overline{5} / \mathrm{MAC}) *\left(\left(\mathrm{CON} \_\operatorname{INC}(3)-\mathrm{CON} \_\operatorname{INA}(3)\right) / \mathrm{SEP}\right.$ TH $+38.92 *\left(\mathrm{CON} \_\operatorname{INC}(3)+\right.$ CON_INA $(\overline{3})) * I C / 2.0 / \mathrm{KAP}) * \overline{100}=0$;

\# NO2- BALANCE \#

FLOW_INC*CON_INC (4) - FLOW_OUTC*CON_OUTC (4) - $(1.0 / 96500.0)$ *E_AREA

*( $(-0.5) * I(1)+I(2) / 6+I(3) / 3+I(4) / 2)-(1.902 E-5 / M A C) *\left(\left(C O N \_I N C(4)\right.\right.$

- CON_INA (4) $) /$ SEP_TH $\left.+38.92 *\left(C O N \_I N C(4)+C O N \_I N A(4)\right) * I C / 2.0 / K A P\right) * 100=0$;

\# N2 BALANCE \#

FLOW_INC*CON_INC (5) - FLOW_OUTC*CON_OUTC (5) $+(1.0 / 96500 / 6) * I(3) *$ E_AREA

$-(1.90 \mathrm{E}-5 / \mathrm{MAC}) *\left(\left(\mathrm{CON} \_\right.\right.$INC $(5)-$ CON_INA $\left.\left.(5)\right) / \mathrm{SEP} \_\mathrm{TH}\right)=0$;

\# NH3 BALANCE \#

FLOW_INC*CON_INC (6) - FLOW_OUTC*CON_OUTC (6) $+(1.0 / 96500 / 6) * I(2) *$ E_AREA

$-(2.168 \mathrm{E}-\overline{5} / \mathrm{MAC}) *(($ CON_INC $(6)-$ CON_INA $(6)) /$ SEP_TH $)=0$;

\# N2O BALANCE \#

FLOW_INC*CON_INC (7) - FLOW_OUTC*CON_OUTC (7) + $(1.0 / 96500 / 4) * I(4) * E \_A R E A$

$-(1.801 E-5 / M A C) *\left(\left(C O N \_I N C(7)-C O N \_I N A(7)\right) / S E P \_T H\right)=0 ;$ 
FLOW_INC*CON_INC (8) - FLOW_OUTC*CON_OUTC (8) - (2.15IE-5/MAC)* .

\# H2 BALANCE \#

FLOW_INC*CON_INC (9) - FLOW_OUTC*CON_OUTC $(9)+(1.0 / 96500 / 2) * I(5) *$ E_AREA

- $(2.322 \mathrm{E}-5 / \mathrm{MAC}) *\left(\left(\mathrm{CON} \_\right.\right.$INC $(9)-$ CON_INA $\left.\left.(9)\right) / \mathrm{SEP} \_\mathrm{TH}\right)=0$;

\# H20 BALANCE \#

FLOW_INC*CON_INC(10) - FLOW_OUTC*CON_OUTC(10) - $(1.0 / 96500.0) * E$ _AREA

$*(I(1) / 2+I(2) * 5 / 6+I(3) * 2 / 3+I(4) * 3 / 4+I(5))=0$;

\# ANOLYTE \#

\# Na+ BALANCE \#

FLOW_INA*CON_INA (1) - FLOW_OUTA*CON_OUTA (1) + $(1.334 E-5 / M A C) *((C O N$ INC (1) - CON_INA (1)) /SEP_TH $\left.-38.92 *\left(C O N \_I N C(1)+C O N \_I N A(1)\right) * I A / 2.0 / K A P\right) * 100=0$;

\# OH- BALAANCE \#

FLOW_INA*CON_INA (2) - FLOW_OUTA*CON_OUTA (2) - $(1.0 / 96500.0) *$ E_AREA

$*(I(6)+I(7))+(5.26 \mathrm{E}-5 / \mathrm{MAC}) *\left(\left(\operatorname{CON} \_I N C(2)-\right.\right.$ CON_INA $\left.(2)\right) /$ SEP_TH $+38.92 *$ $($ CON_INC (2) +CON_INA $(2)) * I A / 2.0 /$ KAP) $* 100=0$;

\section{\# NITRATE BALANCE \#}

FLOW_INA*CON_INA (3) - FLOW_OUTA*CON_OUTA (3) $+(0.5 / 96500.0) * I(7) *$ E_AREA $+(1.902 \mathrm{E}-\overline{5} / \mathrm{MAC}) *\left(\left(\mathrm{CON} \_\right.\right.$INC (3) -CON_INA (3))/SEP_TH $+38.92 *(\mathrm{CON}$ INC (3) + CON_INA $(\overline{3})) * I A / 2.0 /$ KAP $) * 100=0$;

\# NITRITE BALANCE \#

FLOW_INA*CON_INA (4) - FLOW_OUTA*CON_OUTA (4) $-(0.5 / 96500.0) * I(7) *$ E_AREA

$-(1.902 \mathrm{E}-\overline{5} / \mathrm{MAC}) *(($ CON_INC (4) -CON_INA (4))/SEP_TH $+38.92 *($ CON_INC (4) + CON_INA $(\overline{4})) * I A / 2.0 /$ KAP) $* \overline{100}=0$;

\section{\# N2 BALANCE \#}

FLOW_INA*CON_INA (5) - FLOW_OUTA*CON_OUTA $(5)+(1.90 \mathrm{E}-5 / \mathrm{MAC})$ * $(($ CON_INC (5)-CON_INA (5)) /SEP_TH) $=0$;

\# NH3 BALANCE \#

FLOW_INA *CON_INA $(6)$ - FLOW_OUTA ${ }^{*} C O N$ _OUTA $(6)+(2.168 \mathrm{E}-5 / \mathrm{MAC})$ * $(($ CON_INC $(6)$-CON_INA $(6) / /$ SEP_TH $)=0$;

\# N20 BALANCE \#

FLOW_INA*CON_INA (7) - FLOW_OUTA*CON_OUTA $(7)+(1.801 \mathrm{E}-5 / \mathrm{MAC})$ * $(($ CON_INC (7) -CON_INA (7)) /SEP_TH $)=0$;

\# 02 BALANCE \#

FLOW_INA*CON_INA (8) - FLOW_OUTA*CON_OUTA $(8)+(0.25 / 96500) * I(6) * E$ AREA

$+(2.151 E-5 / M A C) *\left(\left(C O N \_I N C(8)-C O N \_I N A(8)\right) / S E P \_T H\right)=0 ;$

\# H2 BALANCE \#

FLOW_INA*CON_INA (9) - FLOW_OUTA*CON_OUTA $(9)+(2.322 \mathrm{E}-5 / \mathrm{MAC})$ * $(($ CON_INC (9) -CON_INA $(9)) /$ SEP_TH $)=0$;

\# H2O BALANCE \#

FLOW_INA*CON_INA $(10)-$ FLOW_OUTA*CON_OUTA $(10)+(0.5 / 96500) *$ E_AREA $*(I(6)+I(\overline{7}))=0$;

\# CALC. THE CONVERSION PER PASS \#

CONV_PASS1 $=i .0-\left(\right.$ FLOW_OUTC ${ }^{*}$ CON_OUTC (3) $/\left(\right.$ FLOW_INC ${ }^{*}$ CON_INC (3)) );

CONV_PASS2 $=1.0-\left(\right.$ FLOW_OUTC ${ }^{*} C O N \_O U T C(4) /\left(\right.$ FLOW_INC ${ }^{*} C O N \_I N C$ (4) $\left.)\right)$; 
CONV_PASS3 $=1.0-\left(\left(\right.\right.$ ELOW_OUTC $*$ CON_OUTC $(3)+$ FLOW_OUTC $\left.* C O N \_O U T C(4)\right) /$ (FLOW_INC*CON_INC (3)+FLOW_INC*CON_INC (4)));

TOT_NO3_CONV $=1.0-($ FLOW_OUTC*CON_OUTC $(3) /(63.0 * 1.95 E-3))$;

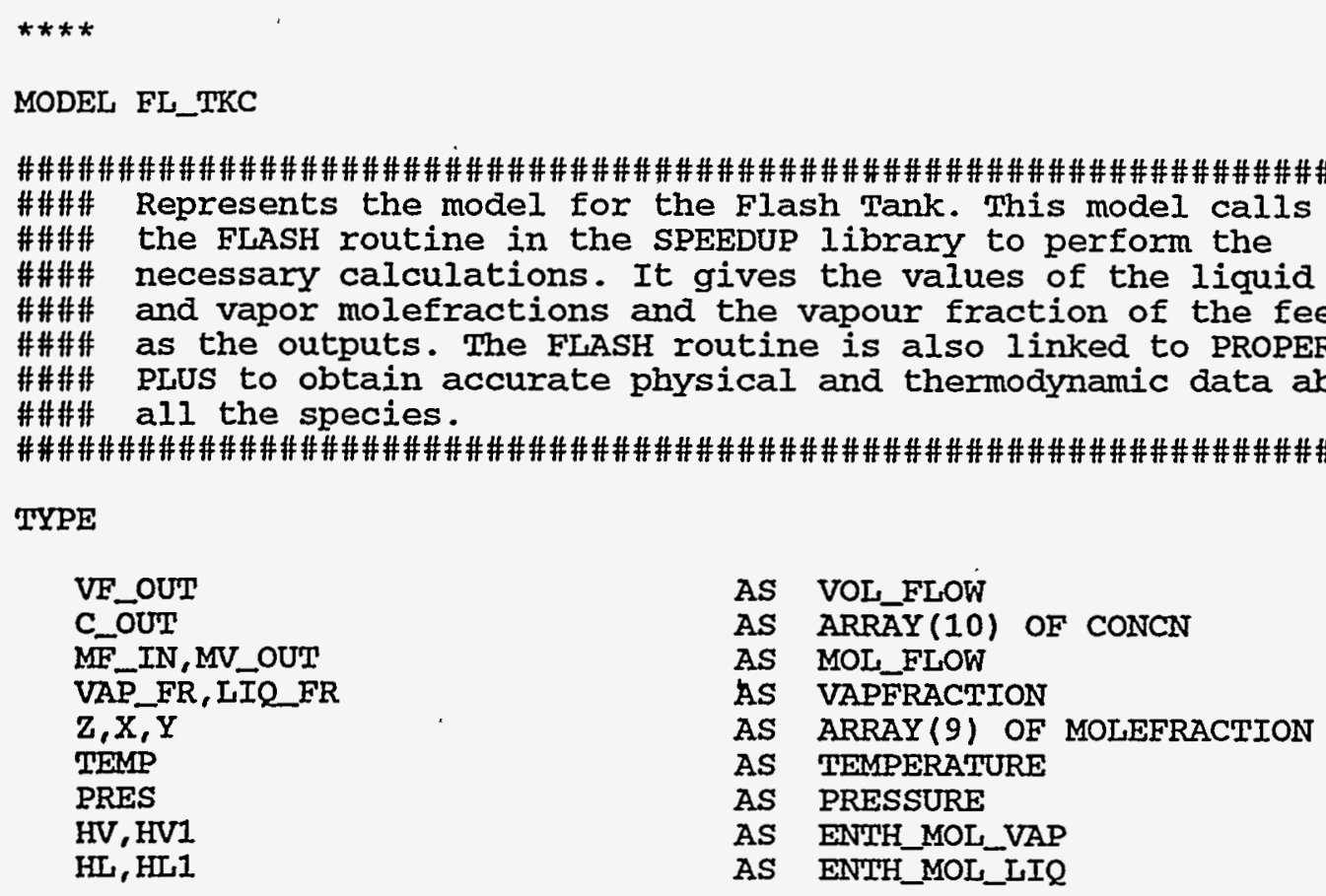

\section{STREAM}

INPUT 1

OUTPUT 1

MF_IN, Z, TEMP, PRES

OUTPUT 2

VF_OUT, C_OUT

MV_OUT, Y

EQUATIONS

VAP_FR + IIQ_FR = 1.0;

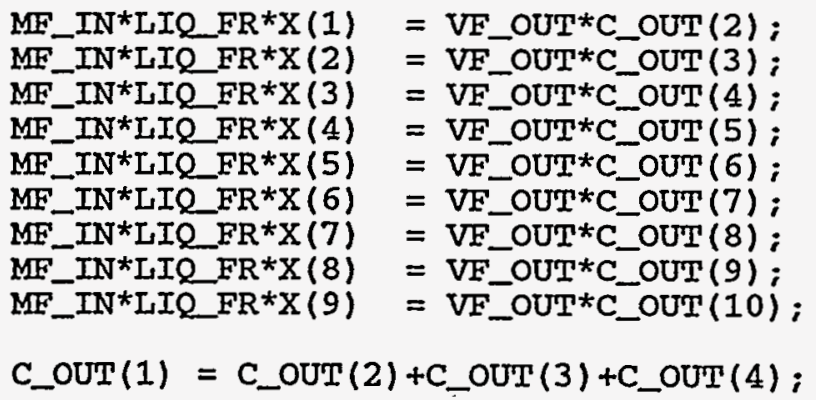

MV_OUT = MF_IN*VAP_FR;

\# DUMMY EQNS \#

$\mathrm{HV}=\mathrm{HV} 1$

HL = HL1;

PROCEDURE

(Y,X,VAP_FR,HV,HL) FLASH (TEMP,PRES, Z) INPUT 1

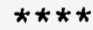 \\ MODEL NNET}




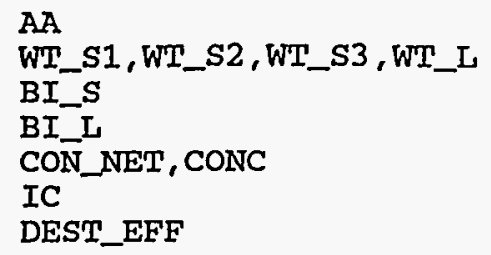

STREAM

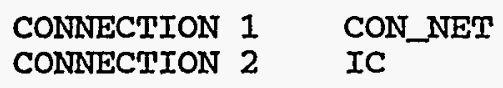

JUTPUT 1 OF JUTPUT 1 OF JUTPUT 1 OF JUTPUT 1 OF JUTPUT 1 OF JUTPUT 2 OF JUTPUT 2 OF JUTPUT 1 OF JUTPUT 1 OE JUTPUT 2 OF ZONNECTION :ONNECTION

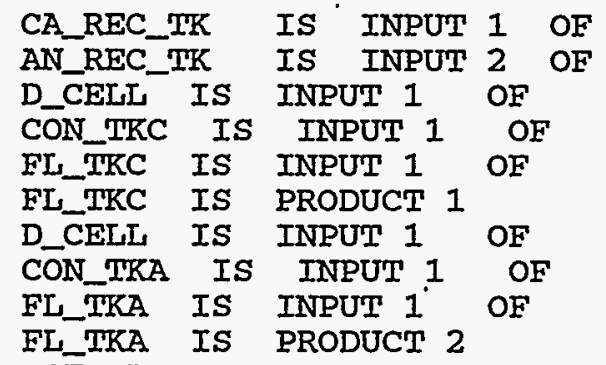

$\begin{array}{lll}\text { D_CELL } & \text { TYPE } & \text { LIQUID } \\ \text { D_CELL } & \text { TYPE } & \text { LIQUID } \\ \text { CON_TKC } & \text { TYPE } & \text { LIQUID } \\ \text { FL_TKC } & \text { TYPE } & \text { MAINSTREAM } \\ \text { CA_REC_TK } & \text { TYPE } & \text { LIQUID } \\ & \text { TYPE } & \text { VAPOUR } \\ \text { CON_TKA } & \text { TYPE } & \text { LIQUID } \\ \text { FL_TKA } & \text { TYPE } & \text { MAINSTREAM } \\ \text { AN_REC_TK } & \text { TYPE } & \text { LIQUID } \\ & \text { TYPE } & \text { VAPOUR }\end{array}$




UNIT ; FT_TKC IS FL_TKC

UNIT N_NET IS NNET

OPERATION

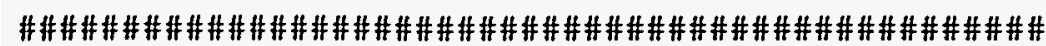

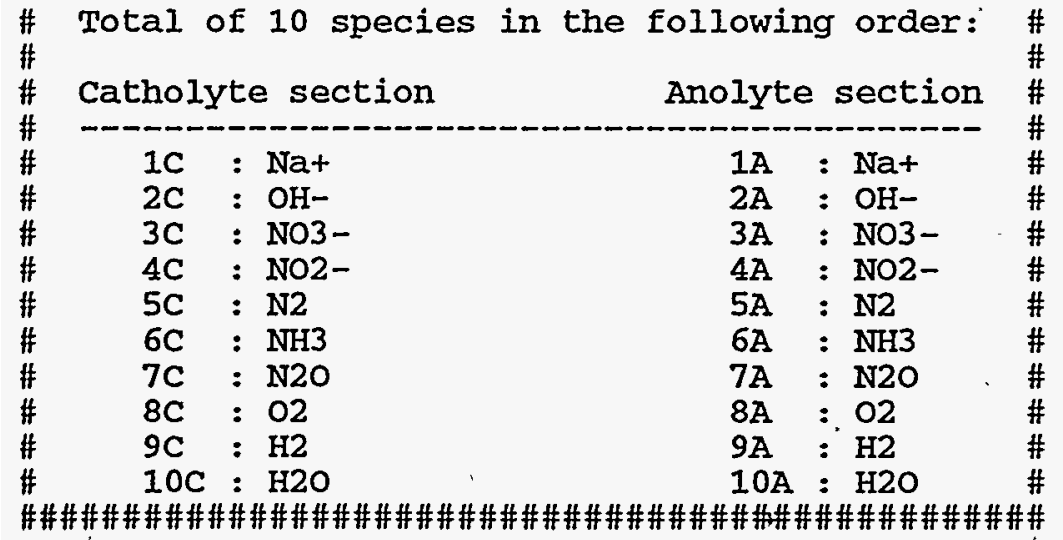

SET

WITHIN D_CELI

$\begin{array}{ll}\text { FLOW_INC } & =63.0 \\ \text { FLOW_INA } & =63.0 \\ \text { V_CELL } & =3.5 \\ \text { RES } & =0.01825 \\ \text { KAP } & =1.0 \\ \text { DEL__ } & =1.645 \mathrm{E}-2 \\ \text { SEP_TH } & =0.05 \\ \text { MAC } & =5.0\end{array}$

WITHIN CA_REC_TK

$$
\text { V_RES }=700.0
$$

WITHIN AN_REC_TK V_RES

$=7000.0$

WITHIN CON_TKC TEMP

$=25.0$

WITHIN FL_TKC VE_OUT $=63.0$

WITHIN CON_TKA TEMP

$$
=25.0
$$

WITHIN FL_TKA

$$
\text { VF_OUT }=63.0
$$

WITHIN N_NET

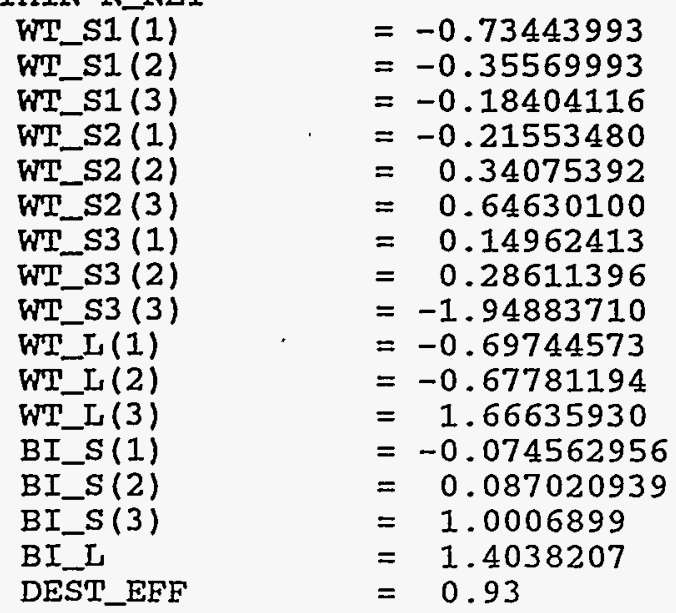




\section{INITIAL}

\begin{tabular}{|c|c|}
\hline $\begin{array}{l}\text { NITHIN D_CELL } \\
\text { Q_TOT }\end{array}$ & $=0.0$ \\
\hline $\begin{array}{l}\text { WITHIN CA_REC_TK } \\
\text { C_OUT (1) } \\
\text { C_OUT (2) } \\
\text { C_OUT (3) } \\
\text { C_OUT (4) } \\
\text { C_OUT (5) } \\
\text { C_OUT (6) } \\
\text { C_OUT (7) } \\
\text { C_OUT (8) } \\
\text { C_OUT (9) } \\
\text { C_OUT (10) }\end{array}$ & $\begin{array}{l}=3 \cdot 88 \mathrm{E}-3 \\
=1 \cdot 33 \mathrm{E}-3 \\
=1 \cdot 95 \mathrm{E}-3 \\
=0.6 \mathrm{E}-3 \\
=0.1 \mathrm{E}-9 \\
=0.1 \mathrm{E}-9 \\
=0.1 \mathrm{E}-9 \\
=0.1 \mathrm{E}-9 \\
=0.1 \mathrm{E}-9 \\
=50 \cdot 0 \mathrm{E}-3\end{array}$ \\
\hline $\begin{array}{l}\text { WITHIN AN_REC_TK } \\
\text { CON_OUT (1) } \\
\text { CON_OUT (2) } \\
\text { CON_OUT (3) } \\
\text { CON_OUT (4) } \\
\text { CON_OUT (5) } \\
\text { CON_OUT (6) } \\
\text { CON_OUT (7) } \\
\text { CON_OUT (8) } \\
\text { CON_OUT (9) } \\
\text { CON_OUT (10) }\end{array}$ & $\begin{array}{l}=3.88 \mathrm{E}-3 \\
=3.8797 \mathrm{E}-3 \\
=0.195 \mathrm{E}-6 \\
=0.6 \mathrm{E}-7 \\
=0.1 \mathrm{E}-9 \\
=0.1 \mathrm{E}-9 \\
=0.1 \mathrm{E}-9 \\
=0.1 \mathrm{E}-9 \\
=0.1 \mathrm{E}-9 \\
=50.0 \mathrm{E}-3\end{array}$ \\
\hline
\end{tabular}




\section{WSRC-TR-95-0435}

Distribution: $\quad$ K. Geddes, DOE-HQ

W. L. Kuhn, PNL

A. M. Blackmon, DOE-SR, 703-A

M. Schwenker, DOE-SR, 703-H

L. M. Papouchado, 773-A

W. L. Tamosaitis, 773-A

W. E. Lawrence, PNL

R. E. White, USC

S. D. Fink, 773-A

D. T. Hobbs, 773-A

J. L. Steimke, 786-5A

J. T. Coleman, 773-41A

TIM, 773-52A 